\title{
TA-55 Change Control Manual
}

LA-13348-M Plutonium Facility November 1997

TA-55 Change Control Manual

Issued to:

Z Number:

Copy Number:

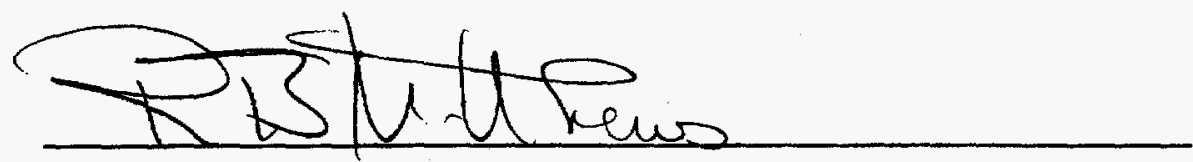

R. Bruce Matthews

NMT Division Director 
Edited by Larry W. Collins and Lynne Atencio, Group CIC-1

Photocomposition by Katherine E. Valdez, Group CIC-1

Graphic Support by Susan L. Carlson, Group CIC-1

\section{Abstract}

This manual is the guide for initiating change at the Los Alamos Plutonium Facility, TA-55. It describes the change and work control process employed at TA-55 to ensure that all proposed changes are properly identified, reviewed, approved, implemented, tested, and documented so that operations are maintained within the approved safety envelope.

An Affirmative Action/Equal Opportunity Employer

This report was prepared as an account of woork sponsored by an agency of the United States Government. Neither The Regents of the University of California, the United States

Government nor any agency thereof, nor any of their employees, makes any warranty, express or implied, or assumes any legal liability or responsibility for the accuracy, completeness, or usefulness of any information, apparatus, product, or process disclosed, or represents that its use would not infringe privately oumed rights. Reference herein to any specific commercial product, process, or service by trade name, trademark, manufacturer, or otherwise, does not necessarily constitute or imply its endorsement, recommendation, or faooring by The Regents of the University of California, the United States Government, or any agency thereof. The views and opinions of authors expressed herein do not necessarily state or reflect those of The Regents of the University of California, the United States Government, or any agency thereof. The Los Alamos National Laboratory strongly supports academic freedom and a researcher's right to publish; therefore, the Laboratory as an institution does not endorse the viewpoint of a publication or guarantee its technical correctness. 


\section{DISCLAIMER}

Portions of this document may be illegible electronic image products. Images are produced from the best available original document. 


\section{TA-55 Change Control Manual*}

Thomas W. Blum

Ronald D. Selvage

Kenneth H. Courtney

Contributors

Denise C. Galvez

J. Dee Hoisington

John L. Parker

Steven J. Salazar

Vicente D. Sandoval

David R. Schmitt

Wayne D. Smyth

Eliud F. Vigil

*This document is the first revision. Subsequent revisions may be limited in distribution. 


\section{TA-55 Change Control Manual}

\section{Review and Approval Documentation}

Prepared by:

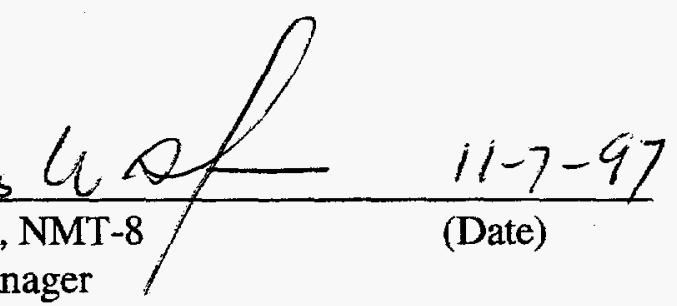

Reviewed by:

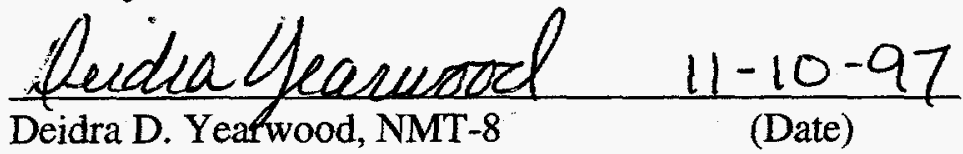

Group Leader

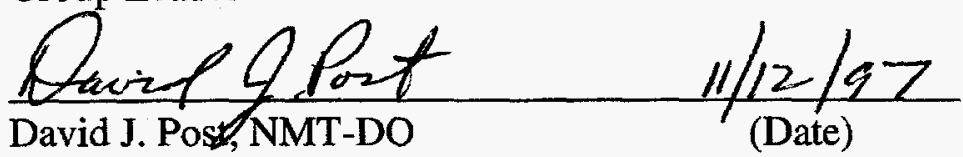

Facility Manager

Approved by:

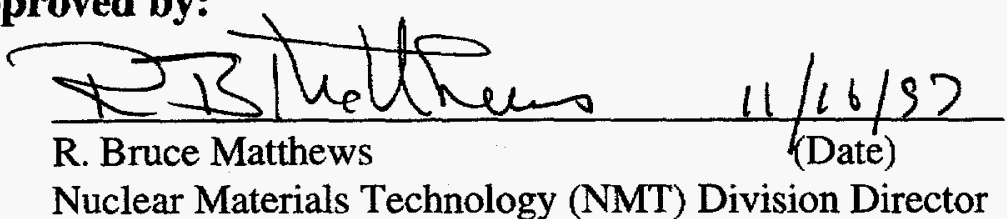




\section{Manual Organization}

Contents

Table of Contents

List of Forms

Section 1 ........ Introduction

Section 2 ......... Responsibilities

Section 3 ......... Processes or Experiments

Section 4 ......... Facility Changes

Section 5 ........ Software Changes

Section 6 ......... Making Procedure Changes

Section 7 ........ Design Document Changes

Section 8 ........ Noncomforming Items and

As-Found Changes

Section 9 ......... Hazards Analysis

Section 10 ....... Unreviewed Safety Question

Determination

Section 11 ...... Initiating a Work/Change Request

Section 12 ...... Design Change Package

Section 13 ....... Definitions

Section 14 ....... References

Appendix A .... Important Phone Numbers

Appendix B ..... Prioritizing Work 


\section{CONTENTS}

\section{SECTION 1}

INTRODUCTION



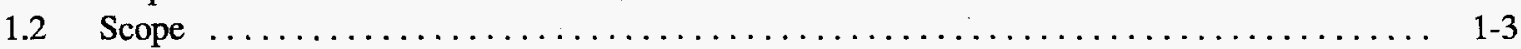

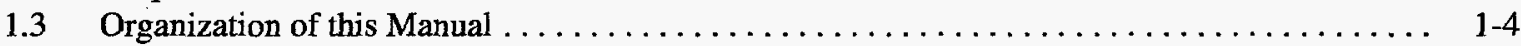

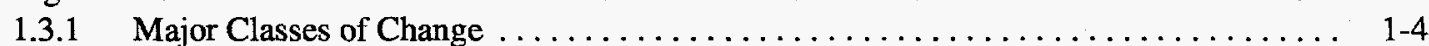

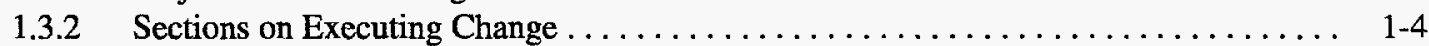

TA-55 Change Control Processing By Major Change Category $\ldots \ldots \ldots \ldots \ldots \ldots \ldots \ldots \ldots \ldots \ldots \ldots$

\section{SECTION 2}

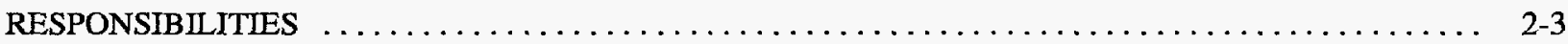

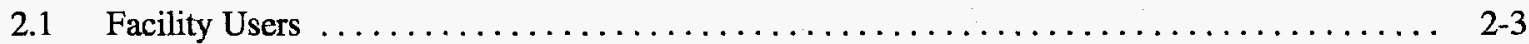

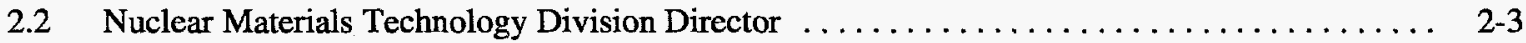



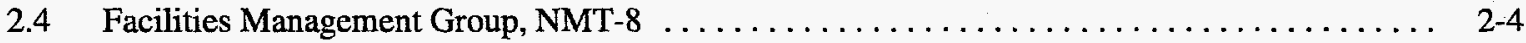

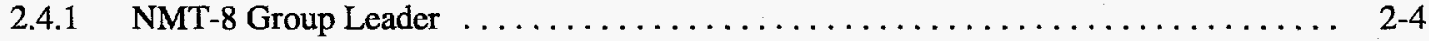



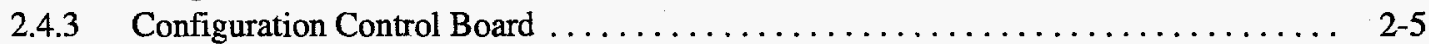

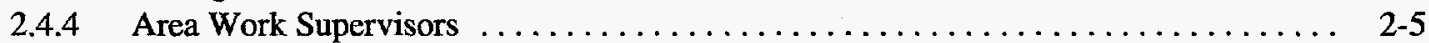

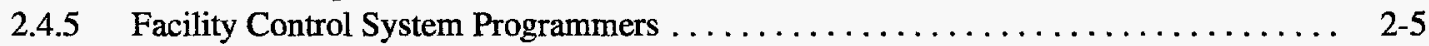

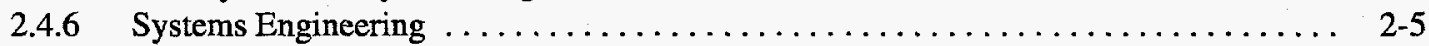

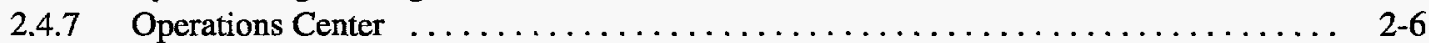

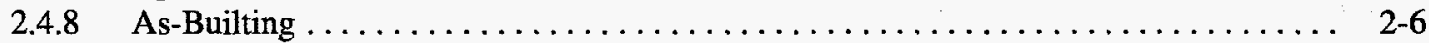

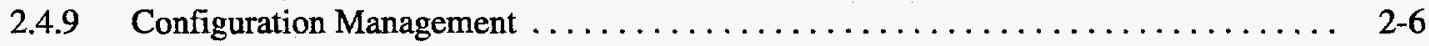

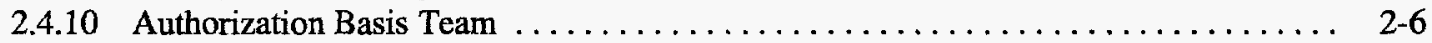

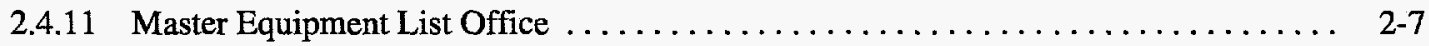



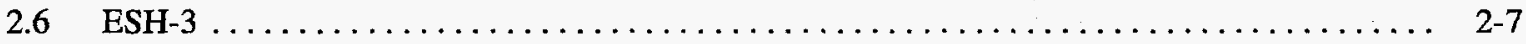

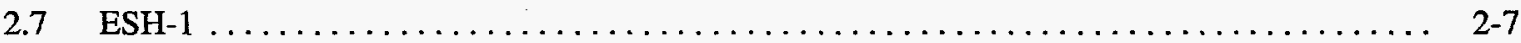

\section{SECTION 3}

NEW PROCESS OR EXPERIMENT OR CHANGES TO AN EXISTING PROCESS OR EXPERIMENT . . $\quad 3-3$

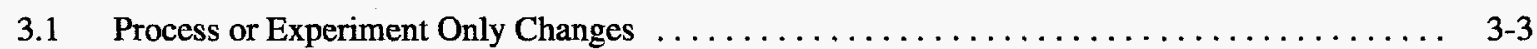

3.2 Process or Experiment Changes Involving Gloveboxes or

\section{SECTION 4}

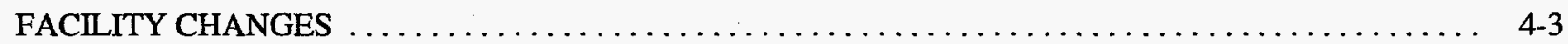

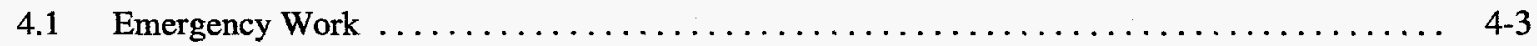

4.2 Making Permanent Changes to Facility SSC $\ldots \ldots \ldots \ldots \ldots \ldots \ldots \ldots \ldots \ldots \ldots \ldots \ldots \ldots \ldots$

4.2.1 Management Consequence of Failure Categories $\ldots \ldots \ldots \ldots \ldots \ldots \ldots \ldots \ldots \ldots$ 4. 4

4.2.2 Executing Permanent Facility Changes Requiring Configuration Management ...... 4-5

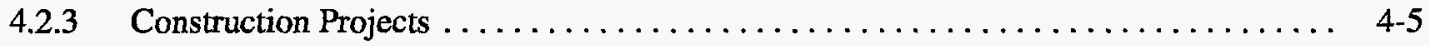

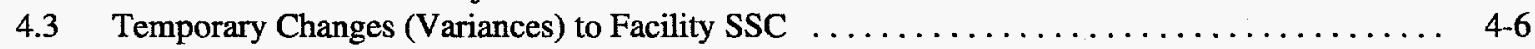

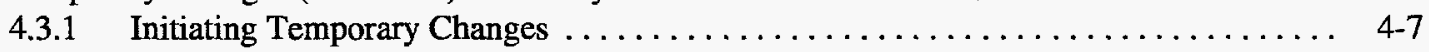

4.3.1.1 Filling out the VCR $\ldots \ldots \ldots \ldots \ldots \ldots \ldots \ldots \ldots \ldots \ldots \ldots \ldots \ldots \ldots \ldots, 4$

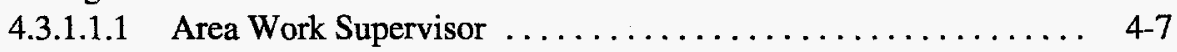


4.3.1.1.2 Systems Engineer $\ldots \ldots \ldots \ldots \ldots \ldots \ldots \ldots \ldots \ldots \ldots \ldots, 4-8$

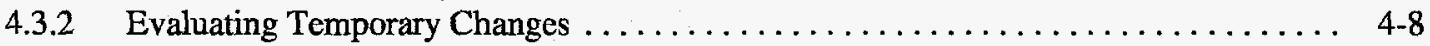

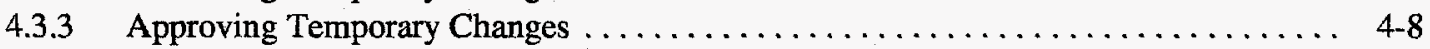

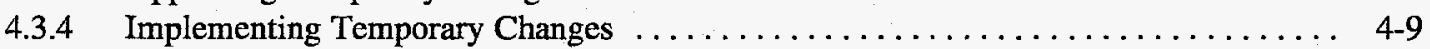

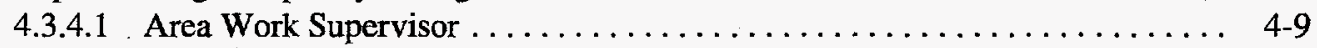

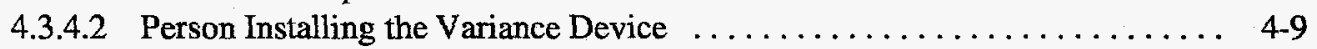

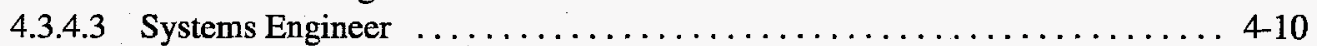

4.3.4.4 Operations Center Shift Supervisor . . . . . . . . . . . . . . . 4-10

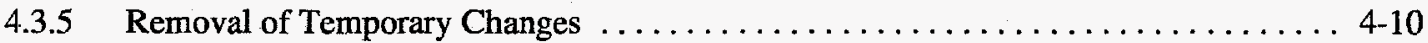

4.3.5.1 Area Work Supervisor .......................... 4 40

4.3.5.2 Person Removing Variance Device $\ldots \ldots \ldots \ldots \ldots \ldots \ldots \ldots \ldots \ldots . \ldots \ldots$ 4-10

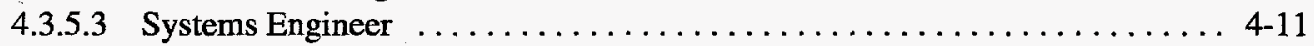

4.3.5.4 Operations Center Shift Supervisor . . . . . . . . . . . . . . $\ldots \ldots \ldots$ 4-11

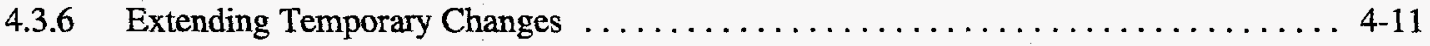

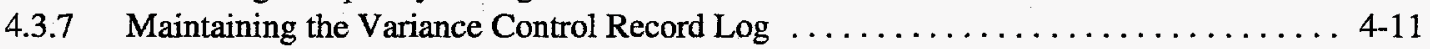



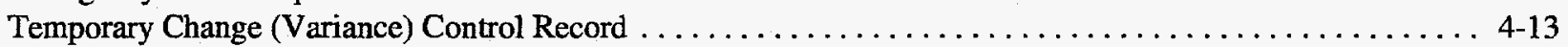

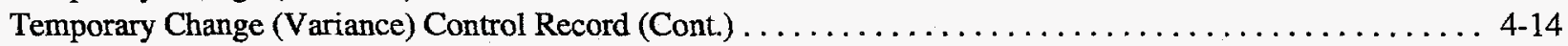

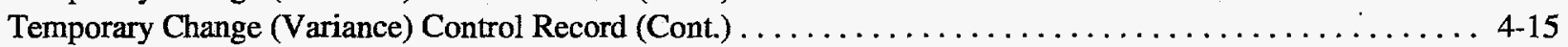

Temporary Change (Variance) Control Record (Cont.) . . . . . . . . . . . . . . . . . . . . . . . . 4-16

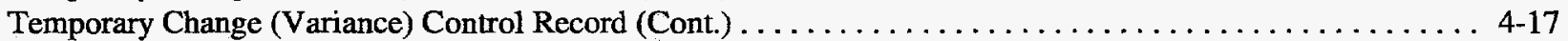

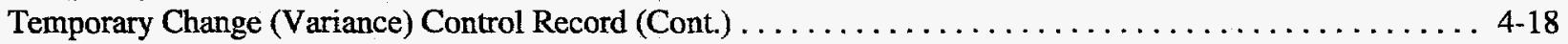

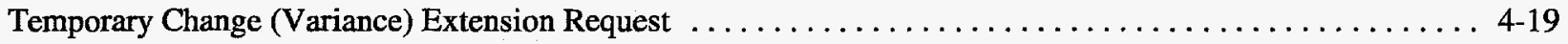

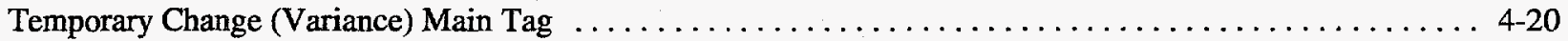

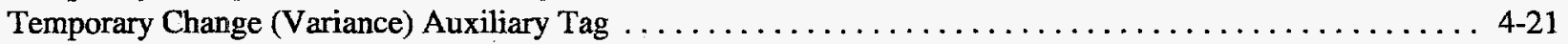

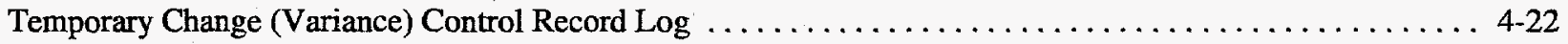

\section{SECTION 5}

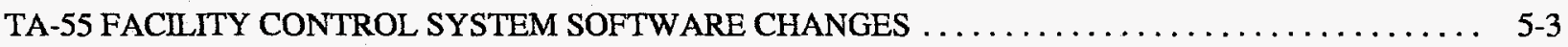



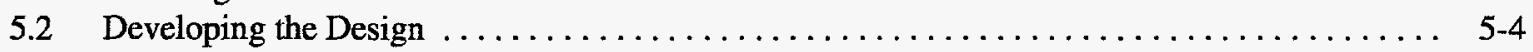

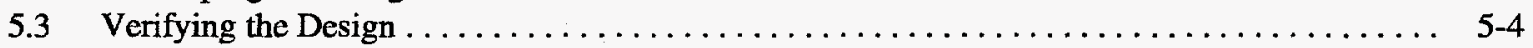

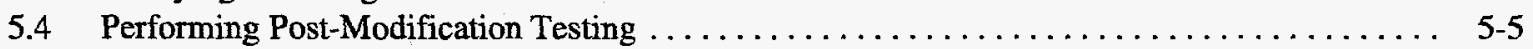

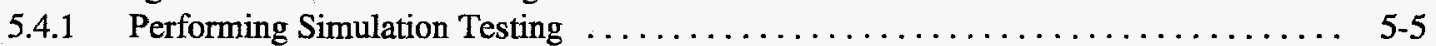

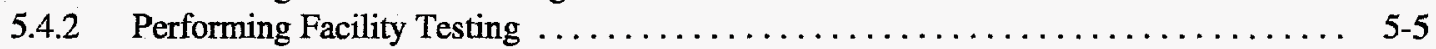

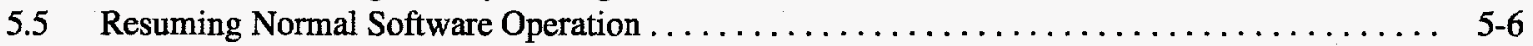

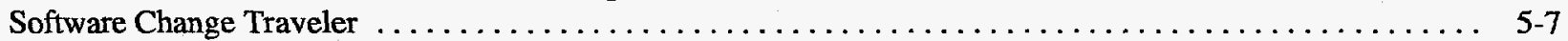

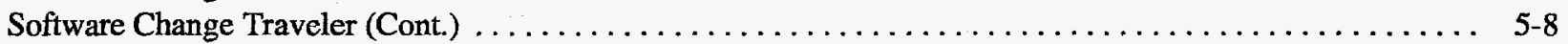

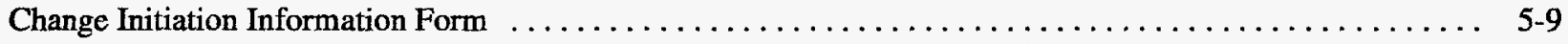







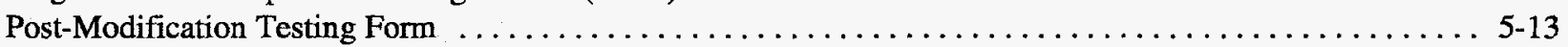

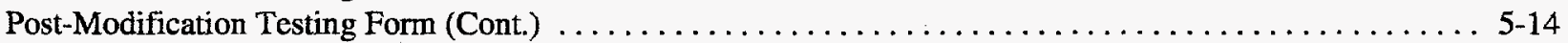



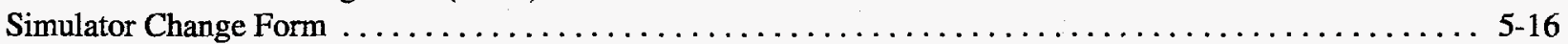

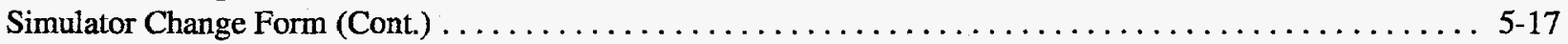




\section{SECTION 6}



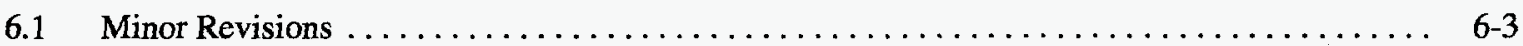

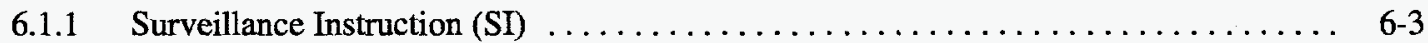

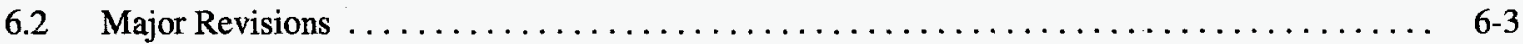

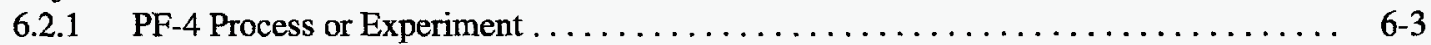

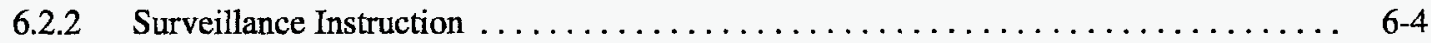

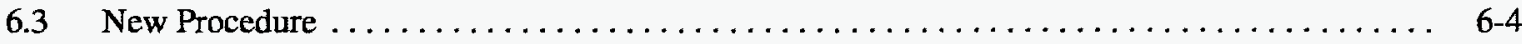

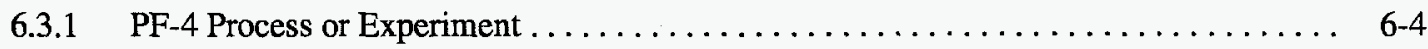

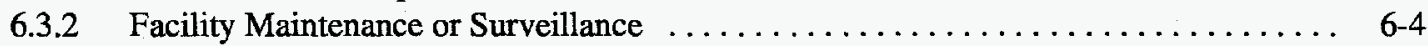

\section{SECTION 7}



\section{SECTION 8}

NONCONFORMING ITEMS AND AS-FOUND CHANGES $\ldots \ldots \ldots \ldots \ldots \ldots \ldots \ldots \ldots \ldots \ldots$

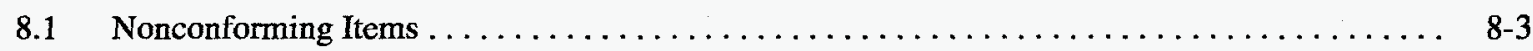

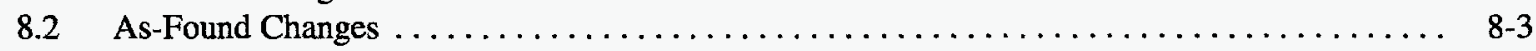

\section{SECTION 9}

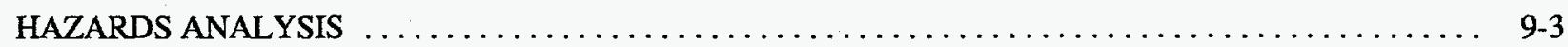

9.1 Completing the Hazards Analysis Screening Form $\ldots \ldots \ldots \ldots \ldots \ldots \ldots \ldots \ldots \ldots \ldots$

9.2 The Process Hazards Analysis Information Checklist $\ldots \ldots \ldots \ldots \ldots \ldots \ldots \ldots \ldots \ldots \ldots \ldots \ldots$

9.2.1 Preparing the Process Hazards Analysis Information Checklist ............. 9-4

9.2.1.1 Applicable Theoretical Chemistry and Physics for a Process .......... 9-4

9.2.1.2 Process Flow Diagrams and Material Balances ............... 9-4

9.2.1.3 Process Equipment Layouts $\ldots \ldots \ldots \ldots \ldots \ldots \ldots \ldots \ldots \ldots \ldots \ldots .9 .4$

9.2.1.4 Process Piping and Instrumentation Drawings $\ldots \ldots \ldots \ldots \ldots \ldots \ldots .9-5$

9.2.1.5 Process Electrical One-Line Drawings ................... 9-5

9.2.1.6 Design Energy and Mass Balances ..................... 9-5

9.2.1.7 Major Material Inventories (Nuclear and Chemical) $\ldots \ldots \ldots \ldots \ldots$ 9.5

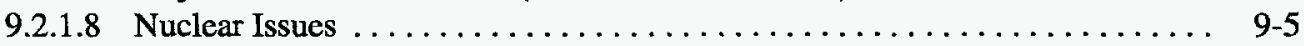

9.2.1.9 Material Safety Data Sheets and Chemical Hazard Information ........ 9-6

9.2.1.10 Mechanical Equipment Data Sheets $\ldots \ldots \ldots \ldots \ldots \ldots \ldots \ldots \ldots$ 9-6

9.2.1.11 Control System and Alarm Description $\ldots \ldots \ldots \ldots \ldots \ldots \ldots \ldots \ldots$ 9.6

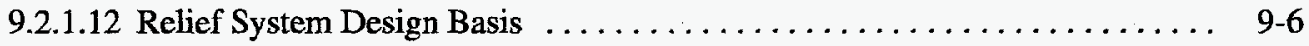

9.2.1.13 Computer Control System Hardware and Software $\ldots \ldots \ldots \ldots \ldots \ldots \ldots$ 9-7

9.2.1.14 Operating and Maintenance Procedures $\ldots \ldots \ldots \ldots \ldots \ldots \ldots \ldots .9 .7$

9.2.1.15 Previous Safety Studies, Accidents, Incident Reports,

Unusual Occurrence Reports . ..................... 9-7

9.2.1.16 Laboratory Research Reports, Technical Articles from Periodicals, etc. . . . . 9-7

9.2.1.17 Pertinent Industry Standards and Regulations $\ldots \ldots \ldots \ldots \ldots \ldots \ldots$ 9-7

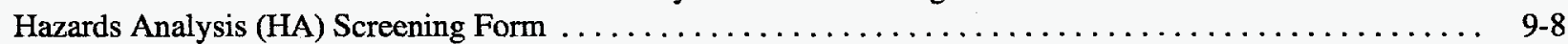

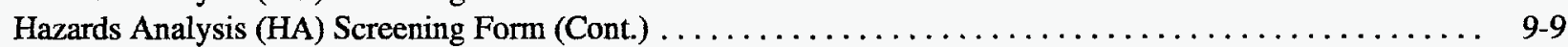

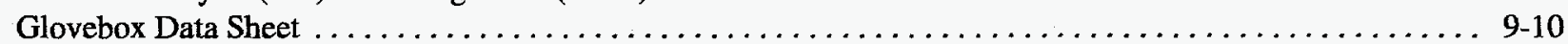

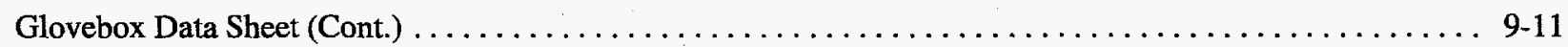

Process Hazard Analysis Information Checklist $\ldots \ldots \ldots \ldots \ldots \ldots \ldots \ldots \ldots \ldots \ldots \ldots \ldots \ldots \ldots .9 .12$ 


\section{SECTION 10}

UNREVIEWED SAFETY QUESTION DETERMINATION (USQD) $\ldots \ldots \ldots \ldots \ldots \ldots \ldots \ldots \ldots \ldots \ldots$

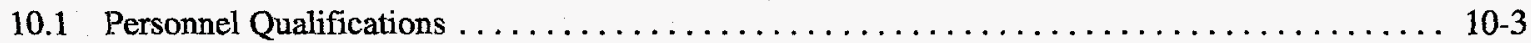

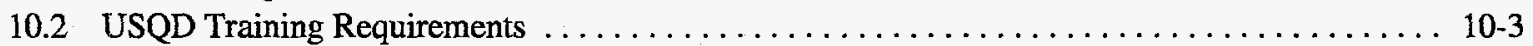

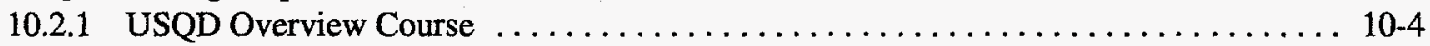

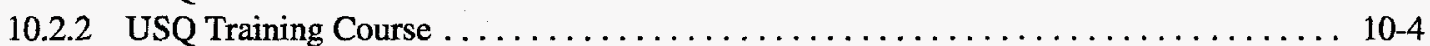

10.3 Performing Unreviewed Safety Question Determination $\ldots \ldots \ldots \ldots \ldots \ldots \ldots \ldots \ldots \ldots \ldots$



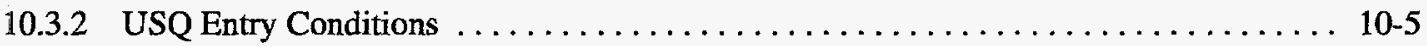

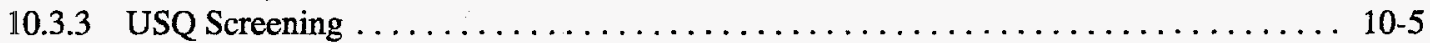

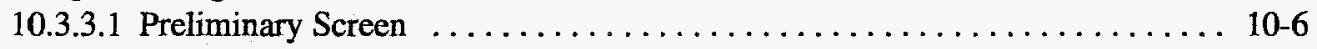

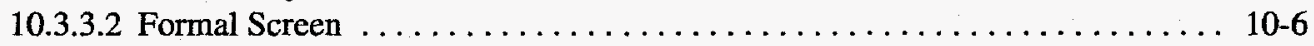

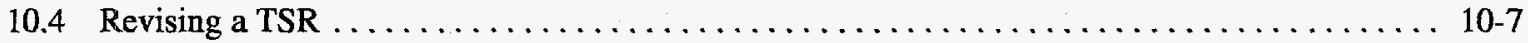

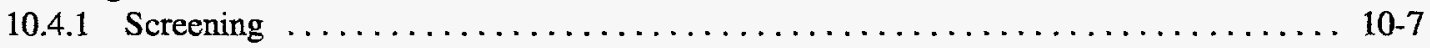

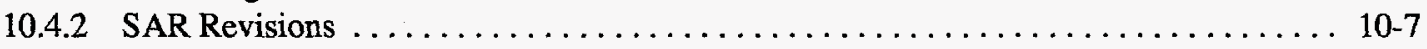

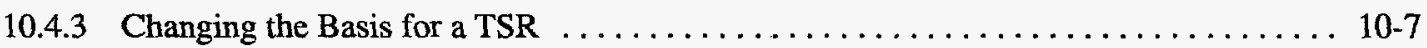

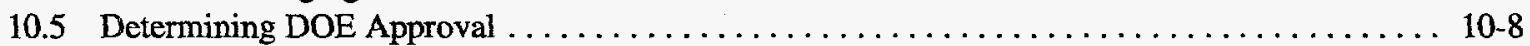

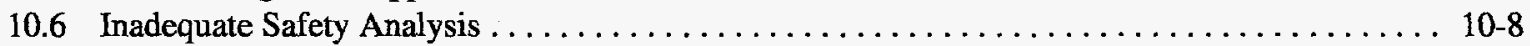

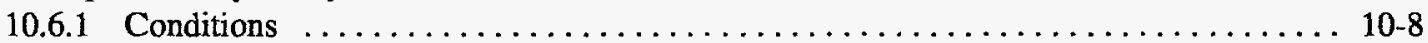

10.6.2 TSRs, Operational Events, and USQDs . . . . . . . . . . . . . . . . . . . 10-9

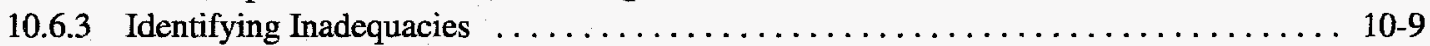

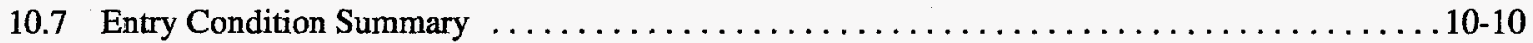

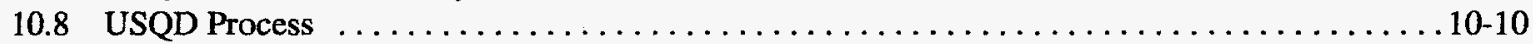

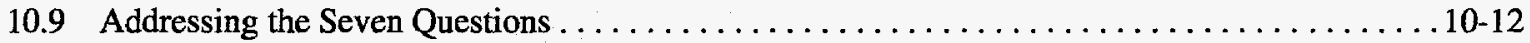

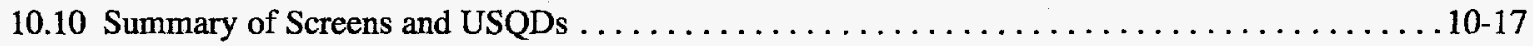

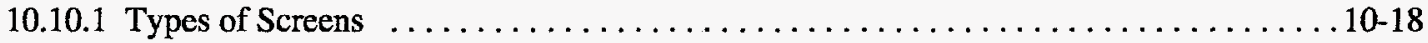

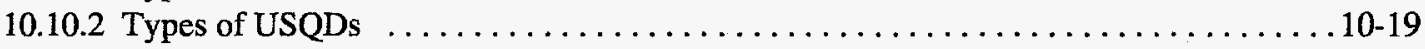

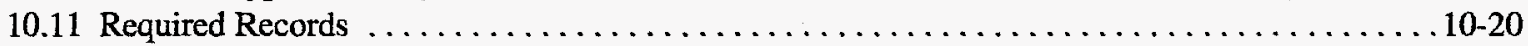

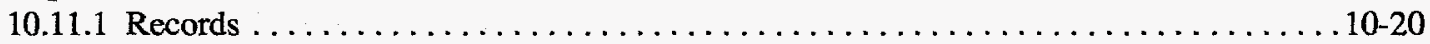

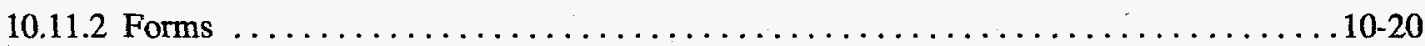

10.11.3 Disposition of Records ............................... 10-20

10.11.3.1 Disposition of Records for a Positive USQD . . . . . . . . . . . . . . 10-21

10.11.3.2 Disposition of Records for a Negative USQD . . . . . . . . . . . . . 10-21

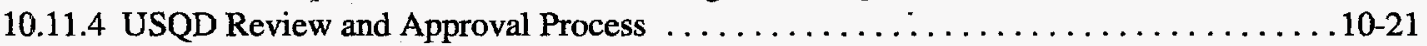

10.11.5 Laboratory USQD Sign-Off and Closure .......................

Unreviewed Safety Question Determination and Screening Worksheet (Form 1617) . . . . . . . . . 10-23

Unreviewed Safety Question Determination and Screening Worksheet (Form 1617) (Cont.) . . . . . . . . . 10-24

Unreviewed Safety Question Determination and Screening Worksheet (Form 1617) (Cont.) ........... 10-25

Unreviewed Safety Question Determination and Screening Worksheet (Form 1617) (Cont.) . . . . . . . . . 10-26

Unreviewed Safety Question Determination and Screening Worksheet (Form 1617) (Cont.) ........... 10-27

\section{SECTION 11}



11.1 Completing Section 1.0 of the Work/Change Request Form $\ldots \ldots \ldots \ldots \ldots \ldots \ldots \ldots \ldots \ldots \ldots \ldots \ldots$

11.2 Completing Section 2.0 of the Work/Change Request Form $\ldots \ldots \ldots \ldots \ldots \ldots \ldots \ldots \ldots \ldots$



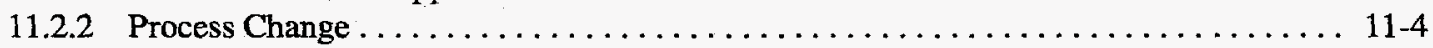

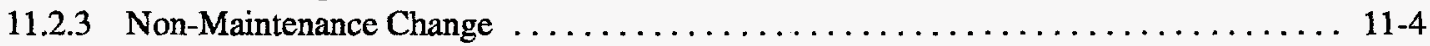






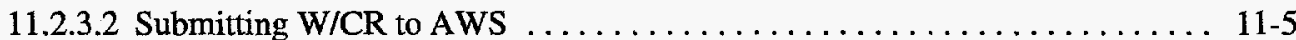

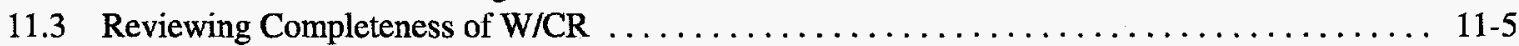

11.4 Completing Section 3.0 of the Work/Change Request Form $\ldots \ldots \ldots \ldots \ldots \ldots \ldots \ldots \ldots \ldots \ldots \ldots$

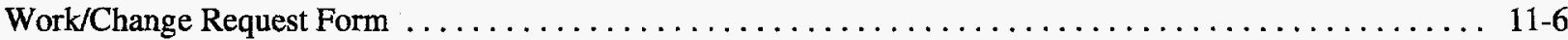

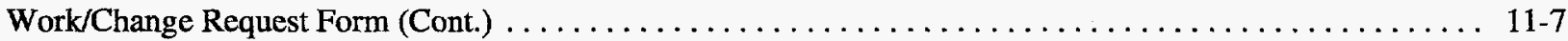

\section{SECTION 12}

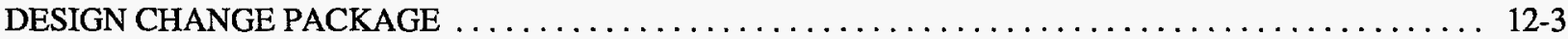

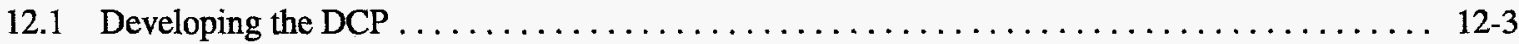

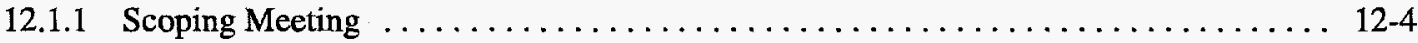

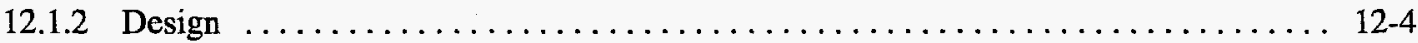

12.1.2.1 Issuing Drawing and Project Identification Numbers $\ldots \ldots \ldots \ldots \ldots \ldots$ 12-5

12.1.2.2 Engineering Review, Approval, and Release for Construction ........ 12-5

12.1.2.3 Quality Assurance/Quality Control Review $\ldots \ldots \ldots \ldots \ldots \ldots \ldots \ldots$ 12-6

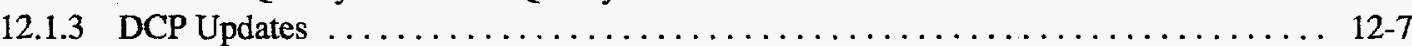

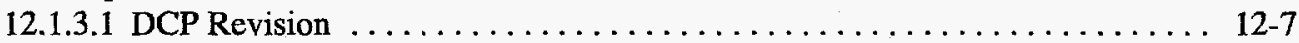

12.1.3.2 Post-Modification Testing $\ldots \ldots \ldots \ldots \ldots \ldots \ldots \ldots \ldots \ldots \ldots \ldots \ldots \ldots, 12-7$

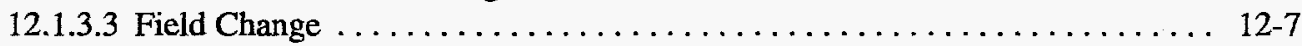

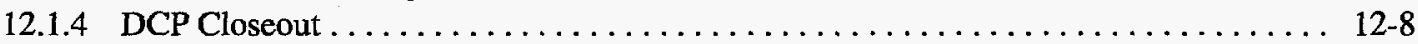

12.1.4.1 Verifying that Work Was Performed According to DCP Design ....... 12-8

12.1.4.2 Updating Related Documentation . . . . . . . . . . . . . . . . . . . .

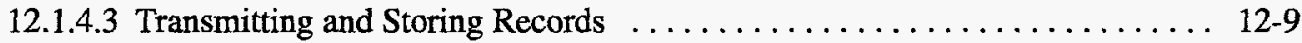

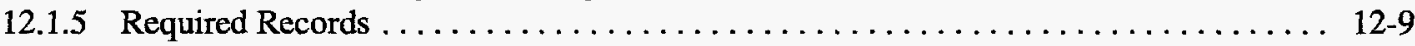

Design Requirements Checklist ........................................ 12-10

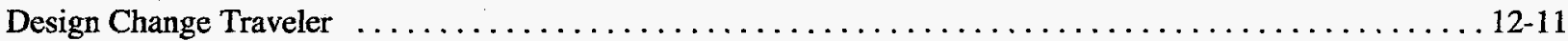

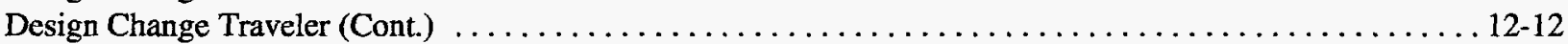

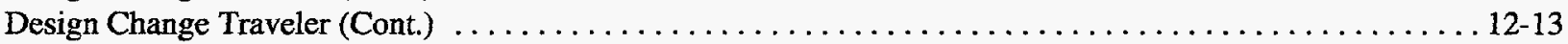

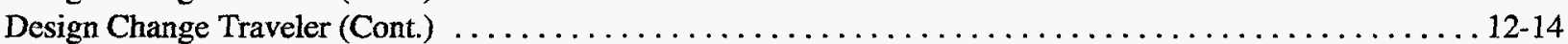

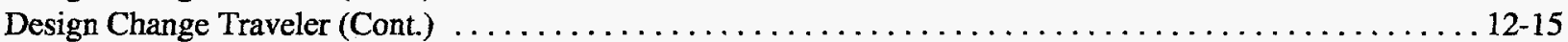



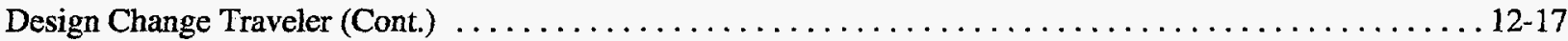

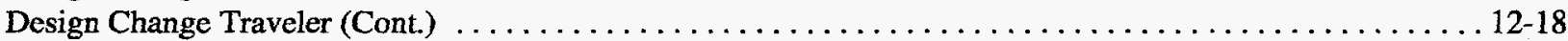

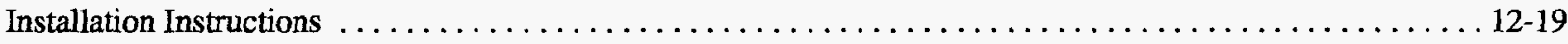

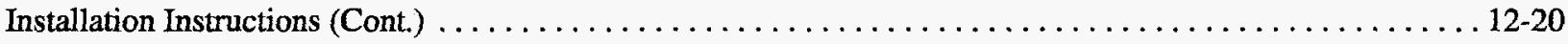

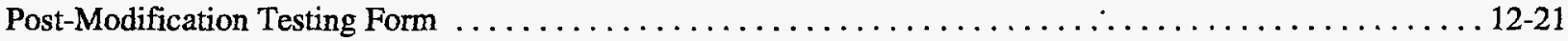

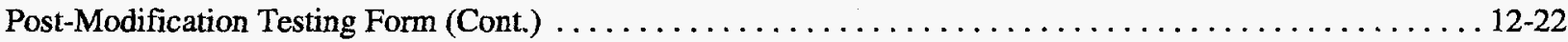

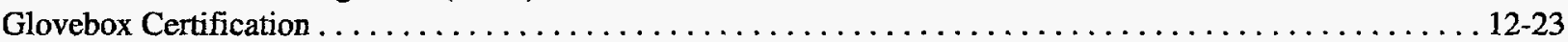

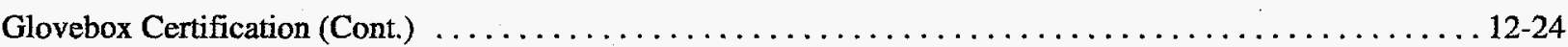

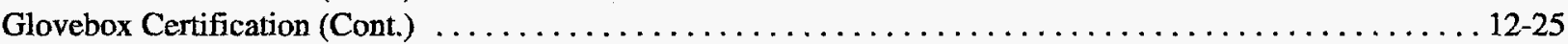

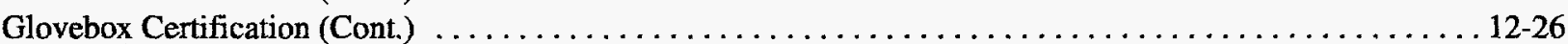

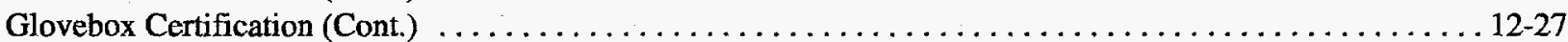





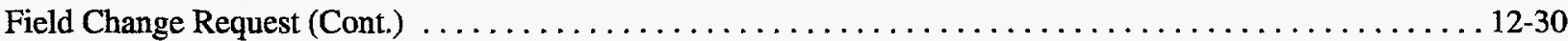

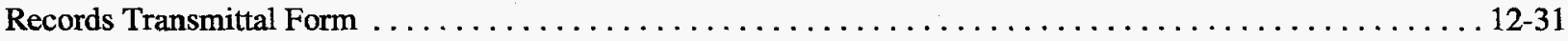





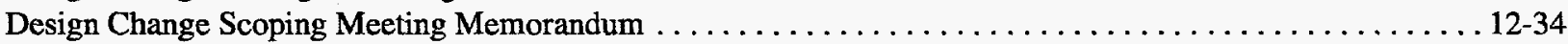






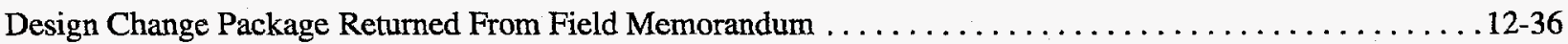

Design Change Package Close-Out Memorandum

\section{SECTION 13}

DEFINITIONS

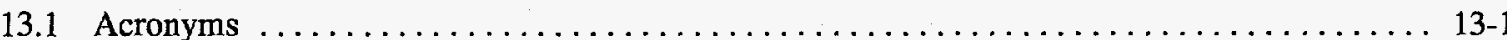



\section{SECTION 14}

REFERENCES

\section{APPENDIX A}

\section{APPENDIX B}

PRIORITIZING WORK

B-1

B.1 Work Control Prioritization of Design Change Packages (and Associated Work Requests) ..... B-

B.2 DCP/WR Prioritization Overview

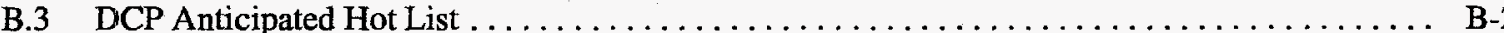

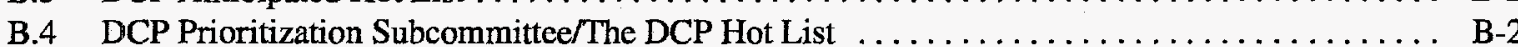




\section{LIST OF FORMS}



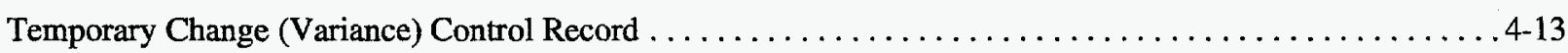

Temporary Change (Variance) Control Record (Cont.) .....................

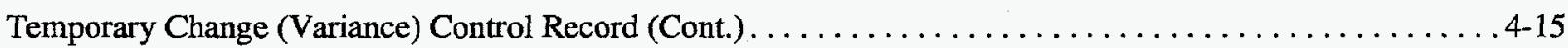





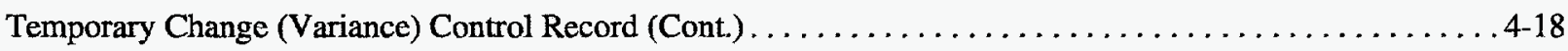

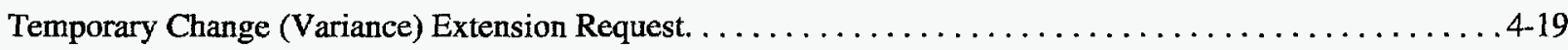

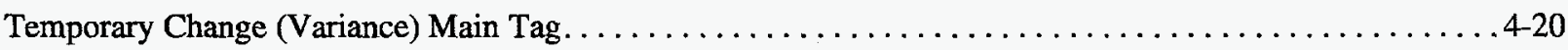

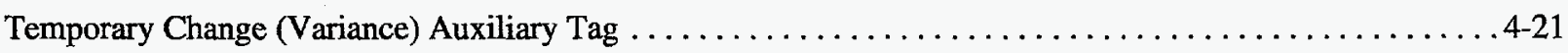

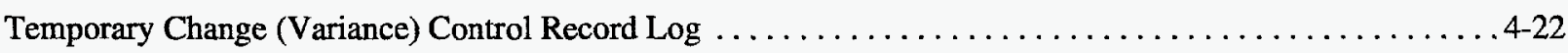

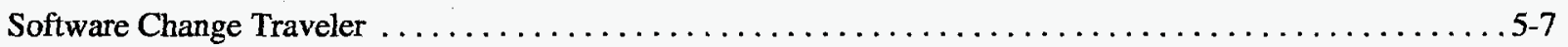

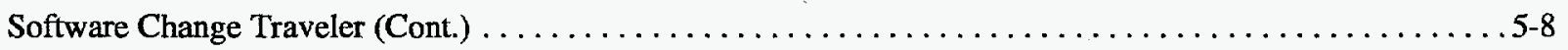

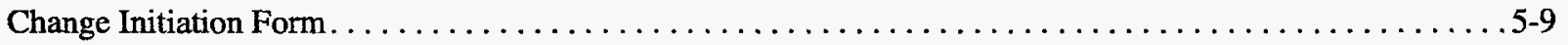

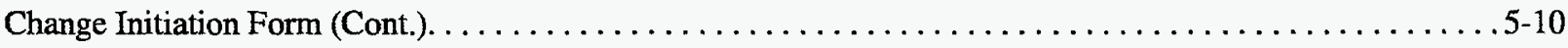

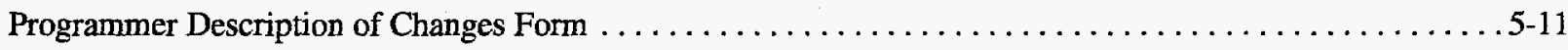



Post-Modification Testing Form. . . . . . . . . . . . . . . . .



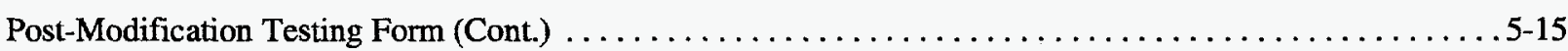

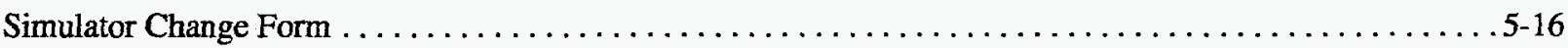



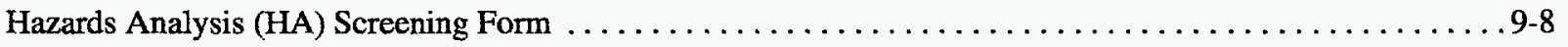

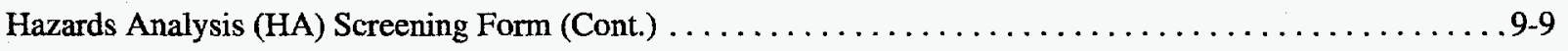



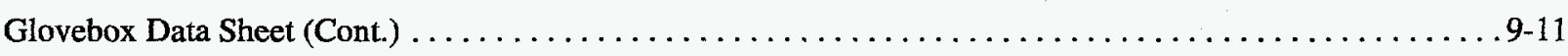

Process Hazard Analysis Information Checklist. . . . . . . . . . . . . . . . .

Unreviewed Safety Question Determination and Screening Worksheet (Form 1617) . . . . . . . . . . 10-23

Unreviewed Safety Question Determination and Screening Worksheet (Form 1617) (Cont.) . . . . . . . . . 10-24

Unreviewed Safety Question Determination and Screening Worksheet (Form 1617) (Cont.) . . . . . . . . 10-25

Unreviewed Safety Question Determination and Screening Worksheet (Form 1617) (Cont.) . . . . . . . . . 10-26

Unreviewed Safety Question Determination and Screening Worksheet (Form 1617) (Cont.) ............ 10-27 


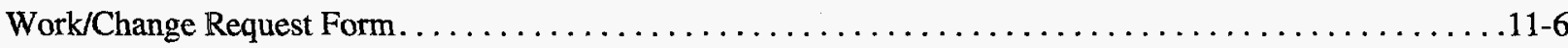

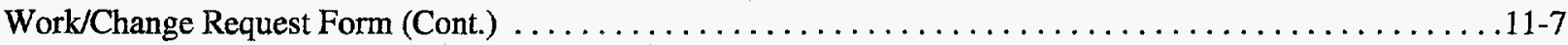

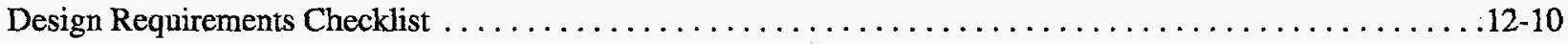

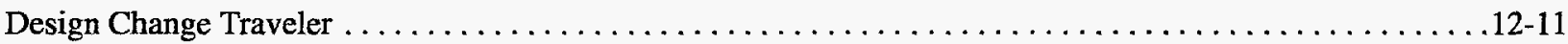



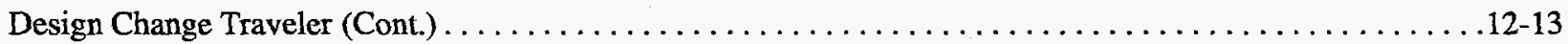

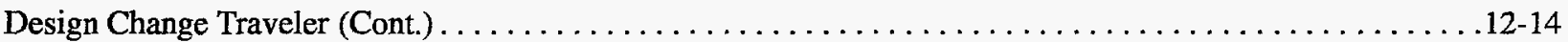

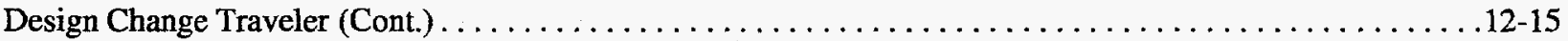

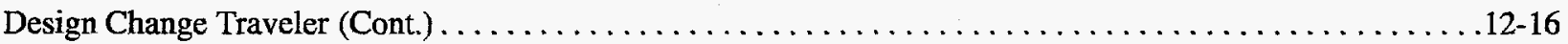



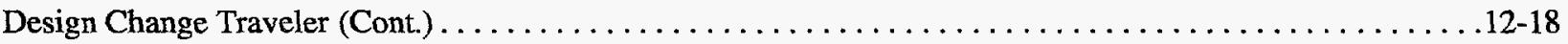

Installation Instructions . . . . . . . . . . . . . . . . . . . . . . . . . . . . . . . . .

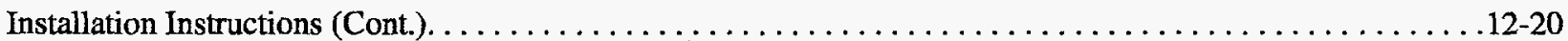

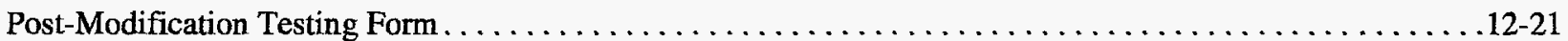

Post-Modification Testing Form (Cont.) $\ldots \ldots \ldots \ldots \ldots \ldots \ldots \ldots \ldots \ldots \ldots \ldots \ldots \ldots \ldots \ldots \ldots \ldots \ldots \ldots \ldots \ldots \ldots \ldots, 22$

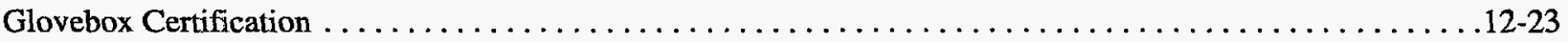

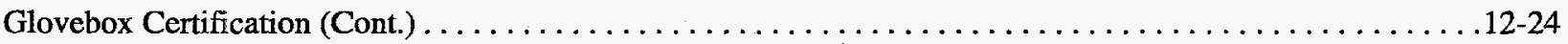

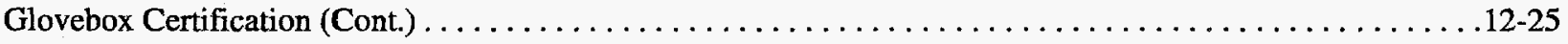

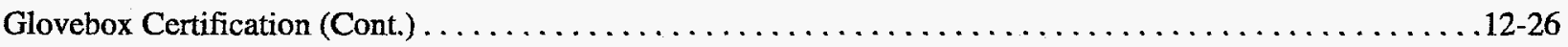

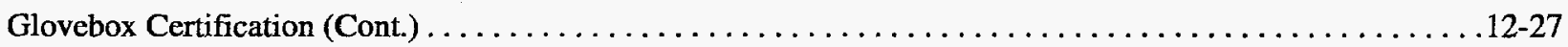

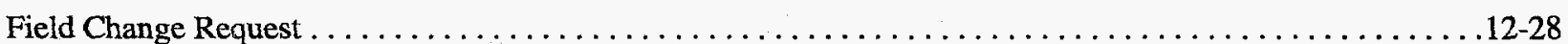

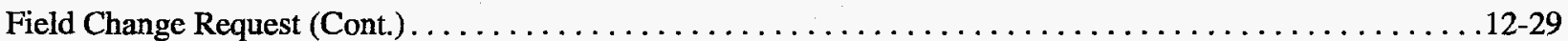

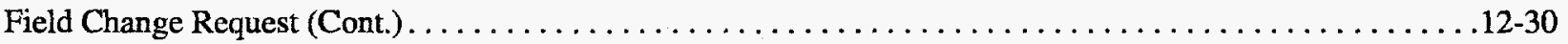

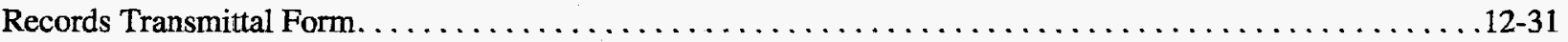

Design Change Package Close-Out Memorandum. ......................

Design Change Package Tracking Number Memorandum. . . . . . . . . . . . . . . . . . . 12-33

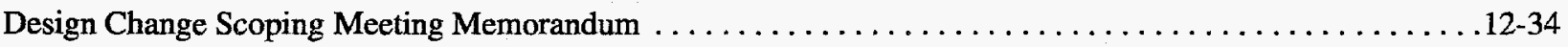

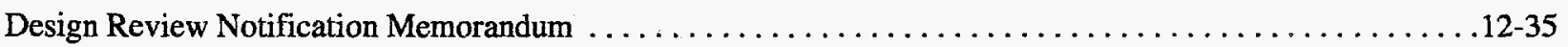

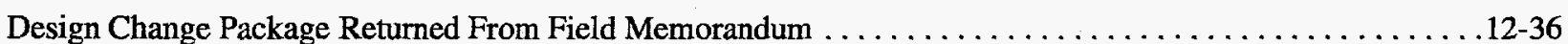

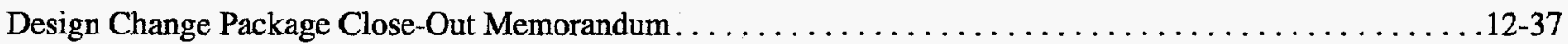

xviii Table of Contents 


\section{Section 1: Introduction}

\section{SCOPE}

New/Modified
Processes or
Experiments

GPP \& Line

Item Funded

Construction

Projects
Temporary or Permanent Changes to TA-55 that Affect SSCs Described in Safety Analysis
Major Mods to Maintenance or Surveillance Procedures

\section{TYPES OF CHANGES}

Process or

Experiment Changes
Facility Changes
Software

Changes to FCS
Procedure Changes

Design
Document
Changes

As-found

Changes \&

Nonconforming Items 
•

•

• 


\section{INTRODUCTION}

This manual is the guide for initiating change at TA-55. It describes the change and work control processes employed at TA-55 to ensure that all proposed changes are properly identified, reviewed, approved, implemented, tested, and documented so that operations are maintained within the approved safety envelope. All Laboratory groups, their contractors, and subcontractors doing work at TA-55 follow requirements set forth herein.

Persons who are about to perform work at TA-55 should first ask themselves

- Is there a change?

- Does the change increase hazards?

- Who has the authority to approve the change?

- Is the work approved?

This manual will assist the reader in answering these questions.

\subsection{Purpose}

The purpose of the TA-55 Change Control Manual is to

- provide a single instructional reference on how change shall be managed at the TA-55 facility

- establish a common understanding of the various processes among requesters and change administrators

- promote greater communications among individuals involved in changes throughout the TA-55 facility

\subsection{Scope}

This manual applies to all

- new and modified processes and experiments inside the TA-55 Plutonium Facility, PF-4

- general plant project (GPP) and line item funded construction projects at TA-55 (See section 4.2.3.)

- temporary and permanent changes that directly or indirectly affect structures, systems, or components (SSCs) as described in the safety analysis, including Facility Control System (FCS) software

- major modifications to procedures

This manual does not apply to maintenance performed on process equipment or facility SSCs or the replacement of SSCs or equipment with documented approved equivalents. 


\subsection{Organization of this Manual}

This manual is organized around major classes of changes occurring at TA-55 deemed important by the U.S. Department of Energy (DOE) or Nuclear Materials Technology (NMT) management as subject to change control (see the flow diagram at the end of this section). This document performs two functions:

- describes the unique attributes differentiating each of these major classes of change

- identifies the necessary steps to execute each of the different major classes of change

The change execution steps describe how requesters and change administrators implement each of the five major classes of change.

Because many of these executing steps are common to several of the classes of change, they have been grouped together into sections. As each of the classes of change is described, the reader is referred to the appropriate section detailing how to execute that specific class of change.

\subsubsection{Major Classes of Change}

Major classes of change are:

- process or experiment changes in PF-4 (see section 3)

- facility changes (see section 4)

- software changes to the Facility Control System (see section 5)

- procedure changes (see section 6)

- design document changes (see section 7)

- as-found changes and dispositioning nonconforming items (see section 8 )

\subsubsection{Sections on Executing Change}

The purpose of these sections is to provide the individual requesting a change with a description of the tasks required to execute each of the six major classes of change. The narratives define what the sequence of tasks is and who is responsible for performing each of these required tasks. Sections on executing change are:

- Section 9: Hazards Analysis

- Section 10: Unreviewed Safety Question Determination

- Section 11: Initiating a Work/Change Request

- Section 12: Building and Processing a Design Change Package 

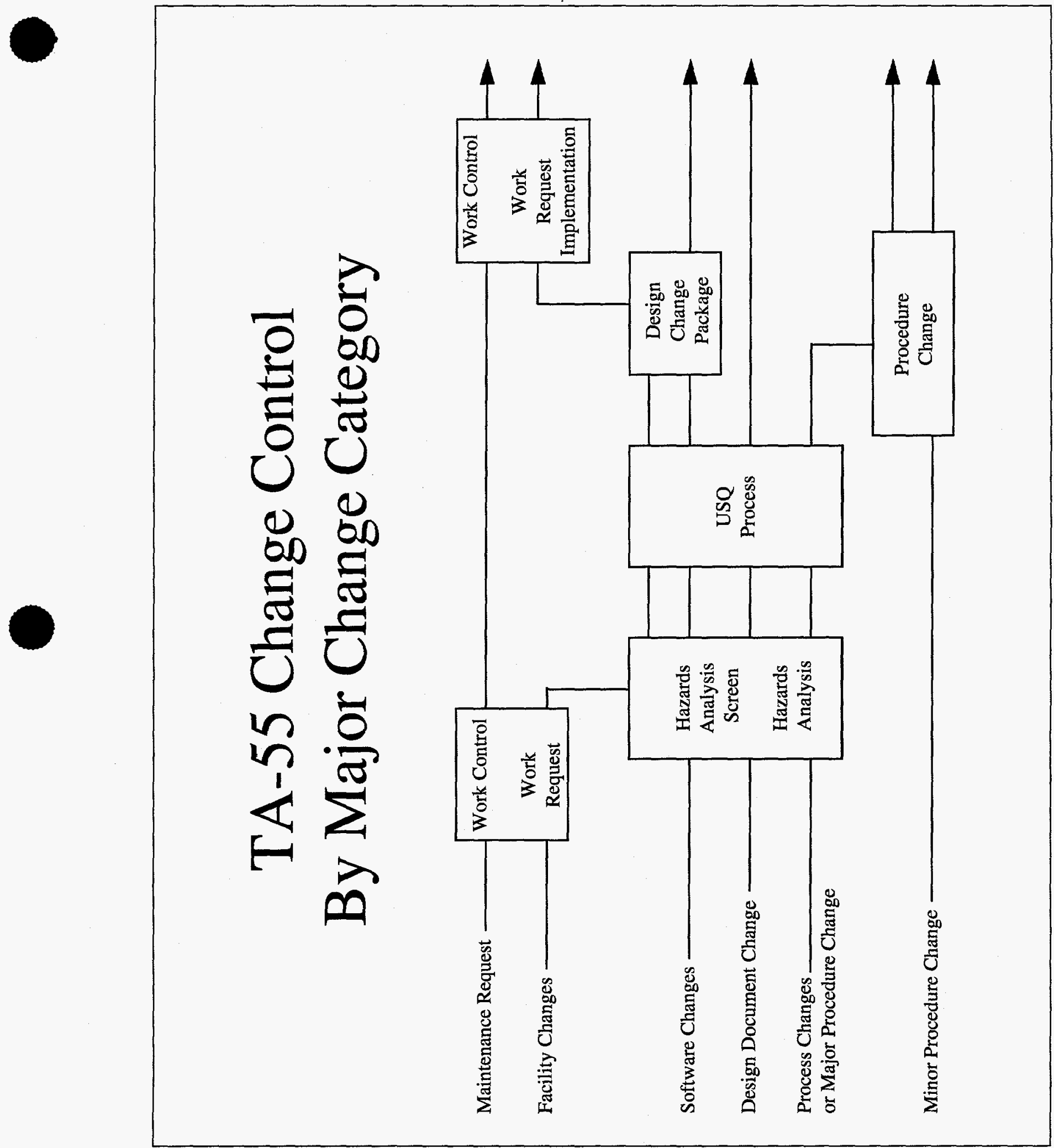


\section{Section 2: Responsibilities}

1. Facility Users

- Provide information for USO

- Complete ES\&H Project Summary

- Perform Hazards Analysis Screens

2. NMT Division Directo - Comformance w/ DOE Orders, Federal \& State Regulations. Laboratory requirements - Signs positive USQ

3. TA-55 Group Leaders

- Ensure operations w/in safety envelope of Hazards Analysis

- Provide information for USQDs and safety analysis documentation

Provide designs that meet appropriace requirements
4. Fac. Mgmt. Group NMT-8

- Update safery analysis

- Perform USO evaluations

- Support Operating Groups

\subsection{NMT-8 Group Leader \\ - Approves USQ Screets \& USQDS \\ HY-3 of positive USODs \\ - Provides list of changes involving USODs \\ - Ensure changes incorporated in \\ SAR updace \\ 4.2 USQ Reviewer \\ - Trained \& authorized to perform \\ USO Screens and USODS}
4.3 Configuration Control Beard - Approve changes reguiring USQD - Review \& approve changes upo - Approst from line management. - Approves changes prior to operati
if significant field changes were required

\subsection{Area Work Supervisors - Assure work planned, hazards reviewed, controls implemented - Verify Work/Change Requests - Conplete Variance Control Record for semporary mods - verify VCR tags \\ 4.5 FCS Programmers - Implement requested changes - Determine what tests are necessary - Define changes to simulator and involved system \\ - File archiving, simulation testing, facility testing (if required)}

\subsection{Systems Engineers - Ensure variance is appropriare way to make temporary mods - Approve design changes for new}

4.7 Operations Center Supervisor - Oversee temporary change control process

- Approves any sofwware testing on actual factity hardware

- Ensures training on software changes

\subsection{As-Builting}

- Issue project and drawing mambers - Maintains, distributes, stores

facility drawings

4.9 Configuration Management - Ensures requirements, physical piant. and documentation consistent

4.10 Authorization Basis Team - Maintains FSAR

- Performs/reviews Process Hazards Analysis - Oversees USO process

4.11 Master Equipment List Office - Assigns identification numbers to SSC

- Provides MEL Documentation
5. Facility Safety Review Committee - Revicw changes requiring USQD - Revier all Positive USQDs;

recommend approval to NMT-DO - Periodic audits of Hazards Analysis Screens

\section{ESH-3}

- Reviewsisigns all Work/Change Requests

- Independent reviews of USQDs

7. ESH-1

- Reviews/kigns all Work/Change

Requests 
•

•

• 


\section{RESPONSIBILITIES}

\subsection{Facility Users}

All who use TA-55 facilities, including Laboratory employees and contractors and their design agents

- follow the requirements outlined in this manual

- provide sufficient information about the change to enable the Facilities Management Group (NMT-8) to determine whether a unreviewed safety question (USQ) exists

- complete an ES\&H Project Summary Sheet for their project or process (this includes addressing the National Environmental Policy Act [NEPA] concerns)

- perform Hazards Analysis Screen

\subsection{Nuclear Materials Technology Division Director}

Nuclear Materials Technology (NMT) division director signs all positive USQ safety evaluations and has responsibility for the conformance of facilities and operations at TA-55 to applicable

- U.S. Department of Energy (DOE) Orders

- Laboratory requirements

- Federal regulations

- New Mexico state regulations

\subsection{TA-55 Group Leaders}

TA-55 group leaders

- ensure that operations under their charge are within their approved safety envelope as defined by the TA-55 Hazards Analysis

- provide information needed for performing safety evaluations and updating safety analysis documentation and designs that meet the appropriate design requirements and standards commensurate with the change

- see that group personnel, their contractors, and other groups/individuals that they host follow the requirements in this manual 


\subsection{Facilities Management Group, NMT-8}

Facilities Management Group, NMT-8,

- reviews and updates this manual

- updates safety analysis documentation

- performs USQ evaluations

- provides support to TA-55 operating groups through

- authorization basis office

- work control

- configuration management (CM)

- as-built program

- systems engineering

- maintenance

- area work supervisors (AWSs)

- Master Equipment List (MEL) documentation

\subsubsection{NMT-8 Group Leader}

- approves all USQ screens and USQ safety evaluations

- notifies ESH-3 of any positive unreviewed safety question determinations (USQDs)

- semi-annually sends ESH-3 a list of any changes that require a USQD and have been implemented at the facility

- ensures that all changes made under this procedure are reflected in the safety analysis report (SAR) update process

\subsubsection{USQ Reviewers}

- USQDs

- Only trained and authorized personnel review USQ screens and USQ safety evaluations. A list of these people is kept in the NMT-8 Group Office. 


\subsubsection{Configuration Control Board}

The Configuration Control Board (CCB) is responsible for reviewing and approving proposed changes that result in a positive USQD or other changes as recommended by the appropriate line manager. If significant field changes are required during the implementation phase, the $\mathrm{CCB}$ reviews and approves the changes before operations can begin.

\subsubsection{Area Work Supervisors}

AWSs

- provide assurance to the facility manager that

- work is planned

- hazards are reviewed

- controls have been developed and implemented to control the hazards in their area of responsibility

- verify that the Work/Change Request (W/CR) is filled out correctly and the appropriate information is attached

- fill out the Variance Control Record (VCR) and the VCR Extension Request (when necessary)

- ensure that the variance tags (found in the Operations Center) are filled out and installed properly

\subsubsection{Facility Control System Programmers}

Facility Control System (FCS) programmers

- make requested changes to the FCS software and determine what tests are necessary to prove the changes function correctly

- define the changes to the simulator, as well as the systems involved

- perform file archiving, simulation testing, and facility testing (if necessary)

Refer to section 5 for a more extensive description of the FCS software change process.

\subsubsection{Systems Engineering}

System engineer

- ensures that the variance is the appropriate method for making a temporary change to the structure, system, or component (SSC)

- reviews safety impacts of proposed changes to facility systems 
- reviews and approves design for new construction and changes or modifications to facility SSC

\subsubsection{Operations Center}

The Operations Center supervisor oversees the temporary change control process and

- ensures that variances are carefully reviewed for possible impact on operations

- approves any software testing that takes place on the actual facility hardware

- ensures that any training associated with the software changes has taken place before final software installation

\subsubsection{As-Builting}

As-Builting

- maintains, distributes, and stores facility drawings

- issues project identification numbers and engineering $\mathrm{C}$ and $55 \mathrm{Y}$ drawing numbers

\subsubsection{Configuration Management}

Configuration Management (CM)

- ensures that the design requirements, the physical plant, and the documentation are consistent throughout the life cycle of TA-55

- assists facility users and their agents with the TA-55 change process

\subsubsection{Authorization Basis Team}

The Authorization Basis Team

- maintains the authorization basis documentation (FSAR, TSRs, HA, USQDs, etc.)

- performs and reviews process hazards analyses

- oversees the USQ process at TA-55 


\subsubsection{Master Equipment List Office}

MEL Administrator

- assigns identification numbers/symbols to SSC

- provides MEL documentation consistent with $\mathrm{CM}$ standards

\subsection{Facility Safety Review Committee}

The Facility Safety Review Committee (FSRC)

- may independently review any change requiring a USQ determination

- reviews all positive USQ determinations and recommends approval (or not) to the NMT division director

- periodically audits TA-55 operating groups to ensure that hazards analysis screens are being performed properly

\subsection{ESH-3}

The Facility Risk Management Group, ESH-3,

- is available for performing independent reviews of all safety evaluations prepared under this procedure, but review by this group is not required

- reviews and signs off on all W/CRs

\subsection{ESH-1}

The Radiological Protection Group, ESH-1, reviews and signs off on all W/CRs. 


\section{Section 3: New Process or Experiment or Changes to an Existing Process or Experiment}

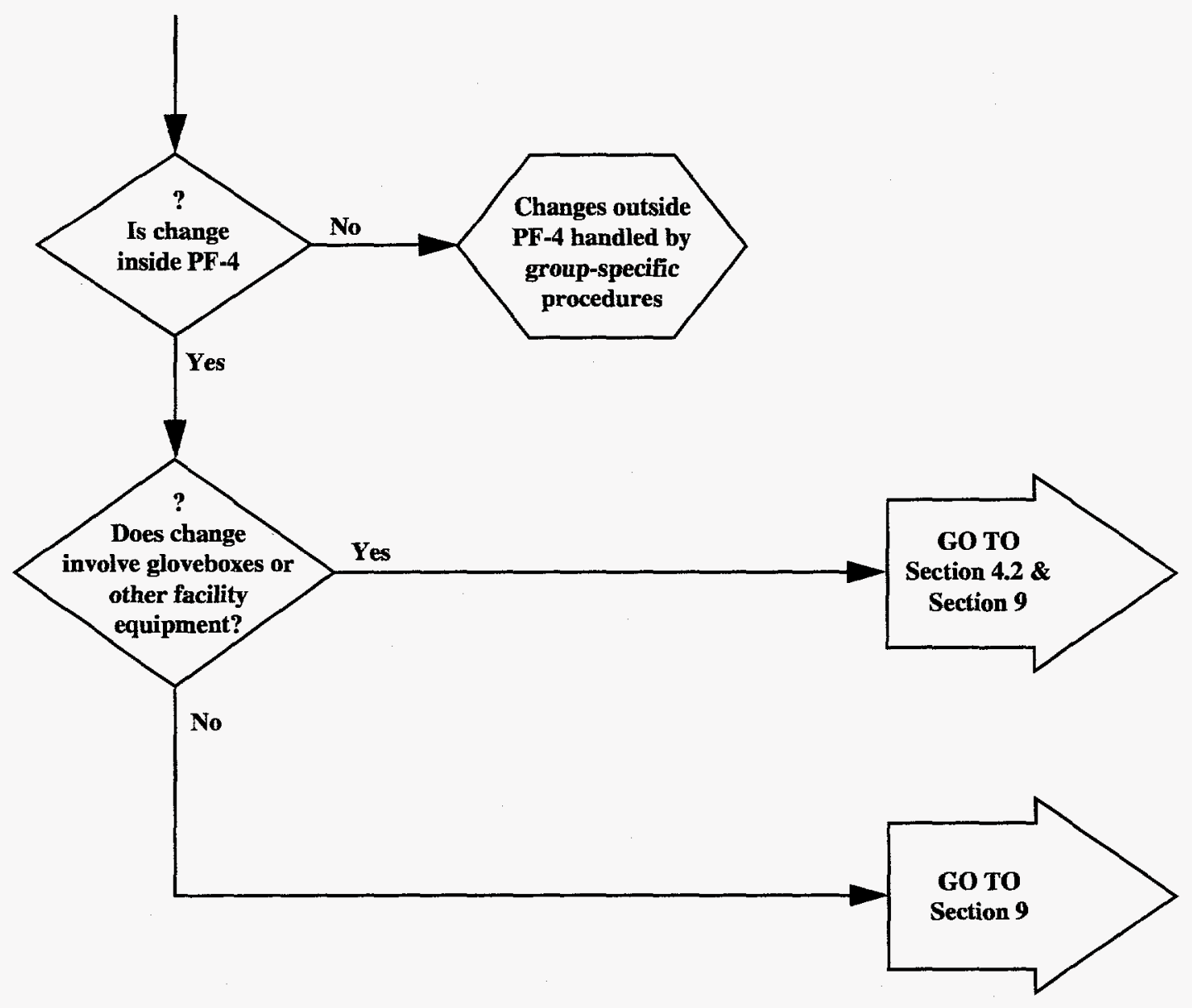


•

•

• 


\section{NEW PROCESS OR EXPERIMENT OR CHANGES TO AN EXISTING PROCESS OR EXPERIMENT}

NOTE: The procedural steps for introducing a new process or experiment in $\mathrm{PF}-4$ are the same as those used for making a change to an existing process or experiment in PF-4.

This section covers new processes or experiments or changes to an existing process or experiment in PF-4. Changes related to activities performed outside of PF-4 (i.e., PF-3 cold laboratory areas) are controlled by group specific procedures. A few examples of process or experiment changes are

- change in criticality limits or SNM form

- changes in the chemistry

- change of set points or operating parameters

- equipment changes

- changes in electrical, motion, pressure, heat, cold, or radiant sources

Some process equipment is considered safety significant because of its importance to worker safety or the safety class features of PF-4. The guidance in section 3.2 of this manual must be followed when making changes to safety significant process equipment. Examples of safety significant process equipment include, but are not limited to,

- IFIT ceiling armor

- cold welder pressure vessel

- cold welder pressure safety valve

- $\mathrm{H}_{2}$ detector, GB-116

- $\mathrm{H}_{2}$ excess flow valves in Rooms 114 and 305

\subsection{Process or Experiment Only Changes}

Process or experiment only changes do not involve modifications or changes to gloveboxes or any other facility structure, system, or component (SSC). To make process only changes, complete a Hazards Analysis screen per the instructions in section 9 of this manual. Change procedure per instructions in section 6 of this manual. To determine readiness, follow the guidance in 538-GEN, Startup and Restart of Operations of TA-55 Facilities. 


\subsection{Process or Experiment Changes Involving Gloveboxes or Other Facility SSC Under Change Control}

A list of facility SSC under change control is found in section 4.2 of this manual. To make process or experiment changes involving gloveboxes or other facility SSC,

- complete a Hazards Analysis Screen per instructions in section 9 of this manual

- initiate a Work/Change Request per instructions in section 11 of this manual

- participate in the design process per sections 12.1.1 and 12.1.2 of this manual

- change procedure per instructions in section 6 of this manual

- follow the guidance in 538-GEN, Startup and Restart of Operations of TA-55 Facilities. 


\section{Section 4: Facility Changes}




•

•

• 


\section{FACILITY CHANGES}

\subsection{Emergency Work}

Emergency work is authorized by the Operations Center shift supervisor when immediate action is necessary to stabilize a situation/condition involving SSC critical for the operation of TA-55 facilities. In such cases, required documentation (i.e., Work/Change Request, USQ, Design Change Package, etc.) shall be prepared after the situation/condition is stabilized. For all emergency work, an Emergency Work Request Memorandum must be completed and kept on file in the Operations Center. An emergency work request form is included at the end of this section.

\subsection{Making Permanent Changes to Facility SSC}

The following is a list of facility SSCs under change control:

- safety class or safety significant SSCs

- confinement system (PF-4 structure, high-efficiency particulate air [HEPA] filters and plenums, vault doors, ventilation exhaust and intake plenums, ductwork from plenums to the structure, and supply air intake valves)

- electrical distribution system (EDS)

- chemical storage tank berms

- vault racks and shelving

- gloveboxes

- ventilation system

- hydrogen detector on glovebox GB 116

- emergency paging system

- uninterruptible power supply (UPS)

- instrument air system (IAS)

- criticality alarm system

- Isotope Fuels Impact Tester (IFIT) ceiling armor

- fire suppression system, including fire water supply system

- FCS

- systems described in the facility SAR

- continuous air monitoring (CAM) system

- diesel generator 
- wet vacuum

- dry vacuum

- primary chilled circulating water system

- positive or negative pressure chilled circulating water system

- in-line and fixed head air sampling system

- process air

- process gas

- industrial waste lines

- fire detection system

- acid chemical feed system

- fire suppression halon system

- PF-4 trolley

- industrial gas services

- vault chilled circulating water

- industrial water

- breathing air

- caustic waste lines

- caustic chemical feed system

- emergency lighting

- safety showers and eyewashes

- tanks or tank systems required to meet Resource Conservation and Recovery Act (RCRA) requirements

A DCP is required if

- Change affects any facility SSC listed above.

- Change affects an SSC with a Management Consequence of Failure Category of M1, M2, or M3. (See section 4.2.1.)

- Change results in new construction at TA-55.

- CM determines, at their discretion, that a DCP is required.

\subsubsection{Management Consequence of Failure Categories}

Graded approach categories assigned to SSCs are defined as

- Category M1 
- Failure of the SSC may cause the death or serious injury or illness of a member of the public or may cause severe damage to the environment beyond the boundaries of the Laboratory.

- Category M2

- Failure of the SSC may cause minor injury, illness, irritation, or annoyance to a member of the public or may cause death or serious (disabling) injury or illness of a Laboratory worker, or may cause damage to the environment within the Laboratory boundaries, or may allow loss or theft of Category I quantities of special nuclear material (SNM) or national security information, or may cause the total loss of the use of a facility or major process or may have a severe mission or economic impact.

- Category M3

- Failure of the SSC would have no impact on the public, but it may cause minor injury or illness to a Laboratory worker, or may cause damage to the environment limited to the immediate area around the facility, or may allow loss or theft of Category II or III quantities of SNM or classified information, or may cause damage to a facility or process, or have a serious mission or economic impact.

- Category M4

- Failure of the SSC would have no probable impact on the public, Laboratory workers, the environment, or safeguard and security concerns, but it may cause minor damage to a facility or process resulting in mission interruption or inconvenience.

\subsubsection{Executing Permanent Facility Changes Requiring Configuration Management}

To execute facility changes requiring configuration management

- complete a Hazards Analysis Screen (process only changes) per instructions in section 9 of this manual

- complete a USQ screen per instructions in section 10 of this manual

- initiate a Work/Change Request per instructions in section 11 of this manual

- participate in the design process per sections 12.1.1 and 12.1.2 of this manual

\subsubsection{Construction Projects}

All GPP and Line Item construction projects at TA-55 require a DCP developed in accordance with instructions provided in this manual. For these large projects, the group or project leader responsible for development of the DCP develops the design and supporting materials in accordance with the Facilities, Security, and Safeguards (FSS) Projects Document Manual. Use the Projects Document Manual for other large projects that warrant the same level of detail. 
FSS project leaders overseeing construction activities at TA-55 do the following:

1. Ensure that required interfaces are established with NMT-8. Failure to do so could result in significant delays or unanticipated costs.

2. Contact $\mathrm{CM}$ immediately for assistance in meeting requirements for doing work at TA-55.

3. Ensure that NMT-8 Systems Engineering is a partner in the design and design review process.

4. Ensure that the design agent contacts the NMT-8 administrator for the MEL to obtain proper procedure for identifying and numbering equipment at TA-55.

5. Schedule construction through NMT-8 Work Control.

6. Follow the guidance in sections 10 through 12 of this manual.

\subsection{Temporary Changes (Variances) to Facility SSC}

Temporary changes (variances) made to a facility structure, system, or component (SSC) described in the safety analysis or the facility safety analysis report (SAR) are controlled. The guidance herein for temporary changes does not apply when the temporary change is covered by an approved safe operating procedure (SOP) and the Operations Center has been notified of the installation and removal of the temporary change or variance device. The following are examples of temporary change or variance:

- lifted leads

- electrical jumpers

- pulled circuit cards

- disabled annunciator alarms

- mechanical jumpers or bypasses

- temporary set point changes

- installation or removal of blank flanges

- disabled relief or safety valves

- plugged floor drains

- temporary pipe supports

Instructions for initiating, evaluating, approving, implementing, disposing, and extending temporary changes are discussed below and can also be found on the back of the Variance Change Record (VCR). A VCR is included at the end of this section. 


\subsubsection{Initiating Temporary Changes}

A temporary change is granted for an initial 90 -day maximum period. Area work supervisor (AWS) initiates the temporary change by performing the following steps:

1. Obtain a unique sequential tracking number from the Operations Center VCR Log. The assigned number consists of VCR-WW-XXX-Y, where

- VCR is the acronym for Variance Control Record

- WW is the fiscal year the VCR was initiated (e.g., 96)

- $\mathrm{XXX}$ is the sequential VCR number (e.g., 001)

- $\mathrm{Y}$ is the optional alpha character signifying VCR extension

2. Record the tracking number in the top right-hand corner of every sheet of the VCR in the space provided.

\subsubsection{Filling out the VCR}

\subsection{Area Work Supervisor}

1. Briefly state subject of variance.

2. State the names of the affected systems.

a. Include the 4-digit identification number of the affected systems.

(Reference the Master Equipment List [MEL].)

b. Include the 4-digit identification number of the affected equipment/ component. (Reference the MEL.)

3. Check the type of variance. If the request is to extend an existing variance, see the section below. If the request is to supersede an existing variance, reference that variance in the space provided.

4. Denote impacted system grade.

5. If known, denote consequence of failure category.

6. Describe the proposed variance and why it is necessary.

a. Include/attach all necessary technical information to completely describe the temporary change.

b. State the requested length of the variance. 


\subsection{Systems Engineer}

1. Describe the facility equipment, components, and functions that the variance will impact. Indicate functions that will be bypassed and components that will be replaced or altered.

2. List applicable documents that are affected by the proposed variance.

a. Attaching marked-up drawings depicting the requested variance is encouraged, but not required.

b. List procedures that may have to be temporarily revised to support the variance. If appropriate, also attach marked-up procedures.

3. List any special instructions for installation, operation, or other considerations related to the variance.

4. To ensure impacted SSCs are operable after removal of the variance device, state testing requirements and return-to-service instructions.

5. Define any limits or precautions that should be applied when installing the variance devices or operating the impacted equipment.

\subsubsection{Evaluating Temporary Changes}

1. Systems engineer responds to the questions in section 2.0 of the VCR checking Yes, Don't Know, or No in the appropriate box. If any response is Yes or Don't Know, then check the "Yes" box in section 2.1 of the VCR.

2. To complete the Technical Assessment, the systems engineer enters the unreviewed safety question (USQ) process in section 10 of this manual. Information from the USQ process is recorded in section 3 of the VCR.

NOTE: If the proposed variance results in a positive USQ screen, then Configuration Control Board (CCB) approval is required. If the proposed variance results in a positive unreviewed safety question determination (USQD), then Facility Safety Review Committee (FSRC) and DOE approval are required.

\subsubsection{Approving Temporary Changes}

Operations Center personnel do the following after the technical assessment and USQ review are satisfactory.

1. Assign an expiration date (not to exceed 90 days). 
2. Issue variance tags to the AWSs for their preparation and attachment to the VCR. AWS signs in the space provided.

3. Signify approval by signing and dating in the spaces provided along with the cognizant systems engineer.

\subsubsection{Implementing Temporary Changes}

The following steps are performed upon approval of the VCR.

\subsubsection{Area Work Supervisor}

1. Evaluate the change to determine if a Work/Change Request (W/CR) is required. If required, follow the instructions in section 9 of this manual. In either event, proceed to the next step.

2. Determine lockout/tagout requirements. (See 503-GEN, Lockout and Tagout for Red Locks, and 546-GEN, Lockout and Tagout for Blue Locks.)

3. Obtain variance tags from the Operations Center.

4. Deliver a complete VCR package to the person performing the variance device installation.

\subsubsection{Person Installing the Variance Device}

1. Install the variance device in accordance with approved practices and procedures.

2. AWS and the person installing the variance device attach the VCR tag to the variance device and any auxiliary tags to related components impacted by the temporary change.

NOTE: Independent verification of the variance device installation is required for all safety class and safety significant SSC described in the safety analysis. Verification is conducted by personnel familiar with the requirements for temporary change and who have a working knowledge of the variance device(s) and the system(s) to which they are being applied.

3. Notify the Operations Center that the variance device(s) are installed.

4. Return the VCR package to the Operations Center for retention.

5. Indicate successful installation of the variance device(s) by initialing the VCR Log. 


\subsubsection{Systems Engineer}

Perform a functional check of the installed variance to ensure that it will support the system/component's design function during operation. Documentation of the functional check must be provided and retained with the VCR package. The PostModification Testing Form in section 12 of this manual may be used for this purpose.

\subsubsection{Operations Center Shift Supervisor}

1. Retain the original VCR and VCR package.

2. Perform a monthly review of the VCR Log to identify those VCRs that have expired or are no longer needed.

\subsubsection{Removal of Temporary Changes}

\subsubsection{Area Work Supervisor}

1. Initiate a W/CR. (See section 5.)

2. Determine lockout/tagout requirements. (See 503-GEN, Lockout and Tagout for Red Locks, and 546-GEN, Lockout and Tagout for Blue Locks.)

3. Deliver a complete VCR package to the person performing the variance device removal.

\subsubsection{Person Removing Variance Device}

1. Remove the variance device in accordance with approved practices and procedures.

2. Remove all VCR tags and any auxiliary tags.

3. Verify that all lockout/tagout tags have been removed.

4. Perform any post-maintenance tests required.

5. Notify the Operations Center that

- Variance device(s) have been removed.

- System/components have been returned to the normal position.

- All post-maintenance tests have been successfully completed.

6. Deliver the VCR package to the Operations Center for retention and initial the VCR Log. 


\subsubsection{Systems Engineer}

1. Perform a functional check of the system/component to ensure that it meets its design function before placing it into operation.

2. Perform any acceptance tests required to ensure it is ready to be returned to service.

NOTE: Steps 1 and 2 must be documented and the documentation returned with the VCR package. The Post-Modification Testing Form in section 12 of this manual may be used for this purpose.

3. Indicate that the system/component is returned to service by signing the VCR.

\subsubsection{Operations Center Shift Supervisor}

1. Indicate acceptance of the system/component for operations by signing the VCR.

2. Forward the VCR package to the NMT-8 Information Resources Management (IRM) for retention.

\subsubsection{Extending Temporary Changes}

Following the initial 90-day variance period, only one extension with a maximum of 90 days may be granted. When more time is required on the initial variance, perform the following steps.

1. AWS fills out the VCR Extension Request.

2. Systems engineer, in consultation with the Operations Center shift supervisor, grants a variance extension.

3. If more time is needed on the variance after the 90-day extension period, the AWS initiates a new VCR.

\subsubsection{Maintaining the Variance Control Record Log}

VCR Log is managed by and retained in the Operations Center. VCR Log provides the Operations Center with the accurate and up-to-date status of variances. 


\section{Emergency Work Request Memorandum}

\section{Los Alamos}

NATIONALLABORATORY

Memorandum

NMT-8 Group Office

TA-55 Facilities Management
To/Ms: $\quad$ File, TA-55 Operations Center FromMS:

Phone/FAX:

Date:

\section{SUBJECT: EMERGENCY WORK REQUEST}

The following is approved as emergency work. (Appropriate documentation shall be compiled after the emergency situation is stabilized.)

Brief Description of Work:

Approved by:

Operations Center Shift Supervisor

Date:

Distribution:

Dave Post

Deidra Yearwood

Tom Blum

David Romero

Derek Gordon

Tom Carter

John Parker 


\section{Temporary Change (Variance) Control Record}

VCR -

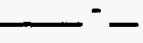

1.0 INITIATE VARIANCE

AWS Name: Date:

1.1 Subject:

1.2 System:

1.2.1 System Number:

1.3 Type of Variance:

[ ] Initial Issue

[ ] Supersedes Existing Variance Reference Old VCR -

1.5 Reason for, Length of, and Description of Proposed Variance:

1.6 Impacted Equipment and Functions: [By Systems Engineer (SE), 1.6 through 1.9]

1.7 Impacted Design Documents, Drawings, and Procedures: Document No. Title
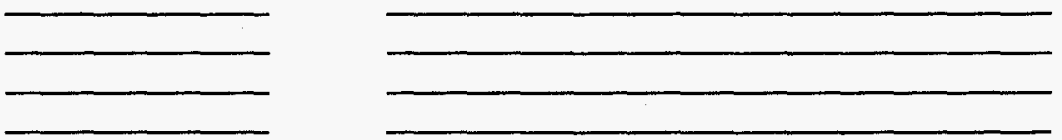

1.8 Special Actions, Instructions, or Retest Requirements:

1.9 Limits and Precautions:
Redline Attached

[ ] Yes [ ] No

[ ] Yes [ ] No

[ ] Yes [ ] No

[ ] Yes [ ] No 


\section{Temporary Change (Variance) Control Record (Cont.)}

Page 2 of 6

INSTRUCTIONS

\subsection{INITIATE VARIANCE}

The VCR is to be initiated by the appropriate AWS. Use additional continuation sheets as necessary.

Note: A variance may be granted for an initial 90 day maximum period. Following the initial variance period, one extension of 90-days maximum to the initial variance may be granted. If more time is required, a new variance must be initiated.

Obtain a sequential number from the Operations Center VCR Log and record it on each page in the space provided.

1.1 Subject: Briefly state subject of variance.

1.2 System: State the name(s) of the affected system(s)

1.2.1 System Number: Include the 4-digit identification number of the affected system(s). Ref: Master Equipment List.

1.2.2 Equipment Number: Include the identification number of the affected equipment (component). Ref: Master Equipment List.

1.3 Type of Variance: Check the type of variance. If request is to extend an existing variance, use the VCR Extension Request. If request is to supersede an existing variance, reference that variance in the space provided. Note: VCRs cannot be revised.

\subsection{SSC Classifications:}

1.4.1 Denote impacted system grades.

1. SC: safety class

2. SS: safety significant

3. MC: mission critical

4. BOP: balance-of-plant

Ref: Master Equipment List.
1.4.2 If known, denote consequence-of-failure (COF) categories (M1, M2, M3) for impacted components. Ref: Master Equipment List.

1.5 Reason for, Length of, and Description of Proposed Variance: Describe the proposed variance and why it is necessary. Include/attach all necessary technical information to completely describe the temporary change. State the requested length of the variance.

To be completed by the SE:

1.6 Impacted Equipment and Functions:

Describe the facility equipment, components, and functions that the variance will impact. Indicate functions that will be bypassed and components that will be replaced or altered.

1.7 Impacted Design Documents, Drawings, and Procedures: List applicable documents that are affected by the proposed variance. Attaching markedup drawings depicting the requested variance is encouraged but not required. List procedures that may have to be temporarily revised to support the variance. If appropriate, also attach marked-up procedures.

\subsection{Special Actions, Instructions, or Retest} Requirements: List any special instructions for installation, operation, or other considerations related to the requested variance. To ensure impacted SSC(s) are operable after removal of the variance device, state retest (e.g., functional testing) requirements and return-to-service instructions.

1.9 Limits and Precautions: Define any limits or precautions that should be applied when installing the variance devices or operating the impacted equipment. 


\section{Temporary Change (Variance) Control Record (Cont.)}

Page 3 of 6

VCR -

\subsection{TECHNICAL ASSESSMENT}

"Yes" or "Don't Know" in response to any of the questions in the following checklist will require a WRITTEN TECHNICAL ASSESSMENT of the variance to be performed.

\begin{tabular}{|c|c|c|c|}
\hline Technical Assessment Checklist & Yes & Don't Know & No \\
\hline $\begin{array}{l}\text { 1. Will the change fail to meet design requirements (e.g., pressure, temperature, } \\
\text { voltage, current, material compatibility)? }\end{array}$ & & & \\
\hline $\begin{array}{l}\text { 2. Will the change significantly increase the loading on any emergency electrical } \\
\text { system? }\end{array}$ & & & \\
\hline $\begin{array}{l}\text { 3. Will the change alter the performance characteristics of any safety-class or } \\
\text { safety-significant system or component? }\end{array}$ & & & \\
\hline $\begin{array}{l}\text { 4. Will the operation or failure of the change affect more than one train of a } \\
\text { redundant system? }\end{array}$ & & & \\
\hline $\begin{array}{l}\text { 5. Will the change create conditions beyond those assumed in the fire hazards } \\
\text { analysis? }\end{array}$ & & & \\
\hline 6. Will the change increase the potential for personnel hazard or equipment damage? & & & \\
\hline $\begin{array}{l}\text { 7. Will the change significantly reduce operator's ability to monitor or control any } \\
\text { safety system? }\end{array}$ & & & \\
\hline $\begin{array}{l}\text { 8. Will the change increase the potential for higher levels of airborne radioactivity } \\
\text { or off-site dose? }\end{array}$ & & & \\
\hline 9. Will the change affect seismic qualification or stress analysis of any system? & & & \\
\hline 10. Is the intent of the original procedure/instruction altered? & & & \\
\hline
\end{tabular}

2.1 Technical Assessment Required.... [ ] No [ ] Yes

3.0 EVALUATION (By SE)

USQ Screen No.

USQ Evaluation No.

completed/approved and attached..... completed/approved and attached

$\mathrm{CCB} / \mathrm{FSRC}$ review required and approved

4.0 APPROVE VARIANCE (By Operations Center)

Variance tags prepared, listed in Section 5.0, and attached.

Tags Prepared By:

(AWS)

Sig:

Technical assessment performed and VCR accepted for implementation.

SE Approval:

Operations Center Approval:



Extension Expiration Date:

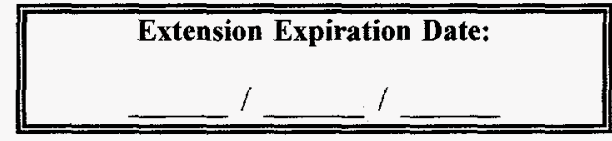




\section{Temporary Change (Variance) Control Record (Cont.)}

Page 4 of 6

\section{INSTRUCTIONS}

\subsection{TECHNICAL ASSESSMENT}

The SE will respond to the questions in the Technical Assessment Checklist, Section 2.0, checking "Yes", "Don't Know", or "No" in the appropriate block. If the response is "No" to all of the questions, continue to Section 3.0.

If any response is "Don't Know" or "Yes", a written technical assessment of the variance is required in order to evaluate its technical acceptability.

2.1 Technical Assessment Required. Check the appropriate requirement and proceed to Section 3.0.

\subsection{EVALUATION}

The SE will assess the impact of the proposed variance on the safe operation of the facility and personnel safety.

USQ Screen. A USQ screen will be performed in accordance with procedure 544-GEN and attached to this VCR. If the screen is positive, a more detailed USQ evaluation per 544-GEN must be performed.

USQ Evaluation. If the USQ screen is positive, perform a USQ evaluation in accordance with procedure 544-GEN, obtain approval, and attach to this VCR. Record the assigned number of the USQ evaluation in the space provided.

\subsection{APPROVE VARIANCE}

Provided the technical assessment and USQ review are satisfactory, assign the expiration date (90-days maximum) to the variance.

The AWS will obtain VCR tags from the Operations Center and attach them to the VCR. Tag numbers and descriptions will be recorded in Section 5.0.
The SE and the Operations Center will signify their approval for installation by signing and dating in the spaces provided.

Maintain the original VCR package in the Operations Center. 


\section{Temporary Change (Variance) Control Record (Cont.)}

Page 5 of 6

VCR -

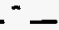

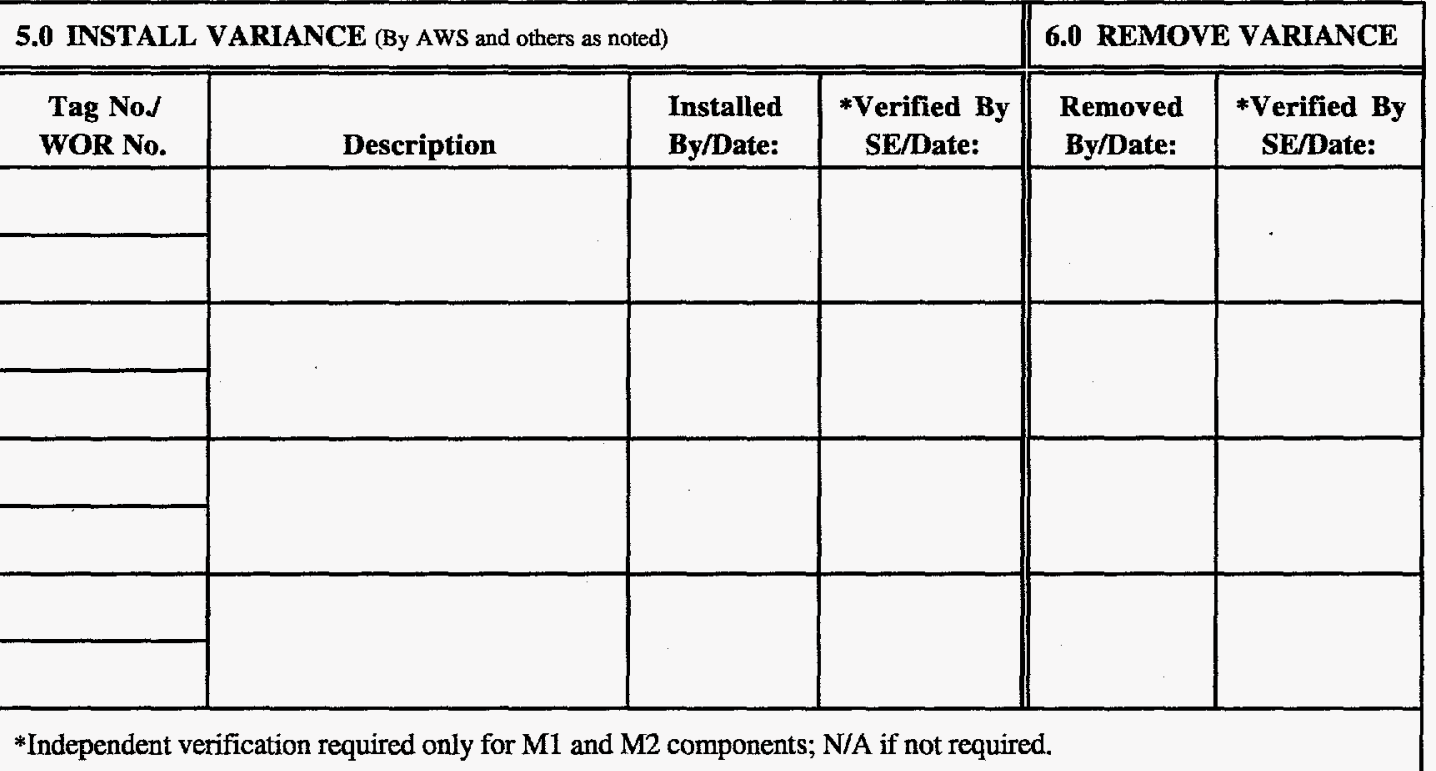

7.0 RETURN SSC TO SERVICE (By Operations Center)

7.1 All special retesting completed satisfactorily and associated documentation attached.

Signature: Date:

(SE)

7.2 All variance tags have been removed and returned to the Operations Center.

Signature: Date: 1

(AWS)

7.3 All VCR tags have been checked against the VCR tag log to ensure all tags have been returned.

7.4 All verifications are complete (where applicable). Impacted SSC(s) are ready to return to normal service. All applicable documentation is attached.

Signature: Date:

(Operations Center shift supervisor) 


\section{Temporary Change (Variance) Control Record (Cont.)}

\section{INSTRUCTIONS}

\subsection{INSTALL VARIANCE}

Upon VCR approval, the AWS will

1. initiate a WOR according to NMT8-FMP-801, Work Order Request Initiation and Work Package Control,

2. determine lockout/tagout requirements, if any (Ref: 503-GEN, Lockout and Tagout for Red Locks and 546-GEN, Lockout and Tagout for Blue Locks), and

3. deliver a complete VCR package with marked- up drawings to the person performing the variance device(s) installation.

The person responsible for performing the installation will

1. install the variance device(s) in accordance with approved practices and procedures,

2. attach the VCR tag and any auxiliary tags,

3. notify the Operations Center that the variance device(s) are installed,

4. return the VCR package to the Operations Center for retention, and

5. indicate successful installation of the variance device(s) by initialing the VCR Log.

The SE will

1. perform a functional check of the installed variance to ensure it will support the system/component's design functions during operation.

The Operations Center shift supervisor will

1. retain the original VCR and VCR package, and

2. perform a monthly review of the VCR $\log$ to identify those VCRs that have expired or are no longer needed.

\subsection{REMOVE VARIANCE}

The AWS will

1. initiate a WOR according to NMT8-FMP-801, Work Order Request Initiation and Work Package Control,

2. determine lockout/tagout requirements, if any (Ref: 503-GEN, Lockout and Tagout for Red Locks and 546-GEN, Lockout and Tagout for Blue Locks), and

3. deliver a complete VCR package with marked- up drawings to the person performing the variance device(s) removal.
The person responsible for performing the removal will

1. remove the variance device(s) in accordance with approved practices and procedures, and return the affected system/component(s) to the normal position

2. remove all VCR tags,

3. verify that all lockout/tagout locks and tags required for this variance have been removed (Ref: 503-GEN, Lockout and Tagout for Red Locks and 546-GEN, Lockout and Tagout for Blue Locks)

4. perform any post-maintenance tests required,

5. notify the Operations Center that the variance device(s) have been removed,

6. notify the Operations Center that the system/component(s) have been returned to the normal position and all post maintenance tests have been successfully completed, and

7. deliver the VCR package to the Operations Center for retention and initial the VCR Log.

\subsection{RETURN SSC TO SERVICE}

The SE will

1. perform a functional check of the system/component to ensure it meets its design function before placing it in operation,

2. perform any acceptance tests required to ensure it is ready to be returned to service, and

3. sign the VCR indicating the system/component is returned to service.

The Operations Center shift supervisor will

1. sign the VCR indicating acceptance of the system/component for operations,

2. destroy all "Interim Documents" except those to be retained in the VCR package, and

3. forward the VCR package to IRM for retention. 


\section{Temporary Change (Variance) Extension Request}






\section{Temporary Change (Variance) \\ Main Tag}

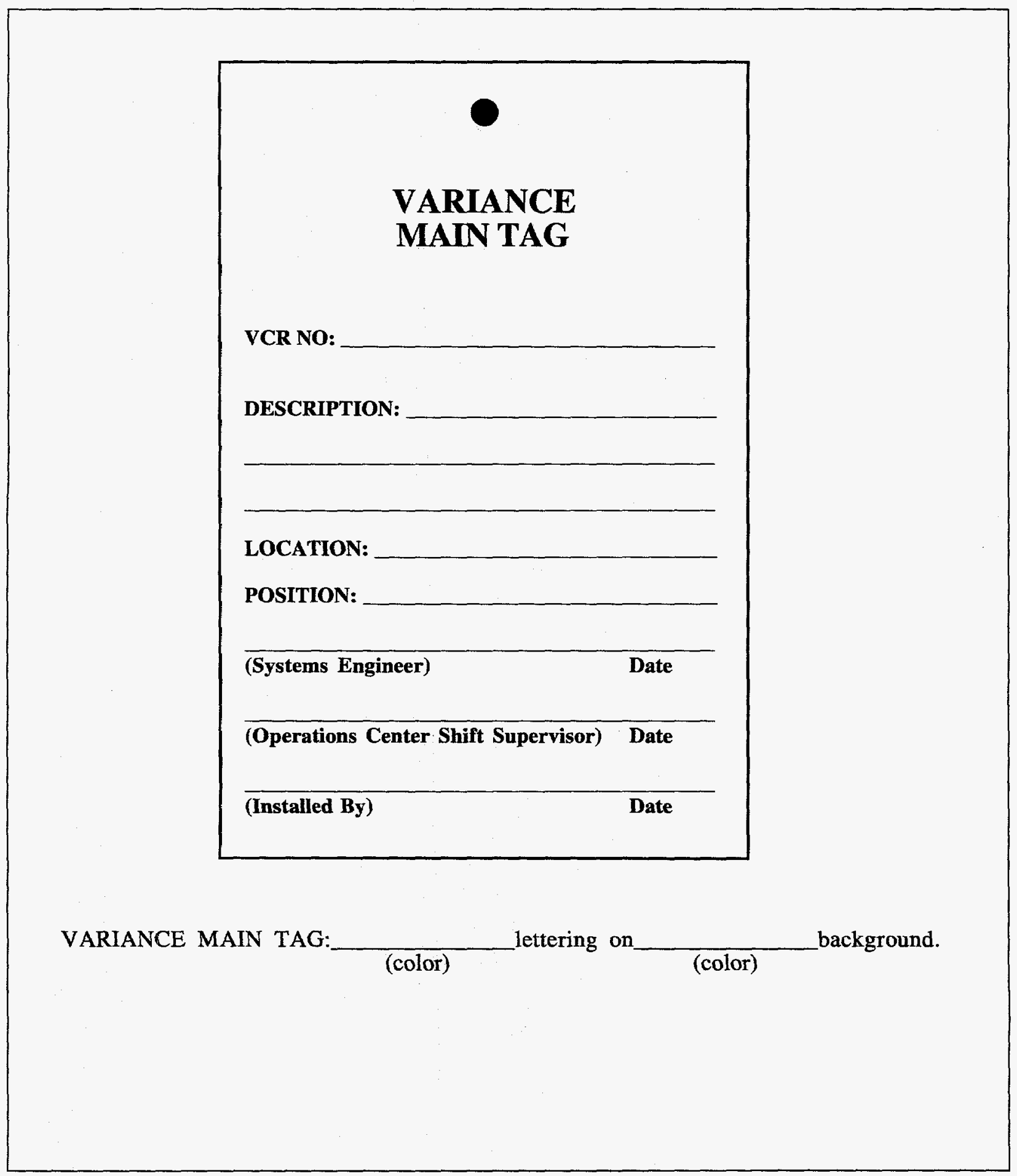




\section{Temporary Change (Variance) Auxiliary Tag}

\section{VARIANCE AUXILIARY TAG}

VCR NO:

DESCRIPTION:

LOCATION:

POSITION:

(Installed By) Date

VARIANCE AUXILIARY TAG: lettering on (color) (color) background. 
Temporary Change (Variance) Control Record Log

\begin{tabular}{|c|c|c|c|c|}
\hline VCR NO. & $\begin{array}{c}\text { DATE } \\
\text { ISSUED }\end{array}$ & $\begin{array}{c}\text { EXPIRATION } \\
\text { DATE }\end{array}$ & $\begin{array}{l}\text { EXTENSION } \\
\text { DATE }\end{array}$ & $\begin{array}{l}\text { RESTORATION } \\
\text { DATE }\end{array}$ \\
\hline & & & & \\
\hline & & & & \\
\hline & & & & \\
\hline & & & & \\
\hline & & & & \\
\hline & & & & \\
\hline & & & & \\
\hline & & & & \\
\hline & & & & \\
\hline & & & & \\
\hline & & & & \\
\hline & & & & \\
\hline & & & & \\
\hline & & & & \\
\hline & & & & \\
\hline & & & & \\
\hline & & & & \\
\hline
\end{tabular}




\section{Section 5: TA-55 Facility Control System Software Changes}

INITIATE SOFTWARE CHANGES

•

•

• 


\section{TA-55 FACILITY CONTROL SYSTEM SOFTWARE CHANGES}

The procedure for software changes discussed here refers only to Facility Control System (FCS) software. No other software change is governed by this manual. Complete a software change request (SCR) anytime a change is made to the existing software, screens, or supporting data files. Design development and testing are done using simulation software. The new version of the software is loaded on the FCS only after the facility manager approves. This section describes the various steps necessary to complete the SCR.

\subsection{Initiating an SCR}

The SCR consists of the following five steps:

1. Initiate SCR

2. Develop design

3. Design verification

4. Post-modification testing

5. Resumption of normal software operation

Anyone who feels there is a problem with the existing software may initiate an SCR. The person initiating the SCR defines the specific changes that are being sought and accepts the changes once they are made.

Configuration Management issues SCR numbers and retains SCR records. It is critical to keep an accurate record of what was changed and why.

The change initiator performs the following steps:

1. Obtain a unique, sequential SCR tracking number from $\mathrm{CM}$. The assigned number consists of the following:

\section{SCR-WW- $\underline{\mathrm{XXX}}$}

where WW is the fiscal year the SCR was initiated; e.g., "96," and XXX is the sequential SCR number; e.g., "001."

NOTE: CM maintains the SCR database.

2. Record the number in the top right-hand corner of every sheet of the SCR in the space provided. 
3. Complete step 1 of the Software Change Traveler.

NOTE: The Software Change Traveler provides the checklist and approval for the SCR.

4. Complete the Change Initiation Form.

a. With the facility manager, identify the various disciplines affected by the software change.

NOTE: During the design verification step, these disciplines are responsible for ensuring that the intended changes do not have an adverse effect on their particular system.

b. Explain the reason for and the description of the change being sought. Provide as much detail as possible when describing the changes to be made to avoid any misinterpretation by the programmer.

5. Submit these forms to the TA-55 facility manager for approval.

\subsection{Developing the Design}

Once the initiation stage has been approved, the designated FCS programmer controls and updates the original SCR throughout the design, testing, and final approval process. The FCS programmer follows these steps:

1. Perform an unreviewed safety question screen per section 10 of this manual.

2. Take the initiator's request and make the necessary changes to the software.

3. On the Programmer Description of Changes Form, provide a detailed description of the changes needed to satisfy the initial request. List all information with as much detail as possible so that it may be easily followed.

4. Once the changes have been made, fill out step 2 of the Software Change Traveler. Include a printout in the documentation comparing the screens/ software so that the changes may be easily identified for tracking purposes.

\subsection{Verifying the Design}

Once the FCS programmer has determined and made the necessary software changes to satisfy the initial requirements, the changes need to be reviewed and verified. After their review, the reviewers sign their names in step 3 of the Software Change Traveler.

1. The initiator signs off that the original intentions were met. 
2. The disciplines affected by the change sign off that the changes do not adversely affect the safe operation of their systems.

3. The facility manager gives approval to the changes.

\subsection{Performing Post-Modification Testing}

After the initiator and various disciplines approve the changes, the FCS programmer completes the testing. The changes may require simulation testing and/or facility testing, or no testing may be required. The FCS programmer performs the following steps:

1. On the Post-Modification Testing Form, the programmer checks which tests are necessary.

2. If no testing is required, s/he gives a valid explanation why it is not required.

\subsubsection{Performing Simulation Testing}

1. In step 1 of the Post-Modification Testing Form, define the required test and acceptance criteria.

2. Determine whether the existing simulation software is adequate to test the changes.

3. If existing simulation software is not adequate, complete a Simulator Change Form.

4. Make changes to the simulation software so that it will adequately test the newly made FCS software changes.

5. After the test, record the results of the simulation testing on the PostModification Testing Form. The FCS programmer signs his/her name, confirming a successful simulation test.

6. Fill out step 4 of the Software Change Traveler.

\subsubsection{Performing Facility Testing}

1. In step 2 of the Post-Modification Testing Form, define the required test and the acceptance criteria.

2. Decide whether the software test can be performed during normal working hours. 
3. Set a date for the test. Get the approval of the Operations Center supervisor to perform the test.

4. After the test, record the results of the facility testing on the PostModification Testing Form. The FCS programmer signs his/her name, confirming a successful simulation test.

\subsection{Resuming Normal Software Operation}

This is the final approval stage of the SCR. All personnel listed below must sign their names in step 5 of the Software Change Traveler to confirm their approval.

1. The FCS programmer properly archives the new version and loads the new version into the FCS.

2. The Operations Center supervisor attests that all operators have been properly trained on the software changes that will be implemented.

3. The TA-55 facility manager approves/disapproves the changeover to the new software and accepts the supporting change documentation to be complete and correct.

4. The FCS programmer turns over the completed documentation to $\mathrm{CM}$ for safekeeping.

5. $\mathrm{CM}$ acknowledges the completion of the procedure. 


\section{Software Change Traveler}

SCR-

\subsection{INITIATE SCR}

Title:

Initiator Name:

Group:

Initiation Date:

Design Documentation

Req'd

No Yes

Attached

1. Change Initiation Information

[x]

1

\subsection{DEVELOP DESIGN}

2. Programmer Description of Changes

3. Attach USQ Screen

[x]

4. Program Compare/Tracking

[x]

$[\mathrm{x}]$



\subsection{DESIGN VERIFICATION}

Initiator Verification

Date:

Facility Manager Verification: Date:

Technical Discipline Review(s)

Verification

Verification

Disc.

Software Date:

Verification

Disc.

Verification

Disc.

Disc.

Date:

Date:

4.0 POST-MODIFICATION TESTING

Design Documentation

5. Post-Modification Testing

6. Simulator Change Form
Req'd

No Yes

$[\mathrm{x}]$

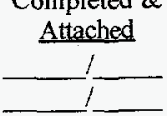

\subsection{RESUMPTION OF NORMAL SOFTWARE OPERATION}

Confirm Software Archive Complete:

$$
\text { FCS Programmer }
$$

Training Complete Date Operations Center Supervisor

TA-55 Facility Manager Approval: Date:

Confirm Software Properly Loaded: Date FCS Programmer

Procedure Complete Date: 


\section{Software Change Traveler (Cont.)}

\section{INSTRUCTIONS}

The purpose of this document is to provide a means to track the SCR through the various developmental stages. It ensures that the proper authorizations have been acquired before the change is implemented in the facility.

Record the SCR number in the upper right-hand corner of the document in the space provided. Obtain the number from CM. Attach additional sheets if necessary.

\subsection{INITIATE SCR}

Title: Provide a brief descriptive title for the SCR.

Initiator Name: Fill in the name of the person initiating the change, group, and the date.

Design Documentation: TA-55 facility manager checks and initials the appropriate places when the Change Initiation Form is completed and attached.

\subsection{DEVELOP DESIGN}

Design Documentation: Programmer checks and initials the appropriate places when the USQ screen and the Program Compare/Tracking have been completed and attached.

\subsection{DESIGN VERIFICATION}

Initiator Verification: Initiator checks over design and verifies that the change intentions were met.
Facility Manager Verification: TA-55 facility manager checks over design and verifies that it meets his/her approval.

Technical Discipline Review(s): The disciplines checked on the Change Initiation Form are required to review the design changes and verify that their systems are not adversely affected.

\subsection{POST-MODIFICATION TESTING}

Design Documentation: Programmer checks and initials the appropriate places when the Post-Modification Testing Form and the Simulator Change Form, if necessary, have been completed and attached.

\subsection{RESUMPTION OF NORMAL SOFTWARE OPERATION}

Record approval signatures for the areas listed:

The FCS programmer signs, attesting that the new version of the software has been archived. The Operations Center supervisor signs after the operators have been informed and trained, if needed, about the changes. The facility manager gives approval if all supporting documentation is complete and the new software is ready to be installed. The programmer signs and dates upon proper loading of the software. $\mathrm{CM}$ signs that the procedure is complete. 


\section{Change Initiation Information Form}

Page 1 of 2

SCR-

Initiator Name:

Group:

Date:

System Grade: [ ] SC [ ] SS [ ] MC [ ] BOP

COF Category: [ ] M1 [ ] M2 [ ] M3 [ ] M4

Technical Discipline Reviewers:
[ ] Air Monitoring
[ ] Fire Protection
[ ] Health Physics
[ ] Waste
[ ] Human Factors
[ ] Gas Systems
[ ] Architectural
[ ] HVAC
[ ] Criticality
[ ] Gloveboxes
[ ] Mechanical
[ ] Seismic
[ ] Independent Software Review
[ ] Electrical
[ ]

1.0 REASON FOR CHANGE:

2.0 CHANGE DESCRIPTION:

Initiation Approval:

Date:

TA-55 Facility Manager 


\section{Change Initiation Information Form (Cont.)}

\section{INSTRUCTIONS}

The purpose of this document is to document the change that is being sought and the reasons for the change. This form is necessary for all SCRs.

Record the SCR number in the upper right-hand corner of the document in the space provided. Obtain the number from $\mathrm{CM}$. Attach additional sheets if necessary.

Fill in the name of the person requesting the change, his/her position, group, and the date the request is initiated.

System Grade: Denote impacted system grades:

1. SC: Safety Class

2. SS: Safety Significant

3. MC: Mission Critical

4. BOP: Balance-of-Point

COF Category: Denote consequence-of-failure categories for impacted components: M1, M2, M3, and M4 categories defined per section 4.2.1 in the TA-55 Change Control Manual.
Technical Discipline Reviewers: TA-55 facility manager or initiator checks the appropriate disciplines for which this change could possibly have an impact.

\subsection{REASON FOR CHANGE}

The requestor provides the reason the change(s) are necessary.

\subsection{CHANGE DESCRIPTION}

The requestor provides a detailed description of the change. All information is listed with as much detail as possible to avoid any misunderstanding from the programmer.

Initiation Approval: TA-55 facility manager reviews the information and gives approval if change is deemed necessary. Complete step 1 for the Software Change Traveler.

The completed form is attached to the Change Traveler and included in the SCR document package. 


\section{Programmer Description of Changes Form}

Programmer Name (print):

Date:

\subsection{AFFECTED SYSTEMS}

Change is to (select one): PLCs HSI Both

\subsection{CHANGE DESCRIPTION}

Text description of required changes:

\subsection{FILE-TRACKING INFORMATION}

Existing Filename/Version/CSCI

New Filename/Version/CSCI

NOTE: Attach a hard copy comparison of the affected software.

Programmer Signature: Date 


\section{Programmer Description of Changes Form (Cont.)}

Page 2 of 2

\section{INSTRUCTIONS}

The purpose of this document is to document the change that is being made to the software as the programmer views it. This form is necessary for all SCRs.

Record the SCR number in the upper right-hand corner of the document in the space provided. Obtain the number from CM. Attach additional sheets if necessary.

Fill in the name of the person making the software changes and the date the form is completed.

\subsection{AFFECTED SYSTEMS}

Check the systems that will be affected by this software change. Make additional notes if needed.

\subsection{CHANGE DESCRIPTION}

The programmer provides a detailed description of the changes needed to satisfy the initial request. List all information with as much detail as possible so that it may be easily followed.

\subsection{FILE-TRACKING INFORMATION}

Provide the existing and new filenames, versions, and/or CSCIs in the space provided.

Attach a hard copy comparison of the affected software.

The programmer signs on the bottom of the form.

The completed form must be attached to the Change Traveler and included in the SCR document package. 


\section{Post-Modification Testing Form}

SCR-

Programmer Name (print):

Date:

Post-modification testing that needs to be performed:

Simulation Testing Facility Testing

None: explain

\subsection{SIMULATION TESTING}

Describe the required simulation test for the specific software changes:

Describe the acceptance criteria for the simulation test:

Does the current simulation adequately test changes (select one): Yes No

If no, initiate Change Request for Simulator.

If yes, perform simulation test.

Describe simulation test results:

Confirm successful simulation test:

Date:

FCS Programmer 


\section{Post-Modification Testing Form (Cont.)}

Page 2 of 3

SCR-

\subsection{FACILITY TESTING}

Describe the required facility test for the specific software changes

Describe the acceptance criteria for the facility test:

Can facility test be performed during normal working hours: Yes No

Date/time to run test:

Approval to run facility test:: Date: Operations Center Supervisor

Describe test results:
Confirm successful facility test:

Date: FCS Programmer 


\section{Post-Modification Testing Form (Cont.)}

Page 3 of 3

\section{INSTRUCTIONS}

The purpose of this document is to document the required post-modification testing needed to verify that the design functions correctly. This form is necessary for all SCRs.

Record the SCR number in the upper right-hand corner of the document in the space provided. Obtain the number from $\mathrm{CM}$. Attach additional sheets if necessary.

Fill in the name of the person testing the software changes and the date the test is initiated. Check the appropriate lines for the tests that need to be completed for this change. If "None" is checked, an explanation must be given.

\subsection{SIMULATION TESTING}

Describe the required simulation testing that is needed to adequately test the system software, as well as the acceptance criteria for the simulation test.

Determine whether the current simulation will adequately perform the necessary testing. If it will, then proceed with the test, describe the results, and sign if the test was successful. If the test was not successful, rework needs to be completed before retesting.

If the current simulation is not adequate, a Simulator Change Form must be completed.

Simulation testing may then be performed once the necessary changes are made to the simulation software.

\subsection{FACILITY TESTING}

Describe the required facility testing that is needed to adequately test the system software, as well as the acceptance criteria for the facility test.

Determine whether the facility testing may be performed during normal working hours. $A$ date and time must be established for the facility testing and approved by the Operations Center supervisor.

Record the test results. If the test passes the acceptance criteria, the programmer signs the bottom of the form, indicating approval.

The completed forms must be attached to the Change Traveler and included in the SCR document package. 


\section{Simulator Change Form}

SCR-

Programmer Name (print):

Date:

1.0 REASON FOR CHANGE

2.0 CHANGE DESCRIPTION

Text description of required simulator changes:

\subsection{TRACKING INFORMATION}

Existing Filename:

New Filename:

Attached is a hard copy comparison using Program Compare or screen print:

Yes No

If no, explain:

Verification that simulator changes are as intended: Date:

FCS Programmer 


\section{Simulator Change Form (Cont.)}

Page 2 of 2

\section{INSTRUCTYONS}

The purpose of this document is to document the required simulation changes needed to verify that the design functions correctly. This form is necessary for only those SCRs requiring a simulator change.

Record the SCR number in the upper right-hand corner of the document in the space provided. Obtain the number from the $\mathrm{CM}$. Attach additional sheets if necessary.

Fill in the name of the person changing the software and the date the change is initiated.

\subsection{REASON FOR CHANGE}

State the reason the simulation software needs to be revised.

\subsection{CHANGE DESCRIPTION}

The programmer provides a detailed description of the changes needed to satisfy the specific request. List all information with as much detail as possible so that it may be easily followed.

\subsection{TRACKING INFORMATION}

Provide the existing and new filenames in the blanks provided.

Check whether a hard copy Program Compare or screen print is attached. This will be checked "Yes" for most cases. If it is checked "No," give an explanation.

The programmer signs on the bottom of the form.

The completed form, if necessary, must be attached to the Change Traveler and included in the SCR document package. 


\section{Section 6: Making Procedure Changes}

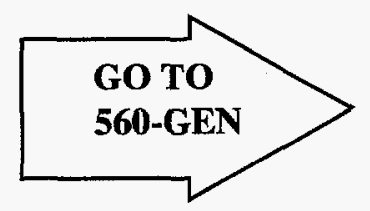


•

•

• 


\section{MAKING PROCEDURE CHANGES}

This section discusses changes to safe operating procedures (SOPs) and surveillance instructions for TA-55 Technical Safety Requirements (TSRs) implementation. Changes to administrative procedures (APs) are discussed in 560-GEN, Reviewing and Approving TA-55 Procedures.

New and changed SOPs are reviewed and approved through a consistent and formal process documented here and in 560-GEN, Reviewing and Approving TA-55 Procedures.

\subsection{Minor Revisions}

Minor revisions include simple wording changes that do not affect the technical content of the procedure or safety of the operation. To make a minor revision to a procedure, follow the guidance in 560-GEN, Reviewing and Approving TA-55 Procedures.

\subsubsection{Surveillance Instruction (SI)}

Because the Operations Center operates 24-hours/day and 7-days/week, they have need of a way for immediately making minor revisions to SIs during off-hours and when performing surveillances. To make a minor change to an SI, follow these steps:

1. Redline the change(s) on the Operations Center copy of the SI.

2. The Operations Center Shift Supervisor approves each change by signing and dating the SI in the margin next to the change(s).

3. The next work day, submit a copy of the red-lined SI to the NMT-8 Document Control Custodian for processing per 560-GEN, Reviewing and Approving TA-55 Procedures.

\subsection{Major Revisions}

Major revisions affect the technical content of the procedure or the potential safety of the operation.

\subsubsection{PF-4 Process or Experiment}

To revise a PF-4 process or experiment, follow the guidance in 560-GEN, Reviewing and Approving TA-55 Procedures, and in section 9.1 of this manual. 


\subsubsection{Surveillance Instruction}

Consistent with the TA-55 TSRs, to make temporary or major changes to Surveillance Instructions, follow these steps:

1. The person requesting the change completes sections 1 and 2 of a Temporary Change (Variance) Control Record (VCR). (A VCR can be found in section 4 of this manual.)

2. The Operations Center completes section 3 of the VCR.

3. If a USQ evaluation is needed, follow the guidance in section 10 of this manual.

4. The Operations Center on-duty supervisor completes section 4 of the VCR. If variance tags are not needed, put N/A in the appropriate spaces and in section 5 of the VCR.

5. Redline the change(s) on the Operations Center copy of the SI.

6. The Operations Center on-duty Supervisor and another member of the facility group approves each change.

7. The next work day, submit a copy of the red-lined SI to the NMT-8 Document Control Custodian for processing per 560-GEN, Reviewing and Approving TA-55 Procedures.

8. The facility manager or his/her designee must approve the change within 14 days.

\subsection{New Procedure}

\subsubsection{PF-4 Process or Experiment}

To establish a new PF-4 process or experiment, follow the guidance in 560-GEN, Reviewing and Approving TA-55 Procedures, and in section 9.1 of this manual.

\subsubsection{Facility Maintenance or Surveillance}

To establish a new facility maintenance or surveillance procedure, follow the guidance in 560-GEN, Reviewing and Approving TA-55 Procedures. 


\section{Section 7: Design Document Changes}




•

• 


\section{DESIGN DOCUMENT CHANGES}

Design document changes entail those changes to design-related documents that define or otherwise control the final design, operation, or maintenance of an operation or facility. Examples of design documents include

- drawings

- as-builts

- calculations

- design specifications

Design document changes fall into one of two categories:

- design document changes that do not support or constitute a design change, such as a change on the title block of a drawing

- design document changes that are prepared to provide the technical basis or support the development and implementation of design changes. Such design document changes are subject to change control and evaluation using the unreviewed safety question (USQ) process described in section 10. 


\section{Section 8: Noncomforming Items and As-Found Changes}

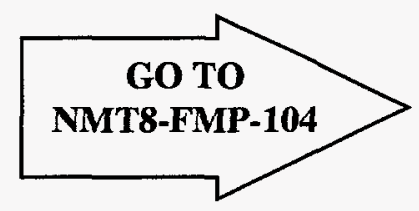


•

•

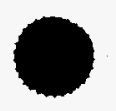




\section{NONCONFORMING ITEMS AND AS-FOUND CHANGES}

This section applies only to facility SSC. All other nonconforming items and as-found changes are dispositioned according to the owning group's Quality Assurance plan.

\subsection{Nonconforming Items}

A nonconforming item is any appurtenance, assembly, component equipment, material module part, structure, subassembly, subsystem, system, or unit that does not conform to defined specifications. Nonconforming items are dispositioned in accordance with NMT8-FMP-104, Controlling Nonconforming Items, Services, Processes, and Documents. Two of the four types of dispositions described in NMT8-FMP-104, Controlling Nonconforming Items, Services, Processes, and Documents, "Use As Is" and "Repair" do not restore items to a state of meeting the original requirements and, hence, constitute a change. Items dispositioned "Use As Is" or "Repair" may require a USQ determination (section 10) and/or a Field Change Request (section 12.1.3.3).

To disposition nonconforming items, follow NMT8-FMP-104, Controlling Nonconforming Items, Services, Processes, and Documents.

\subsection{As-Found Changes}

As-found changes are changes that

- predate formal change controls

- predate the USQ process

- were not properly documented

- were not appropriately reviewed and approved

Disposition as-found changes as nonconforming items in accordance with NMT8FMP-104, Controlling Nonconforming Items, Services, Processes, and Documents. 


\section{Section 9: Hazards Analysis}

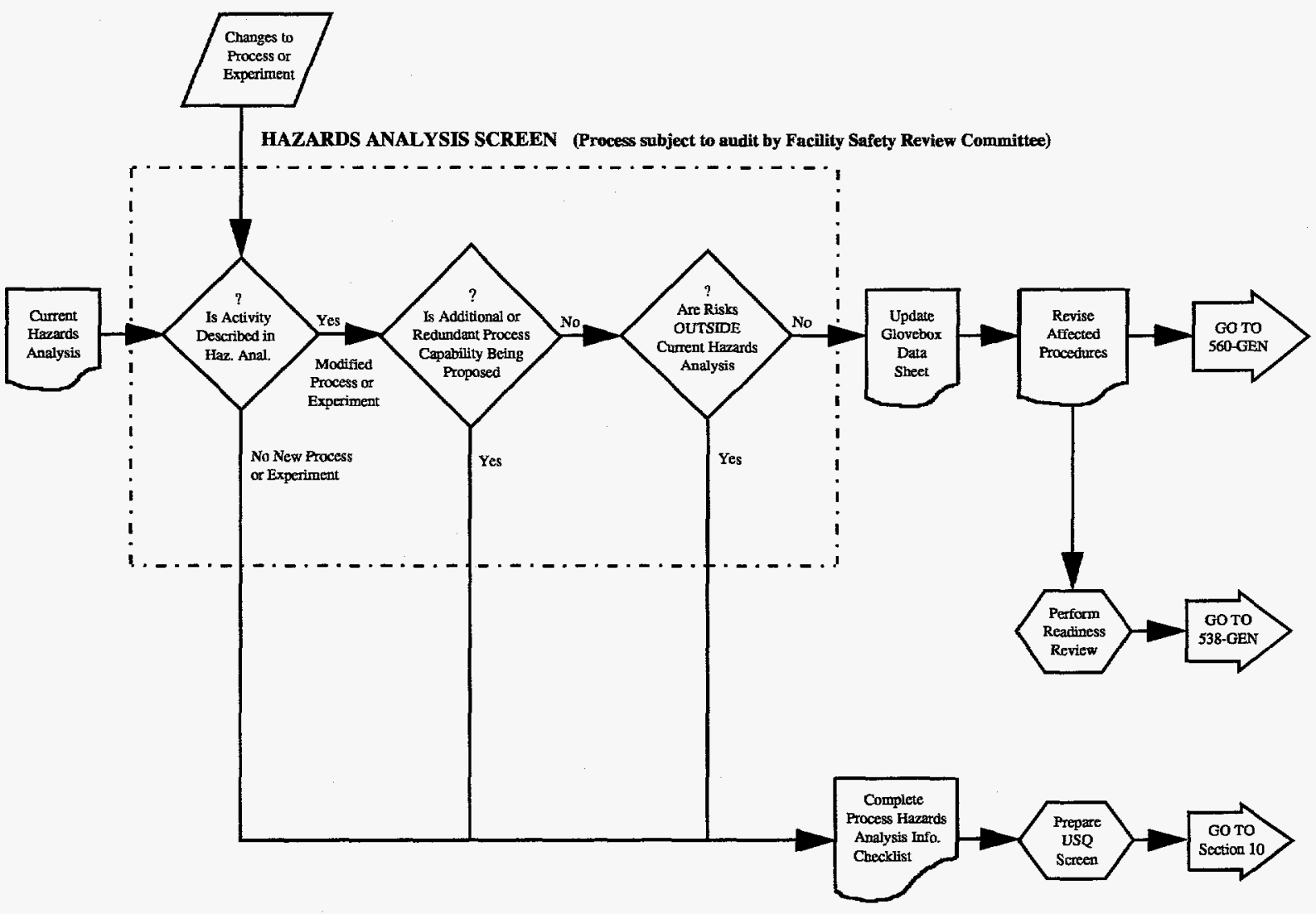





\section{HAZARDS ANALYSIS}

Many changes do not affect the authorization basis and only require a basic review to justify a "no impact" finding. The TA-55 Hazards Analysis and the Hazards Analysis Screen are used for this basic review and to document the findings. All new processes or experiments and changes to existing processes or experiments require a Hazards Analysis Screen. A copy of the TA-55 Hazards Analysis is on file in each group office and with members of the NMT-8 Authorization Basis Team. If needed, any members of the NMT-8 Authorization Basis Team can provide assistance in completing this basic review and documenting the findings.

\subsection{Completing the Hazards Analysis Screening Form}

For all new or modified tests and experiments, the Hazards Analysis (HA) Screening Form must be completed. This form allows the operating groups to make minor changes within their safety envelope without completing an unreviewed safety question (USQ) safety evaluation. Operating groups are responsible for completing the HA Screening Form. Instructions are on the back of the form. If the results of the HA Screening Form are negative, then the change requester updates the Glove Box Data Sheet and returns the new information to an NMT-8 Authorization Basis Team member. Copies of Glove Box Data Sheets for existing processes can be obtained from an NMT-8 Authorization Basis Team member. If the HA screen is positive, then the change requester, with the help of the NMT-8 Authorization Basis Team, completes the Process Hazards Analysis Information Checklist to provide information for a hazards analysis (see section 9.2.1) and begins the USQ process. A copy of the HA Screening Form and Glove Box Data Sheet can be found at the end of this section.

Retain a copy of the Hazards Analysis Screen on file in the originator's group office for review by the Facility Safety Review Committee (FSRC).

\subsection{The Process Hazards Analysis Information Checklist}

The purpose of the Process Hazards Analysis Information Checklist (PHAIC) is to identify the information and documents needed by Authorization Basis Team members to perform a hazards analysis and update the facility authorization basis. An Authorization Basis Team member, in conjunction with the requester, fills out the PHAIC. Appropriately trained operating group personnel may also perform the hazards analysis, provided a member of the Authorization Basis Team reviews this work. A copy of the PHAIC can be found at the end of this section.

It is the responsibility of the change originator to provide the information identified on the PHAIC. All modified processes that receive a positive HA screen as well as new processes cannot start or restart operation without first having a hazards analysis and going through the USQ process. Guidance for the preparation of a process hazards analysis can be found in 588-GEN, Preparation 
of a Process Hazards Analyses (PrHAs) at TA-55. The HA is used to determine the safety of the proposed change and to provide information on potential accidents that will be used in the USQ.

\subsubsection{Preparing the Process Hazards Analysis Information Checklist}

Change requester completes the information at the top of the PHAIC and then meets with a member of the Authorization Basis Team to determine which items on the PHAIC are needed and what level of detail needs to be provided.

All of the items on the PHAIC are listed below, along with a description of what is needed. The actual level of detail for each item will depend upon the complexity of the proposed change and will be decided on a case-by-case basis. The completed PHAIC is part of the basis for the scoping meeting review (discussed in section 10.1.1) and becomes part of the design change package (DCP).

\subsubsection{Applicable Theoretical Chemistry and Physics for a Process}

Provide information on

- chemical reaction equations and stoichiometry for primary and important secondary or side reactions

- type and nature of catalysts used

- reactive chemical data on all streams, including in-process chemicals

- kinetic data for important process reactions, such as decomposition and autopolymerizations

- process limits stated in terms of pressure, temperature, concentrations, feedto-catalyst ratio, etc., along with a description of the consequences of operating beyond these limits

\subsubsection{Process Flow Diagrams and Material Balances}

Process flow diagrams (PFDs) are useful for large process units particularly if they provide material balances, temperatures, and pressures. Material balances are useful to help determine relative stream flow rates and to assist in simple estimates of the relief capacity required for some relief cases. They are also used to help estimate properties such as molecular weight, flash temperatures, and the potential for corrosion. This should include a description of the process steps or unit operations involved, starting with raw material storage and feed preparation and ending with product recovery and storage, and waste streams.

\subsubsection{Process Equipment Layouts}

The plot plan needs to clearly identify the location of the process equipment to be analyzed and proximity to other processes and gloveboxes. There should also be a plot plan that shows the location of fire protection resources and toxic gas or flammable material detectors. 


\subsubsection{Process Piping and Instrumentation Drawings}

Process piping and instrumentation drawings (P\&IDs) identify

- piping classifications

- materials of construction

- flange ratings

- temperature/pressure limits for each classification

- normal process conditions

- flow

- temperature

- pressure for each line and vessel

- control strategy for the equipment

- flow control reset by level

- distributed computing system logic

- feed-forward control schemes

- set points

- failure modes

\subsubsection{Process Electrical One-Line Drawings}

This information is needed for electrical process equipment and indicates where high voltage lines are used.

\subsubsection{Design Energy and Mass Balances}

This information shows the chemical reactions of the process and includes information such as the amount of heat expected to be released.

\subsubsection{Major Material Inventories (Nuclear and Chemical)}

Provide a list of all hazardous and radioactive materials along with the quantity and physical form of each.

\subsubsection{Nuclear Issues}

Provide a list of the following:

- ionizing radiation sources

- radioactive degradation of materials

- radiolytic decomposition of water that yields hydrogen

- tritium degradation of elastomeric seals 
- radioactive activation of materials

- radioactive waste generation

- contamination potential

- SNM in undesirable locations

- radon

- thermal loading from nuclear decay process

- daughter products from nuclear decay process

\subsubsection{Material Safety Data Sheets and Chemical Hazard Information}

Material Safety Data Sheets (MSDSs) define the safety and reactive properties of the chemicals involved. Sometimes MSDSs need to be supplemented by other resources such as product bulletins and safety references (e.g., Chlorine Institute guidelines, National Fire Protection Association [NFPA] standards) to ensure that the process hazards analysis (PHA) team understands all the chemical hazards involved in the system. NFPA standards are particularly useful to help identify potential reactions between the chemical of interest and other chemicals that might be present.

\subsubsection{Mechanical Equipment Data Sheets}

Include information such as vendor drawings and operation and maintenance manuals.

\subsubsection{Control System and Alarm Description}

The PHA team needs a list of the critical alarms and shutdown instrumentation for the unit, including the setpoints for the alarms and interlocks. Include which alarms and interlocks

- the operators are allowed to change

- are under supervisory control

- are hardwired

Provide a description of the general control philosophy (i.e., identifying the primary control variables and the reasons for their selection).

\subsubsection{Relief System Design Basis}

PHA team determines the overpressure scenarios that individual relief valves are capable of handling. This information facilitates the analysis of these scenarios. 


\subsubsection{Computer Control System Hardware and Software}

This information helps the PHA team determine failure modes and controls (temperature regulation, computer shutoffs, etc.) on a process. Specific software codes and programs are not needed.

\subsubsection{Operating and Maintenance Procedures}

Even if the PHA team does not intend to review procedures in detail to identify possible error-likely situations, the team members will often find it necessary to refer to procedures to ensure that safeguards they plan to rely on are documented.

\subsubsection{Previous Safety Studies, Accidents, Incident Reports, Unusual Occurrence Reports}

These reports, if available, help the PHA team to focus on the known hazards of the process, and identify upgrades to prevent or mitigate further occurrences.

\subsubsection{Laboratory Research Reports, Technical Articles from Periodicals, etc.}

This information gives the PHA team a better understanding of the process. Extensive and technically detailed information is not necessarily needed. This information helps reduce questions to the requesting group from the PHA Team.

\subsubsection{Pertinent Industry Standards and Regulations}

Identify pertinent codes, standards, regulatory limits, and any variances to these that are applicable to the process or were used in the design of the process. For example, the American Society of Mechanical Engineers (ASME) Code and American Petroleum Institute (API) Recommended Practices are important resources for industry guidelines on design requirements for pressure vessels, tanks, and pumps. Other industry guidelines, such as those specific to the chemical of interest, those from the NFPA, or those from equipment manufacturers associations (e.g., American Waterworks Association [AWWA], National Electrical Manufacturers Association [NEMA]), are often useful. 


\section{Hazards Analysis (HA) Screening Form}

1. Is the activity described in the TA-55 Hazards Analysis?

[ ] No.

[ ] Yes. Activity Code: Name:

Describe the change or attach a copy of the Work/Change Request Form.

2. Is there a change in material form (i.e., particle size) or criticality limits?

[ ] No [ ] Yes

3. Does the change provide additional or redundant capability in a new location (room, glovebox)?

[ ] No [ ] Yes

4. Could the proposed change increase the probability of occurrence of an accident previously evaluated in the TA-55 Hazards Analysis for the affected process or system?

[ ] No [ ] Yes Justification:

5. Could the proposed change increase the consequences of accident previously evaluated in the TA-55 Hazards Analysis for the affected process or system?

[ ] No [ ] Yes Justification:

6. Could the proposed change increase the probability of occurrence of a malfunction of equipment important to safety evaluated in the TA-55 Hazards Analysis for the affected process or system? Justification:

7. Could the proposed change increase the consequence of a malfunction of equipment important to safety evaluated in the TA-55 Hazards Analysis for the affected process or system? Justification:

8. Could the proposed change create the possibility of an accident of a different type or malfunction of equipment important to safety different from any previously evaluated in the TA-55 Hazards for the affected process or system? Justification: 


\section{Hazards Analysis (HA) Screening Form (Cont.)}

Page 2 of 2

\section{INSTRUCTIONS}

Instructions for completing the Hazards Analysis (HA) Screening Form:

The hazards analysis of record for each operation in PF-4 is in Appendix B of the TA-55 Hazards Analysis. Table B.1, B.2, Y, correspond to groups NMT-1, NMT-2, Y, respectively.

Question 1. Review Appendix B in the TA-55 Hazards Analysis to determine if the activity has been analyzed. If analyzed, check the "yes" box and enter the activity code and name as listed in the table. If the activity is not found in the TA-55 Hazards Analysis, check the "no" box. If "no" then the HA Screen is positive and the PHAI checklist must be completed and a USQ screen is required.

Question 2. Check the appropriate response. NMT-8 must know when additional or redundant process capability is being proposed. Even if the activity has already been analyzed in the TA- 55 Hazards Analysis, relocating a process activity could create new or unanalyzed hazards. If question is answered "yes" the HA Screen is positive and the PHAI checklist must be completed and a USQ screen is required.

Questions 3-7. For every activity in the TA-55 Hazards Analysis, accident causes/scenarios were analyzed and assigned a risk ranking (R) of 1-4, based on a frequency ranking (F) I-V, and a consequence category (C) of A-D. Using the information from Figures 1-3 through 1-5 in Section 1 of the TA-55 Hazards Analysis, determine if the proposed change increases the likelihood or consequences of an accident or introduces an accident or malfunction of equipment of a different type than that previously evaluated for the affected activity. Check the appropriate response on the HA Screen Form. Take into account increases in material quality, different or new chemicals and radioactive materials introduced into the process/experiment, and addition of equipment that could pose new hazards. Provide enough information to allow an independent reviewer to follow the logic of the evaluation.

When evaluating if the proposed change could increase the probability of occurrence or consequence of a malfunction of equipment important to safety, consider the larger SSCs of which the SSC being modified may be a part. If the SSC is a part of, or may affect a larger SSC described in the safety analysis, and if the change alters the design function, or method of performing the function of the larger SSC as described in the safety analyses, then a safety evaluation is required. Examples that would not require a safety evaluation are routine maintenance activities including calibration, refurbishment, replacement with an equivalent component and housekeeping. An equivalent component may be identical, meet all design and seismic specifications and quality class, or have been demonstrated and documented to be equivalent.

If any of the responses to Questions 3-7 are "yes" the HA Screen is positive and the PHAI checklist must be completed and a USQ screen is required.

If all responses to Questions 3-7 were answered "no" and

1. the change does not directly or indirectly affect a configuration management item, revise the affected procedure(s) using the guidance in 560-GEN, Reviewing and Approving New and Changed TA-55 Procedures and consult 538-GEN, Startup and Restart of Operations of TA-55 Facilities to determine what level of a readiness assessment is required.

2. the change directly or indirectly affects a configuration management item, complete a Work/Change Request and revise the affected procedure(s) using the guidance given in 560-GEN, Reviewing and Approving New and Changed TA-55 Procedures. Consult 538-GEN, Startup and Restart of Operations of TA-55 Facilities to determine what level of a readiness assessment is required.

The preparer and responsible group leader signs and dates the Hazards Analysis Screening Form indicating that the results, to the best of their knowledge, are accurate. The HA screen is maintained in the group file for annual review by the FSRC. The preparer must also update the Glovebox Data Sheet for the affected glovebox and return it along with a copy of the HA screen to the TA-55 Authorization Basis Office. 


\section{Glovebox Data Sheet}

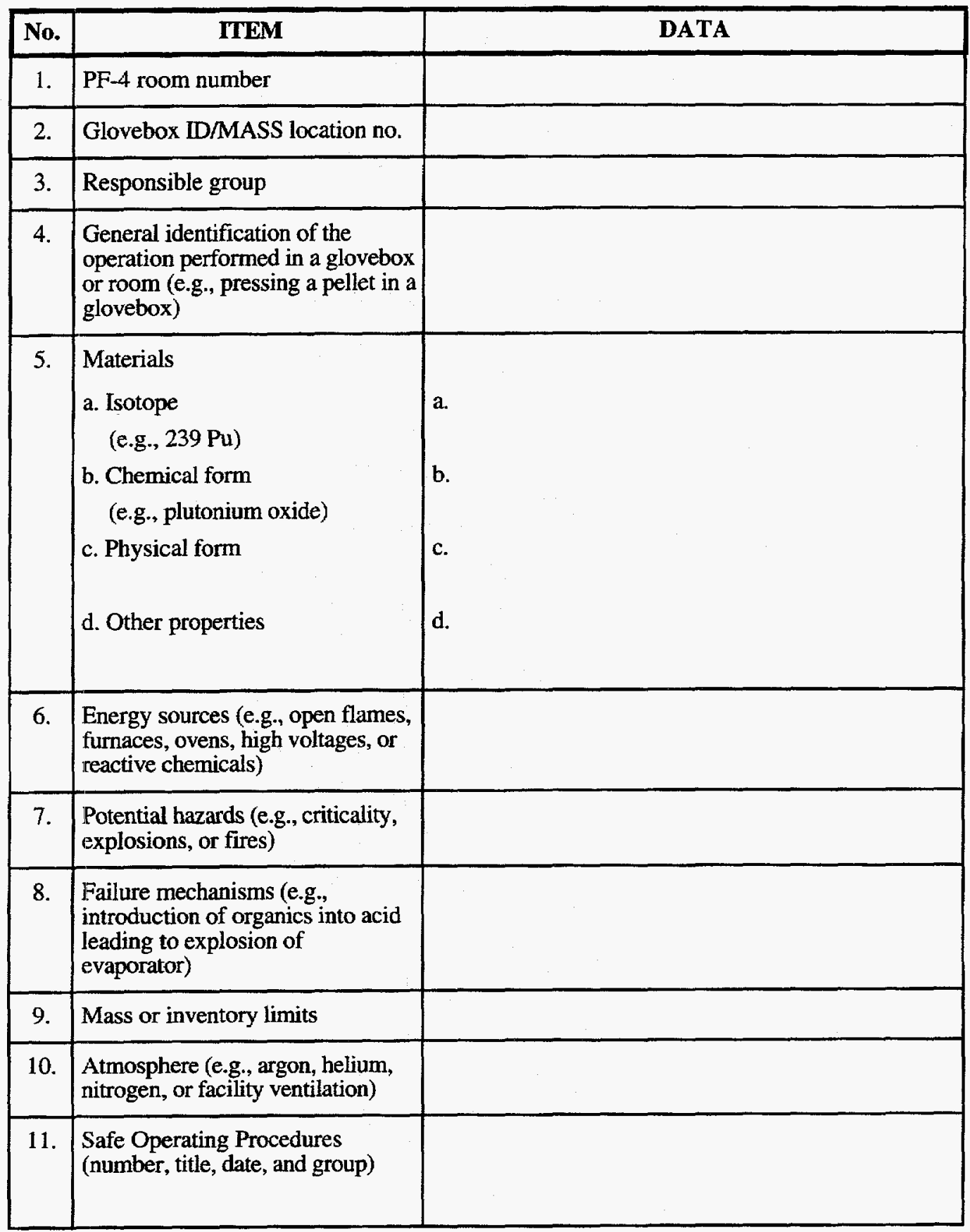

\section{9-10 Hazards Analysis}




\section{Glovebox Data Sheet (Cont.)}

\begin{tabular}{|c|l|l|}
\hline No. & \multicolumn{1}{|c|}{ ITEM } & DATA \\
\hline 12. & $\begin{array}{l}\text { Typical amount processed } \\
\text { (e.g., 5-liter batch) }\end{array}$ & \\
\hline 13. & $\begin{array}{l}\text { Adjacent gloveboxes or operations } \\
\text { (e.g., GB-\#/G-\#\# and ...) }\end{array}$ & $\begin{array}{l}\text { (e.g., 1 M hydrofluoric acid) } \\
\text { operations } \\
\text { (e.g., dissolution in nitric acid) }\end{array}$ \\
\hline 15. & $\begin{array}{l}\text { Chemicals/reagents } \\
\text { a. Chemical } \\
\text { b. Physical form } \\
\text { (e.g., solution) } \\
\text { c. Chemical characteristics } \\
\text { (e.g., corrosive) } \\
\text { d. Quantity } \\
\text { (e.g., 1 liter) }\end{array}$ & c. \\
\hline
\end{tabular}

16. Potential Hazards

Biological agent

Chemical (hazardous, toxic)

Confined space/limited egress

Compressed gas

Contamination

Cryogenic liquid

Electrical

Explosive/pyrophoric

Fire

Flammable gas/liquid

Ionizing radiation
Laser

Maintenance activity

Mechanical

Nonionizing radiation

Nuclear criticality

Pressure

Spill/gas release

Thermal energy

Vacuum

Other (specify)

None

Other: 
DCP:

Title:

Date

Requester:

Authorization Basis (AB) POC:

Requester Phone:

AB POC Phone:

\begin{tabular}{|c|l|c|c|}
\hline Item & \multicolumn{1}{|c|}{ Requirement Description } & $\begin{array}{c}\text { Date } \\
\text { Rec'd }\end{array}$ & Give Reason if Not Applicable \\
\hline \hline 1. & Applicable theoretical chemistry and physics for a process & & \\
\hline 2. & Process Flow Diagrams & & \\
\hline 3. & Process equipment layouts & & \\
\hline 4. & Process piping and instrumentation diagrams & & \\
\hline 5. & Process electrical one-line drawings & & \\
\hline 6. & Design energy and mass balances & & \\
\hline 7. & Major material inventories (chemical and nuclear) & & \\
\hline 8. & Nuclear Issues & & \\
\hline 9. & MSDSs & & \\
\hline 10. & Mechanical equipment data sheets & & \\
\hline 11. & Control system and alarm description & & \\
\hline 12. & Relief system design basis & & \\
\hline 13. & Computer control system hardware & & \\
\hline 14. & Operating procedures (if available) & & \\
\hline 15. & Maintenance procedures (if available) & & \\
\hline 16. & Previous safety studies, accidents, incident reports, unusual & & \\
\hline occurrence reports (if known) & Laboratory research reports, and technical articles & & \\
\hline 18. & Pertinent industry standards and regulations & & \\
\hline
\end{tabular}









\section{UNREVIEWED SAFETY QUESTION DETERMINATION (USQD)}

\subsection{Personnel Qualifications}

Both USQ screening and the USQD process may be complex. Ensure that personnel involved in preparing a USQD, reviewing a USQD, or performing any type of safety analysis or review of safety or authorization basis documents are qualified through training and experience, and are thoroughly familiar with this procedure and with DOE Order 5480.21 and its interpretation guidance.

Involved personnel must be thoroughly familiar with

- the approved safety analysis of TA-55 and other relevant material

- DOE orders regarding SARs

- other safety related documents and analyses

- safety/risk analysis techniques

Ensure that personnel involved in the preparation and review of USQDs are qualified by

- attending the Laboratory- or DOE-sponsored USQ training course

- having a minimum of a bachelors degree in a technical field and two years of experience in an engineering, scientific or technical discipline, or the equivalent

The facility manager assesses qualifications. NMT-8 group office maintains a list of all qualified USQ screen and USQD preparers and reviewers. The facility manager or designee is the approval authority for all USQ screens and USQDs. Because the screening process is generally at a lesser technical level, personnel who perform USQ screens may be qualified by attending the Laboratory USQD overview course. Personnel performing screens must be familiar with the authorization basis as described above.

Direct questions to ESH-3 regarding personnel qualifications in these minimum requirements.

\subsection{USQD Training Requirements}

Contact the ES\&H Management Training team, 5-5062, for information concerning these courses. 


\subsubsection{USQD Overview Course}

The USQD overview course is a half-day session that covers essential and basic aspects of the facility authorization basis and DOE Order 5480.21, Unreviewed Safety Questions, December 1991. The overview course is the minimum level of training to qualify to perform USQD screening.

\subsubsection{USQ Training Course}

Required classroom training consists of the USQ training course offered by DOE or the Laboratory through ESH-13. The USQ training course is longer than the USQD overview course, is more detailed, and includes group activity involving case studies, details concerning probability and consequences, and in-depth reviews of safety analysis techniques and TSRs. Retraining is required by the Laboratory on a 3-year schedule.

\subsection{Performing Unreviewed Safety Question Determination}

Proposed changes at TA-55 are evaluated for USQs through two levels of review. First, a USQ screen quickly identifies minor changes that are inconsequential or have no impact on the authorization basis. The USQ screen ensures that all changes receive some form of safety review and helps concentrate efforts on changes that may exceed the safety envelope established by the authorization basis.

Then, changes identified in the screening process that require additional review are evaluated by Authorization Basis personnel against the authorization basis through an unreviewed safety question determination (USQD). If the USQD is positive, a USQ has been found, and the proposed change must be approved by the U.S. Department of Energy (DOE) before it is implemented.

\subsubsection{Authorization Basis}

The first step in evaluating any significant proposed change or existing condition is the analysis of facility safety. When a process change or new activity is proposed, perform a hazard analysis in accordance with 588-GEN, Preparation of a Process Hazards Analyses (PrHAs) at TA-55, to determine if the proposed change or activity is safe. It is important to realize that the hazard analysis is not a USQD Safety Evaluation. If the change is recognized as an unsafe condition, obviously it would not be implemented as planned. The change would be modified and reanalyzed until it is safe, or it would be canceled.

Even though the proposed change is shown to be safe, it may still affect the authorization basis for the facility. Reviewing and evaluating proposed changes 
require comparing the changes against the authorization basis. The authorization basis is comprised of the TA-55 final safety analysis report (FSAR) and technical safety requirement (TSR), and can also include USQD reports, basis for interim operations (BIO), environmental assessment (EA), environmental impact statement (EIS), justification for continued operation (JCO), and activity-specific commitments made to comply with Laboratory and DOE rules, orders, or policies. As such, identification and subsequent evaluation of a potential USQ requires a thorough understanding of the facility authorization basis. To ensure that the entire authorization basis for TA-55 is used when comparing a proposed change, a memo listing the current documents is kept in the NMT-8 group office.

The USQ process establishes the approval authority required, not the safety of a change or situation. Determine that the change is safe before the USQ process is initiated.

\subsubsection{USQ Entry Conditions}

The following five entry conditions require determination that the action is safe and all require evaluation through USQ screening or the USQD process or both:

- revisions to the basis of the TSRs

- changes in the facility

- changes in procedures

- conduct of new tests or experiments

- discovery of new information, of analytical errors, discrepant-as-found states, omissions or other inadequacies in the safety analysis (inadequate safety analysis)

NOTE: Facility safety analysis report (SAR) revisions that might cause a change to a TSR qualify as an input category. If TSRs are significantly revised, however, DOE approval is required-a USQD is not necessary.

Each entry condition requires specific activities. The flow charts in USQD and Process and Record Keeping describe the required activities. The following sections discuss the process for each entry condition.

If any of the above entry conditions requires a change to the text in the FSAR or TSR, the page numbers and the exact change in the wording of the text must be included with either the screening documentation or the USQD documentation.

\subsubsection{USQ Screening}

USQ screening is the process to determine whether or not it is necessary to conduct a safety evaluation by answering the seven questions of the USQD. 


\subsubsection{Preliminary Screen}

This screening applies to changes that can be classified as inconsequential based on asking the question "are there any possible safety implications associated with this type of change?" Examples include spelling, typographical errors, grammatical changes, clarification or an additional note to reference in authorization basis documents.

The change should not be screened out if it involves a change to the facility or the discovery of a potentially inadequate safety analysis.

If the change passes this screen, document the change and include it in the yearly SAR update.

\subsubsection{Formal Screen}

A more formal screening, answering and justifying the following three questions, is appropriate for entry conditions that are not inconsequential:

- Is it a temporary or permanent change to the facility as described in the existing safety analysis?

- Is it a significant change to the procedures described in the existing safety analysis?

- Is it a test or experiment not described in the existing safety analyses?

If the answer to any question is yes, then a USQD is required before implementation.

If the three questions are answered no, then a USQD is not required.

It is important that the screening process does not inappropriately screen out conditions requiring a USQD. DOE recommends that screening not be used for actual physical modifications to systems described in the safety analysis.

This standard requires answering the full seven questions for changes to structures, systems, or components as described in the safety analysis. These systems may be either explicitly or implicitly described in the SAR, TSRs, or other authorization basis documents.

For changes to procedures, those procedures simply identified or listed (but not summarized or described in some detail) do not require a full USQD. Procedures may include anything described in the safety analysis that defines or describes activities or controls over the conduct of work. 


\subsection{Revising a TSR}

\subsubsection{Screening}

TSR revisions always require DOE approval before implementation. The USQD process is not required unless the TSR change also requires a change to the SAR. Submit the revision through ESH-3 to the DOE for approval.

NOTE: In some cases, an analysis may be required by DOE to evaluate and justify the change against the existing authorization basis, and the USQD process may be useful in these cases.

\subsubsection{SAR Revisions}

Upon originating or proposing a revision to a SAR, facility managers determine whether revisions to the TSRs are also required.

If TSR revisions are required, then facility managers prepare and submit the revisions with their bases, concurrently with the revisions to the SAR, through ESH-3 for DOE approval.

If any discrepancy is discovered between the facility and the TSR:

- report the discrepancy in accordance with DOE 232.1, Occurrence Reporting and Processing of Operations Information

- perform a USQD

- resolve the discrepancy expeditiously (DOE Order 5480.22, Attachment 1, Step 5)

\subsubsection{Changing the Basis for a TSR}

The basis for a TSR may be changed without prior DOE approval, unless the change involves any one of the following:

- a change in the TSR

- a change in the SAR involving a USQ

- a change to the way that operability in the TSR could be met, applied, or interpreted (DOE Order 5480.22, page 44)

A USQD is required for a change to TSR basis involving a SAR change. 


\subsection{Determining DOE Approval}

Use the following table to determine if DOE approval is needed.

\begin{tabular}{|l|l|l|}
\hline \multicolumn{1}{|c|}{ If } & \multicolumn{1}{|c|}{ then } & \multicolumn{1}{c|}{ and } \\
\hline $\begin{array}{l}\text { a SAR change is not } \\
\text { required, }\end{array}$ & $\begin{array}{l}\text { the proposed TSR basis } \\
\text { change would be } \\
\text { within the existing } \\
\text { authorization basis. }\end{array}$ & \\
\hline $\begin{array}{l}\text { the SAR description } \\
\text { must change to } \\
\text { accommodate the } \\
\text { proposed TSR basis } \\
\text { change, }\end{array}$ & $\begin{array}{l}\text { the USQD is needed to } \\
\text { verify that the changes } \\
\text { are within the } \\
\text { authorization basis, }\end{array}$ & $\begin{array}{l}\text { DOE approval is not } \\
\text { required unless the } \\
\text { USQD is positive. }\end{array}$ \\
\hline $\begin{array}{l}\text { a change to an actual } \\
\text { TSR is planned, }\end{array}$ & $\begin{array}{l}\text { DOE approval is } \\
\text { required, }\end{array}$ & $\begin{array}{l}\text { a USQD is not } \\
\text { required. Submit the } \\
\text { change to the DOE for } \\
\text { approval and then } \\
\text { amend the SAR and the } \\
\text { TSR. }\end{array}$ \\
\hline
\end{tabular}

\subsection{Inadequate Safety Analysis}

\subsubsection{Conditions}

An inadequate safety analysis may be identified as the result of the following three general conditions.

- receipt of new information

- discovery of a discrepant-as-found state

NOTE: This is referred to as a backward-looking USQ in section 1.4 of Attachment 2 of the Supplemental Guidance for DOE Order 5480.21. Backward-looking means that you look at existing, as-found conditions and evaluate them as if they were a proposed modification. The condition may be instantly resolved to correct the condition, but a USQD may still be necessary.

- occurrence of an event per DOE Order 232.1, Occurrence Reporting and Processing of Operations Information. 


\subsubsection{TSRs, Operational Events, and USQDs}

A discovered pre-existing condition (the discovery of an inadequate safety analysis) that constitutes a discrepancy between the facility and the TSR requires a USQD and is reportable under DOE Order 232.1, Occurrence Reporting and Processing of Operations Information. Examine other operational events on a case-by-case basis to determine the need for a USQD. If the operational event (such as an off-normal occurrence or unusual occurrence) is the result of, or has an impact on the safety basis of the facility, a USQD is necessary.

A positive USQD resulting from the evaluation of an existing condition is a reportable event.

\subsubsection{Identifying Inadequacies}

In most cases, identification of inadequacies of previous safety analyses or a possible reduction in the margin of safety as defined in the TSRs will require a USQD and will require performing the following steps.

1. For a potential inadequacy, determine if the inadequacy is a reportable occurrence under DOE Order 232.1, Occurrence Reporting and Processing of Operations Information. For assistance, contact ESH-7, the Occurrence Investigation Group.

2. Notify ESH-3 of the situation as soon as it is discovered. A reasonable period is permitted to perform an initial USQD to confirm the potential inadequacy of a previous safety analysis (see Attachment 2, Supplemental Guidance for DOE Order 5480.21, Unreviewed Safety Questions, Sec. 1.5, page 4). If possible, correct the inadequacy or as-found condition for an instantly resolved USQ. DOE may still need to be notified, but they can be informed that the condition no longer exists (see Attachment 2, Supplemental Guidance for DOE Order 5480.21, Unreviewed Safety Questions, Sec. 1.9).

3. Perform a backward-looking USQD.

a. Document the basis for the USQD. Follow the guidance in this manual.

b. Maintain the documents required by this standard throughout the operating life of the TA-55 Plutonium Facility. Ensure complete transfer of all documents to any subsequent facility operator.

c. Make the indicated changes in the SAR to comply with the reevaluated safety envelope.

4. Take action to place the facility in a safe condition until the USQD is completed and, if necessary, until the conditions or changes to configurations are approved by the DOE as part of a revised authorization basis through the USQ process. 


\subsection{Entry Condition Summary}

Different entry conditions for significant changes and existing conditions are handled as follows.

\begin{tabular}{|l|l|}
\hline \multicolumn{1}{|c|}{ If the entry condition is } & \multicolumn{1}{c|}{ then } \\
\hline a TSR change, & $\begin{array}{l}\text { Do not perform a USQD, unless it } \\
\text { also requires a change to the SAR. } \\
\text { Submit the change to DOE for } \\
\text { approval. } \\
\text { Amend the SAR. } \\
\text { Amend the TSRs. }\end{array}$ \\
\hline $\begin{array}{l}\text { a temporary or permanent facility or } \\
\text { procedure change or a new test or }\end{array}$ & $\begin{array}{l}\text { Ask the three screening questions. } \\
\text { If any answer is yes, then perform a } \\
\text { USQD. }\end{array}$ \\
\hline $\begin{array}{l}\text { a discovery of an inadequate safety } \\
\text { analysis. }\end{array}$ & $\begin{array}{l}\text { Skip the screening process. } \\
\text { Perform a USQD. } \\
\text { Report per DOE Order 232.1, } \\
\text { Occurrence Reporting and } \\
\text { Processing of Operations } \\
\text { Information. }\end{array}$ \\
\hline
\end{tabular}

\subsection{USQD Process}

If the entry condition potentially involves a change to authorization basis documents or does not involve an inconsequential change, then complete a USQD that, as a minimum, answers the seven questions listed below. The following text also explains the context of each question.

A yes answer to any of the seven questions means the change has resulted in a USQ. 
The seven questions defining a USQ are divided into three categories:

NOTE: Categories I and II require an initial USQ screening to determine whether the change affects the authorization basis.

I For accidents already reviewed and accepted by the DOE, use the following four questions to evaluate if the proposed change increases the probability of occurrence or the consequences of an accident or malfunction of equipment important to safety that has been previously evaluated in the facility safety analyses:

1. Could the proposed activity increase the probability of occurrence of an accident previously evaluated in the safety analysis?

2. Could the proposed activity increase the consequences of an accident previously evaluated in the safety analysis?

3. Could the proposed activity increase the probability of occurrence of a malfunction of equipment important to safety previously evaluated in the safety analysis?

4. Could the proposed activity increase the consequences of a malfunction of equipment important to safety previously evaluated in the safety analysis?

II To evaluate the possibility of the creation of a new type of accident or malfunction of a different type than any previously evaluated in the safety analysis, ask the following two questions:

5. Could the proposed activity create the possibility of an accident of a different type than any previously evaluated in the safety analysis?

6. Could the proposed activity create the possibility of a malfunction of equipment important to safety of a different type than any previously evaluated in the safety analysis?

III To evaluate the possibility of reducing the margin of safety as defined in the bases of the TSRs, ask the following question:

7. Does the proposed activity reduce the margin of safety as defined in the basis for any TSR?

NOTE: Use a quantitative or qualitative rationale to justify and explain all answers to screening and USQD questions, whether positive or negative. 


\subsection{Addressing the Seven Questions}

Question 1: Could the proposed activity increase the probability of occurrence of an accident previously evaluated in the safety analysis?

1. Compare the proposed change with the accident analysis-specifically, the basis for the calculated probability-in the following documents:

- HA

- FSAR

- operational limits in the TSR

- any other safety documentation constituting the facility's authorization basis

2. Identify the following specific areas within the proposed change that are included as part of the safety analysis:

- material at risk

- material quantity

- material handling

- release fractions

- exposure time

- frequency of operations

- general operational procedures

- specific operational procedures

- prevention systems

- failure modes

- mitigation systems

- failure rates

3. Using professional judgment consistent with the original assumptions of the safety analyses, determine the probability increase based on a qualitative assessment (within existing qualitative ranges). Accident or event frequencies are divided into the following five bins.

\begin{tabular}{|r|l|l|}
\hline & \multicolumn{1}{|c|}{ Category } & \multicolumn{1}{c|}{ Probability (p) [events per year] } \\
\hline I. & Normal Operations & $1<\mathrm{p}<10^{-1}$ \\
\hline II. & Anticipated Events & $10^{-1}<\mathrm{p}<10^{-2}$ \\
\hline III. & Unlikely & $10^{-2}<\mathrm{p}<10^{-4}$ \\
\hline IV. & Very Unlikely & $10^{-4}<\mathrm{p}<10^{-6}$ \\
\hline V. & Improbable & $\mathrm{p}<10^{-6}$ \\
\hline
\end{tabular}


If the proposed change results in an increase in probability from one frequency category to a higher frequency category, then the answer to this question is yes.

If the proposed change results in an increase in probability within a frequency category less than one order of magnitude, then the answer to this question is no.

NOTE: Assessment of the impact of the proposed change may be quantitative or qualitative or both.

\section{Question 2: Could the proposed activity increase the consequences of an accident previously evaluated in the safety analysis?}

1. Compare the proposed change with the current accident analysis.

2. Evaluate the quantifiable areas related to consequences (such as material form, release fraction, exposure, dose, containment and packaging, and shielding) against the proposed change.

3. Evaluate any potential increase in consequences due to any change by comparing the anticipated consequences of an accident with the consequences of a same or similar type accident that has already been analyzed.

If the potential increase in consequences of a certain accident type is increased (even if less increased than the bounding accident of a different type or the most limiting accident consequences), then the answer to this question is yes.

If the potential increase in consequences of a certain accident type is less than the bounding accident of that type, then the answer to this question is no.

NOTE: Ensure that the consequences could not be additive-that is, contribute to the consequences of another accident, thereby exceeding the existing bounding accident of a different type (described in Question 5 of this section). 
The following are the three categories of types of accidents:

\begin{tabular}{|l|l|}
\hline \multicolumn{1}{|c|}{ Accident Category } & \multicolumn{1}{|c|}{ DBA/EBA a Accident Types } \\
\hline 1. Natural Phenomena & $\begin{array}{l}\text { Earthquake } \\
\text { Winds } \\
\text { Lightning } \\
\text { Temperature extremes } \\
\text { Rain }\end{array}$ \\
\hline 2. Externally Induced Events & $\begin{array}{l}\text { Surface vehicle impact } \\
\text { Aircraft impact } \\
\text { Hoist, crane, rigging failure } \\
\text { Structural failure } \\
\text { Adjacent facility accidents } \\
\text { Missile } \\
\text { Electrical and mechanical failure }\end{array}$ \\
\hline 3. Process-Related Events & $\begin{array}{l}\text { Nuclear criticality } \\
\text { Human-factor related } \\
\text { Explosions (including deflagration } \\
\text { and detonation) } \\
\text { Fire } \\
\text { Uncontrolled chemical reactions } \\
\text { Active loss of confinement } \\
\text { Passive loss of confinement }\end{array}$ \\
\hline adesign-basis accidents/evaluation basis accidents \\
\hline
\end{tabular}

NOTE: Use expert judgment and the existing safety analysis to categorize the type of accident.

Question 3: Could the proposed activity increase the probability of occurrence of a malfunction of equipment important to safety previously evaluated in the safety analysis?

Accident analyses often involve calculated or assumed failure of one or more systems important to safety. Other independent systems important to safety may be assumed to function normally and may even mitigate the severity of the accident. If a proposed change either degrades the performance of these systems or increases the challenges to these systems, the probability will increase that equipment important to safety will malfunction. When determining the probability of occurrence, use the probability bins in Question 1.

1. If data are available and practical, determine the value either qualitatively or by a probability analysis.

2. Evaluate credible failure modes associated with the change. For example:

- decreasing the seismic specifications and qualifications in a system or component that is classified as important to safety or related to safety 
- reducing system or equipment redundancy or independence

- significantly increasing the frequency of operation of equipment important to safety, thereby increasing the probability of a failure-rate type of accident in a given time period

- placing additional stress or load (or both) on systems, thereby increasing the probability of a malfunction

Question 4: Could the proposed activity increase the consequences of a malfunction of equipment important to safety previously evaluated in the safety analysis?

1. Evaluate changes that affect equipment and thereby potentially increase releases of hazardous material or energy or radioactive doses above the worst-case limiting consequences in the authorization basis documents.

a. Evaluate equipment that is important to safety, in relation to the change, to determine if the change could result in increased exposures. Use the credible failure modes identified in Question 3. For example:

A valve that was previously designed and analyzed to fail in the open position is changed to a valve designed to fail in the closed position. If failure in the closed position results in an increase in consequences resulting from increased release or exposure, the answer to this question is yes, resulting in a positive USQD.

Question 5: Could the proposed activity create the possibility of an accident of a different type than any previously evaluated in the safety analysis?

An accident involving an initiator or failure that is not considered in the SAR or other safety document is potentially an accident of a different type. Accident types are listed in Question 2. An accident that may be different, but involves a smaller accident consequence than that already addressed in the safety documentation, should not be considered an accident of a different type unless the contribution of . the accident causes the bounding case to be exceeded. Accidents of a different type are limited to those considered to be as likely to happen as those considered in the authorization basis. For example:

- A change that increases the probability of an unanalyzed accident to the point where it becomes as likely as the accidents considered in the authorization basis creates a possible accident of a different type. Installing equipment that is more vulnerable to seismicity may increase the probability of a previously analyzed accident.

- A new accident that was not included in the original analysis, but is now as likely as any other in the accident analysis, could create the possibility of an accident of a different type. 
NOTE: Using a new technique or model for updating an accident analysis may result in a different type of accident or an increase in consequences. New accidents resulting from such an analysis do not constitute USQs, but, nevertheless, must be included as part of the SAR in the annual SAR update.

Question 6: Could the proposed activity create the possibility of a malfunction of equipment important to safety of a different type than any previously evaluated in the safety analysis?

Malfunctions involving equipment not covered by the original safety analysis constitute a malfunction of a different type. Exceptions include the following:

- Malfunctions that may be considered different, but are bounded by the existing accident analysis are not considered malfunctions of a different type. Possible malfunctions of a different type are limited to malfunctions that are considered as likely to happen as those considered in the authorization basis.

- Evaluating existing equipment and systems important to safety, in relation to the change, may be necessary to answer Question 6. Relocation, replacement, alteration, redesigning, reconfiguration, change of use, change of power sources, or change of failure mode of equipment may introduce the possibility of a malfunction of equipment important to safety.

For example, on a system or piece of equipment that is important to or related to safety, replacing a mechanical control by an electronic control that may have a different failure mode may create an equipment malfunction of a different type, which would result in a USQ.

Question 7: Does the proposed activity reduce the margin of safety as defined in the basis for any TSR?

The margin of safety is the difference between the established safety limit and an acceptance limit, if one has been established, or if not, the "peak" value calculated by the accident analysis. To evaluate a change in the margin of safety, some limits (safety margins) must be established in the authorization basis documents. Normally, TSRs describe such structures, systems, or components (SSCs) and their ranges or limits of operation. Any change that raises the established acceptance limit of any SSC would decrease the margin of safety. Therefore, the answer to this question would be yes, making the change a USQ.

1. Base the decision as to whether the margin is reduced on physical parameters such as

- established mechanical specifications

- static and dynamic strength of materials

- design parameters

- operating limits 
- other conditions that have been or can be observed, measured, and calculated

NOTE: The margin, however, may be implicitly rather than explicitly expressed as a numerical value. Therefore, the precise determination of a numerical value associated with a change is not always required.

2. The bases for a TSR should explicitly define or address the margin of safety. If the bases do not specifically address a margin of safety, then review the safety analyses and other appropriate authorization basis documents to determine whether the proposed change, test, experiment, or new information has resulted or would result in reducing the margin of safety.

3. Evaluate existing margin parameters (such as the following) to determine whether the change has reduced the margin of safety by increasing the acceptance limit as set forth in the authorization basis:

- limiting conditions of operation (LCO)

- design parameters for systems and individual components

- other technical specifications

\subsection{Summary of Screens and USQDs}

Once the screen and USQD process has been completed, a decision is made, based on how the questions were answered, on whether the screen or USQD is positive or negative. 


\subsubsection{Types of Screens}

The type of screen is important in how the change is reported and implemented. It is important that the Authorization Basis Team at TA-55 is informed of all implemented changes, so these changes can be incorporated into the FSAR annual update.

\begin{tabular}{|c|c|c|}
\hline $\begin{array}{l}\text { Type of } \\
\text { Screen }\end{array}$ & Definition & Action and Guidance \\
\hline "What if" & $\begin{array}{l}\text { Positive and negative screens } \\
\text { may involve either planned } \\
\text { changes or existing conditions. } \\
\text { A screen performed on a } \\
\text { planned change is a what-if } \\
\text { type of screen (that is, the } \\
\text { change has not been } \\
\text { implemented and is not an } \\
\text { existing condition). }\end{array}$ & $\begin{array}{l}\text { Modify the change before it is } \\
\text { actually implemented. } \\
\text { Example: A what-if type of } \\
\text { screen done on a change turns } \\
\text { out to be positive. It may then } \\
\text { be possible to modify the } \\
\text { change so that the results } \\
\text { would be negative and } \\
\text { performing a USQD could be } \\
\text { avoided. } \\
\text { Or, perform a USQD. } \\
\text { NOTE: Changes falling into } \\
\text { the category of an } \\
\text { inadequate safety } \\
\text { analysis are not } \\
\text { "what-ifs" and in most } \\
\text { cases require a full } \\
\text { USQD. }\end{array}$ \\
\hline Negative & $\begin{array}{l}\text { A formal screening was done, } \\
\text { and all answers were "No." }\end{array}$ & $\begin{array}{l}\text { Have the screen reviewed and } \\
\text { signed by the facility manager. } \\
\text { Maintain the document. } \\
\text { Make any changes needed to } \\
\text { the authorization basis } \\
\text { documents. }\end{array}$ \\
\hline Positive & $\begin{array}{l}\text { One or more of the screen } \\
\text { questions was answered "Yes." } \\
\text { A positive screen really } \\
\text { becomes some type of USQD. }\end{array}$ & $\begin{array}{l}\text { Perform a full USQD by } \\
\text { answering the seven questions. }\end{array}$ \\
\hline
\end{tabular}




\subsubsection{Types of USQDs}

Changes and existing conditions that are not screened out go through a full USQD and are one of four types:

- negative "what if" USQD

- positive "what if" USQD

- negative inadequate safety analysis USQD

- positive inadequate safety analysis USQD

As in the case with screens, the type of USQD determines how the change is reported and implemented.

\begin{tabular}{|c|c|c|}
\hline Type of USQD & Guidance & Action \\
\hline Negative "what if" USQD & $\begin{array}{l}\text { The change may be made at the } \\
\text { discretion of the NMT- } 8 \text { Group Leader. }\end{array}$ & $\begin{array}{l}\text { Maintain a record of the USQD at the } \\
\text { facility. } \\
\text { Notify ESH-3 when the change has been } \\
\text { implemented. } \\
\text { Send a description of the change and } \\
\text { USQD result to ESH-3, who sends a list } \\
\text { semiannually to DOE. }\end{array}$ \\
\hline Positive "what if" USQD & $\begin{array}{l}\text { The change must be submitted to DOE } \\
\text { and receive approval before being } \\
\text { implemented at the facility. } \\
\text { As with a positive "what if" screen, the } \\
\text { change may be modified so that it is no } \\
\text { longer a positive USQD, removing it } \\
\text { from requiring DOE approval. }\end{array}$ & $\begin{array}{l}\text { Maintain a record of the USQD at the } \\
\text { facility. } \\
\text { Submit the change through ESH-3 to } \\
\text { DOE. } \\
\text { Implement the change after DOE } \\
\text { approval has been received. }\end{array}$ \\
\hline $\begin{array}{l}\text { Negative inadequate safety } \\
\text { analysis USQD }\end{array}$ & $\begin{array}{l}\text { These existing conditions have been } \\
\text { evaluated under the USQD process and } \\
\text { found to be negative. }\end{array}$ & $\begin{array}{l}\text { Maintain a record of the USQD at the } \\
\text { facility. } \\
\text { Address any requirement for reporting } \\
\text { under DOE Order } 232.1 \text {, Occurrence } \\
\text { Reporting and Processing of Operations } \\
\text { Information. } \\
\text { Send a description of the change and } \\
\text { USQD result to ESH-3, who sends a list } \\
\text { semiannually to DOE. }\end{array}$ \\
\hline $\begin{array}{l}\text { Positive inadequate safety } \\
\text { analysis USQD }\end{array}$ & $\begin{array}{l}\text { These must be reported to DOE within a } \\
\text { "reasonable time." } \\
\text { NOTE: According to the DOE order } \\
\text { and interpretation guidance, } \\
\text { this means a reasonable time is } \\
\text { given to evaluate the condition, } \\
\text { and when a final decision is } \\
\text { made that the USQD is } \\
\text { positive, it must be } \\
\text { immediately reported to DOE. }\end{array}$ & $\begin{array}{l}\text { Maintain a record of the USQD at the } \\
\text { facility. } \\
\text { Submit the change through ESH-3 to } \\
\text { DOE. } \\
\text { Depending upon the situation, it may } \\
\text { also be necessary to follow the } \\
\text { requirements under DOE Order } 232.1 \text {, } \\
\text { Occurrence Reporting and Processing of } \\
\text { Operations Information, and } 5480.22 \\
\text { (TSR Order). }\end{array}$ \\
\hline
\end{tabular}




\subsection{Required Records}

\subsubsection{Records}

The following records are required for a USQD:

- description of the proposed change, expected effects of the change, systems and parameters affected, and credible failure modes

- actual wording and page number for the text change to the FSAR, if a change to the FSAR is required

- process or procedure used for initial screening that determines if the change affects the SAR, TSR, or other safety documents

- USQD answering the seven questions that determine the existence of a USQ if the USQ screen is positive.

For a full USQD, a completed Unreviewed Safety Question Determination and Screening Worksheet may comprise the required documentation.

\subsubsection{Forms}

The Unreviewed Safety Question Determination and Screening Form is an example of a worksheet used to determine whether the condition

- requires a modification of the SAR or other safety documents

- is of no technical significance

- requires a USQD to determine if the change will result in a USQ

Section 5 of the form is the USQD section of the process. Use this form, the electronic version available on the Laboratory network (Form 1617), or an equivalent form, if necessary.

\subsubsection{Disposition of Records}

TA-55 facility manager maintains facility records of all initial screenings and USQDs that are based on

- proposed changes

- omissions

- inadequacies to facilities

- authorization basis documents

Copies of all USQDs and screens are retained for the life of the facility. Complete transfer of these records to any subsequent contractor is required. Any changes resulting from the USQD are incorporated into the existing SAR or other authorization documents. 


\subsubsection{Disposition of Records for a Positive USQD}

1. Report positive USQDs to ESH-3 and submit them to DOE. DOE approval must be obtained before the change is implemented.

2. Immediately upon discovery, report to ESH-3 positive USQDs involving an inadequate safety analysis.

\subsubsection{Disposition of Records for a Negative USQD}

Semiannually, submit to ESH-3 a list of all implemented changes involving USQDs. For each USQD, this list contains

- USQD ID number

- facility identification

- USQD title

- description of the change or inadequate safety analysis

ESH-3 maintains this list and submits it to DOE on an annual basis.

\subsubsection{USQD Review and Approval Process}

DOE approval is necessary if a change involves a USQ (USQD is positive).

To expedite the review and approval process, use the following table.

\begin{tabular}{|c|c|c|}
\hline Step & Who does it? & Responsibility \\
\hline 1. & Facility Line Management & $\begin{array}{l}\text { Reports positive USQDs of existing conditions to ESH-3 within two weeks of } \\
\text { determination. }\end{array}$ \\
\hline 2. & ESH-3 & $\begin{array}{l}\text { Submits the change, with the USQ documentation, to the DOE for approval and } \\
\text { retains a copy in the ESH-3 USQ file. } \\
\text { NOTE: Unless they are instituted, positive USQDs for proposed changes do not have } \\
\text { negative ramifications on the authorization basis. }\end{array}$ \\
\hline 3. & Facility Line Management & $\begin{array}{l}\text { Submits the change for ESH-3 and other relevant Laboratory review and DOE } \\
\text { approval. } \\
\text { NOTE: The change should be submitted promptly to give sufficient time for review } \\
\text { and approval before the expected implementation date. }\end{array}$ \\
\hline 4. & Facility Line Management & Sends a semi-annual listing of negative USQDs to ESH-3. \\
\hline 5. & ESH-3 & $\begin{array}{l}\text { Submits an annual listing of negative USQDs to the DOE, as part of the yearly SAR } \\
\text { update and review process. }\end{array}$ \\
\hline 6. & Facility Line Management & $\begin{array}{l}\text { In cases where a change does not constitute a USQ (a negative USQD) but still } \\
\text { requires a revision to the SAR, prepares and submits the change to ESH-3 as part of } \\
\text { the yearly upgrade and review process. }\end{array}$ \\
\hline 7. & ESH-3 & $\begin{array}{l}\text { Maintains a record of all USQDs that are based on proposed changes, omissions, or } \\
\text { inadequacies to authorization basis documents. } \\
\text { Maintains the listing of negative USQDs in the USQ file (see USQD Process and } \\
\text { Record Keeping). } \\
\text { Report any known inadequacy resulting in a USQ, immediately upon its discovery, to } \\
\text { the DOE/AL through the USQD process. }\end{array}$ \\
\hline
\end{tabular}




\subsubsection{Laboratory USQD Sign-Off and Closure}

1. Qualified analyst or team completes the USQD process.

2. The change is determined to be either a positive or negative USQD.

3. The following sign the USQD form or worksheet:

- $\operatorname{preparer(s)}$

- independent reviewer

- facility manager or designee

4. For complex or potentially sensitive USQDs, a review by an ESH-3 analyst is also strongly recommended.

5. All positive USQDs are reviewed by the NMT division director. The Facility Review Committee (FRC) reviews the positive USQD and makes a recommendation on approval to the NMT division director. 


\section{Unreviewed Safety Question Determination and Screening Worksheet} (Form 1617)

\section{Los Alamos \\ National Laboratory}

\section{UNREVIEWED SAFETY QUESTION DETERMINATION \\ AND SCREENING WORKSHEET \\ ONE USQD PER FORM}

Facility-Specific Unreviewed Safely Question Determination (USQD) Evaluation Number

Facility Identification

USQD Title

Based on the evaluation presented in this report, the change

$O$ does not constitute an unreviewed safety question.

O does constitute an unreviewed safety question. (DOE approval required prior to implementation. Contact ESH-3 RMP.)

SIGNATURES

\begin{tabular}{|l|l|}
\hline Preparer's Signature & Date \\
\hline Reviewer's Signature & Date \\
\hline Reviewer's Signature (optional) & Date \\
\hline Approval Signature & Date \\
\hline
\end{tabular}

Betain facility copy. Send copies of all USQs (positive USODs) to ESH-3, RMP, MS K489. Follow standard procedures for documentation and reporting USQS, USQDS, and screens. 


\section{Unreviewed Safety Question Determination and Screening Worksheet (Form 1617) (Cont.)}

\section{INTRODUCTION}

As part of the screening and USQD process, the following issues should be reviewed and discussed in the USQD and the screening worksheet.

1. Description of the aspects of the change being evaluated and its expected effects. (For the purposes of this worksheet, "change" will mean any change, test, or new information identified.)

2. Identification of new parameters and systems affected by the issue.

3. Identification of the credible failure modes associated with the issue.

4. References to location of information used for the safety evaluation.

IMPACT ON THE ACCIDENTS EVALUATED AS THE DESIGN BASIS

1. Identify the design basis accidents reviewed for potential impact by the change.

2. Discuss how the parameters and systems affected by the change impact the consequences of these accidents.

3. Identify the design basis accidents, if any, for which failure modes associated with the change can be an initiating event.

4. Discuss the impact of the change and/or failure modes associated with the change on the probability of failure in No. 3 above.

5. Identify the safety systems and systems important to safety affected by the change.

6. Discuss the impact of the change and/or the failure modes associated with the change on the probability of failure of the systems identified.

7. Discuss the impact of the change on the performance of the safety systems.

\section{USQD PROCESS ENTRY CONDITION}

The situation being reviewed is:

$\square$ A change to the facility Safety Analysis Report

A change to the facility

A change in procedure

$\square$ A test or experiment

$\square$ A potential inadequacy of previous safety analyses $\square$ A possible reduction in the margin of safety as defined in TSRs

1. Detailed description of the change or inadequate safety analysidjse engineering drawings and continuation sheets if necessary.)

2. List documents and analyses that constitute the current authorization basis for the facility/process. (Use engineering drawings if necessary and continuation sheets as needed.) 


\section{Unreviewed Safety Question Determination and Screening Worksheet (Form 1617) (Cont.)}

3. Impact on Technical Safety Requirements (TSR/OSR)

Does the situation being reviewed require a change to the TSR? $O$ Yes Explain your answer here and note the TSR sections reviewed. Use continuation sheets as needed.
Even if the answer is No, you must explain this in the space below. If you answered Yes, a modification

of the SAR and notification/approval from DOE are

both required. If the TSR change also requires a change to the SAR, then a screening or a USOD is required. Contact ESH-3, RMP

\footnotetext{
4. USQ Screening

If this issue involves a potentially inadequate safety analysis, then screening is not applicable. Go to Sec. 5 and complete the USQD. For the situation being reviewed:

Is it a change to the facility as described in the safety analyses?

Is it a change to the procedures as described in the safety analyses?

is it a test or experiment not described in the safety analyses?

OYes

YYes $O$ No

OYes ONo

(If you answer "No" to all three questions, skip to Sec. 6 .)
}

Explain your answers here and include any reierences reviewed. Use continuation sheets as needed.

NOTE: If the answer to any question in Sec. 4 above was Yes, then a USOD is required prior to implementation. If the answer to every question in Sec. 4 was No, then a USOD safety evaluation is not required, and you may go to the cover page and obtain the sign-off signatures.

5. USQ Determination (USQD)

For the situation being reviewed, answer each of the following seven questions.

5.1 Could the proposed activity increase the probability of an accident previously evaluated in the Safety Analyses?

$\mathrm{O}^{\text {Yes }} \mathrm{O}$ No Explain your answer below. Use continuation sheets as needed. 


\section{Unreviewed Safety Question Determination and Screening Worksheet (Form 1617) (Cont.)}

$\square$ Click here and TAB to go to Section 6.

5.2 Could the proposed activity increase the consequences of an accident previously evaluated in the saiety analyses? Explain your answer here. Use continuation sheets as needed.

5.3 Could the proposed activity increase the probability of a malfunction of equipment important to safety previously evaluated in the safety analyses? Explain your answer here. Use continuation sheets as needed.

$\mathrm{O}^{\text {Yes }} \mathrm{O}^{\mathrm{No}}$

5.4 Could the proposed activity increase the consequences of a malfunction of equipment important to safety previously evaluated in the safety analyses? Explain your answer here. Use continuation sheets as needed. OYes ONo

5.5 Could the proposed activity create the possibility of an accident different from any previously evaluated in the safety analyses? Explain your answer here. Use continuation sheets as needed.

OYes $\mathrm{O}$ No 


\section{Unreviewed Safety Question Determination and Screening Worksheet (Form 1617) (Cont.)}



If any of the above questions is answered "YES," the proposed change involves an Unreviewed Safety Question.

6. Based on the evaluation presented above, the change

$\mathrm{O}$ does not constitute an unreviewed safety question.

does constitute an unreviewed safety question. (DOE approval required prior to implementation. Contact ESH-3 RMP.)

To obtain the proper signatures and complete page one, refer to Sec. 8.5 of Laboratory standard LS114-01.1. 


\section{Section 11: Initiating a Work/Change Request}

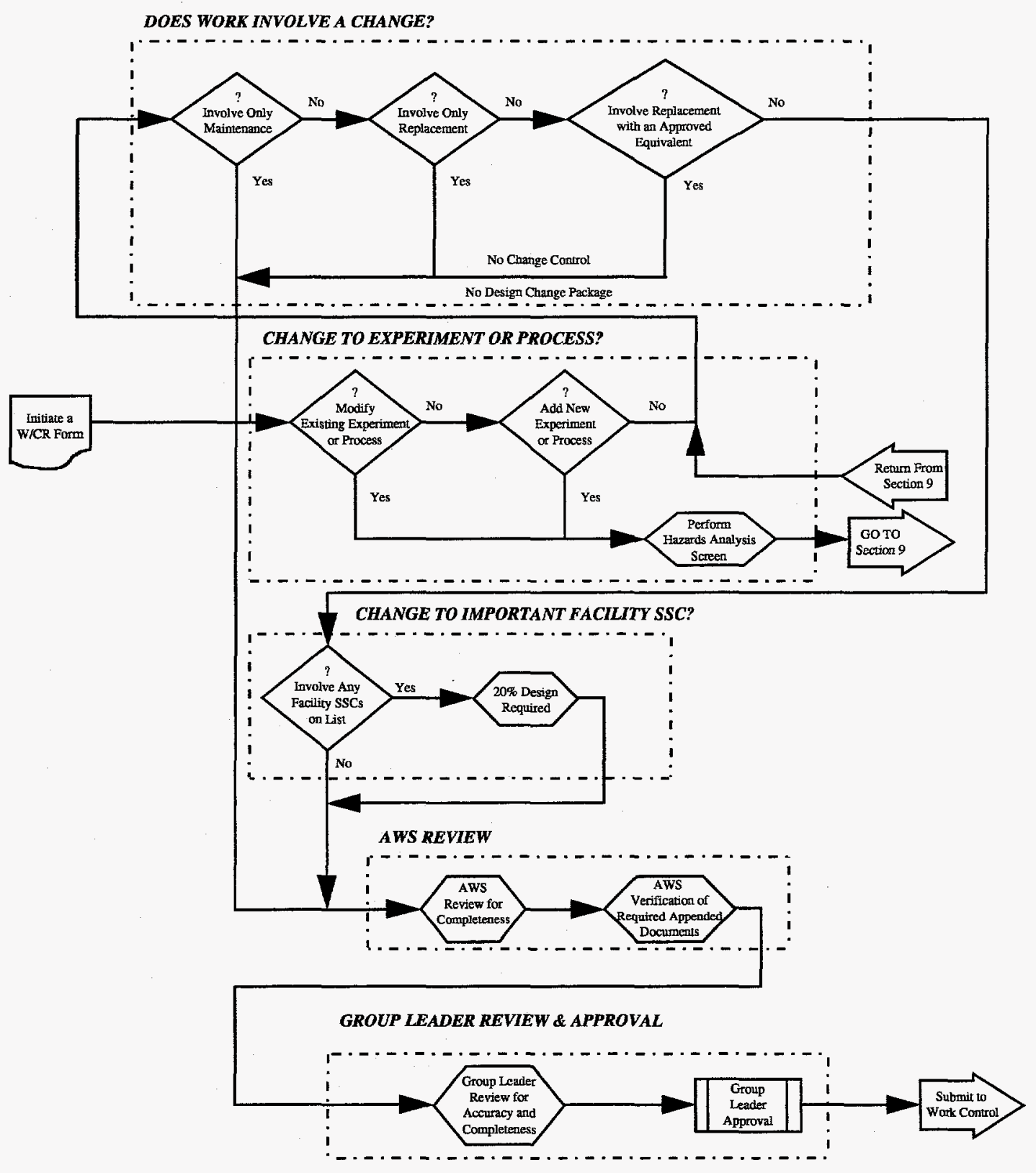


•

•

- 


\section{INITIATING A WORKJCHANGE REQUEST}

A completed Work/Change Request (W/CR) Form is needed for work to be scheduled on the Plan of the Day. Work scheduled on the Plan of the Day includes, but is not limited to, all work performed at TA-55 by a support services subcontractor and maintenance and new construction performed by Laboratory groups and their employees, contractors, and subcontractors.

Anyone at TA-55 with a valid charge code can initiate a W/CR. A W/CR Form is provided at the end of this section for copying or can be obtained by contacting Work Control or an area work supervisor (AWS). A list of telephone numbers for Work Control and AWSs is included in Appendix A.

\subsection{Completing Section 1.0 of the Work/Change Request Form}

Originator fills out the W/CR Form by first providing:

- a short (less than 50 characters) descriptive title of the work being requested

- name and phone number where (s)he can be reached during the day

- the AWS number (if known)

- group and charge code information

- location of the work to be performed

- priority of the work to be performed

- identify the need for the change and provide a description of the proposed work, sufficient in detail to allow an independent reviewer to evaluate the change

\subsection{Completing Section 2.0 of the Work/Change Request Form}

Originator checks all boxes in section 2.0 that apply to the proposed work/change.

\subsubsection{Maintenance and Support}

Maintenance performed on facility structures, systems, or components (SSCs) or replacement of facility systems or components with approved equivalents (documented by NMT-8 Systems Engineering) are not configuration management (CM) items. Notify the maintenance manager whenever a documented approved equivalent replacement has been made so that the Master Equipment List (MEL) and Preventative Maintenance List (PML) are updated. 
NOTE: All SSC substitutions are subject to change control procedures identified herein and must be approved and documented by NMT-8 Systems Engineering.

If the proposed work is maintenance or support, then the originator only needs to sign and date the W/CR Form, and submit it to the appropriate AWS.

\subsubsection{Process Change}

If the change modifies an existing process or experiment or adds a new process or experiment in PF-4, then attach a copy of the Hazards Analysis Screen to the W/CR (see section 9.1).

\subsubsection{Non-Maintenance Change}

CAUTION: Substitutions involving facility SSC that are not documented approved (by systems engineering) equivalent replacements are non-maintenance changes.

If the proposed work is not considered to be maintenance, then the W/CR originator identifies any of the SSCs listed that could be affected by the change and checks the appropriate box(es). (AWS can assist originator in identifying affected SSCs.) If no box has been checked, the change does not fall under change control and a design change package (DCP) is not required. W/CRs not requiring a DCP are processed directly through Work Control in accordance with NMT8-FMP-801, Work Order Request Initiation and Work Package Control. The Work Control Plan of the Day manager performs an independent assessment of all work requests.

If a box has been checked, a twenty percent design must accompany the W/CR.

\subsubsection{Twenty Percent Design}

If any box in section 2.0 on the W/CR Form is checked, complete a twenty percent design. A twenty percent design includes

- a copy of the Hazards Analysis Screen

- a complete work scope/design summary identifying all elements of the work to be performed and design alternatives considered (where applicable)

- building, room, or equipment layout drawings depicting existing conditions and proposed construction (i.e., placement of new gloveboxes or equipment)

- schedule 
This twenty percent design is required to be completed prior to submittal of the W/CR and is the basis of the review at the scoping meeting (discussed in section 12.1.1).

\subsubsection{Submitting W/CR to AWS}

Originator signs and dates the W/CR and submits it to the AWS.

\subsection{Reviewing Completeness of W/CR}

1. AWS reviews for completeness all W/CRs submitted to them by employees at TA-55.

2. AWS verifies that any required documents are appended to the W/CR before signing and dating the form.

3. AWS or designee gets the originator's group leader's approval before submitting the W/CR to Work Control for processing.

\subsection{Completing Section 3.0 of the Work/Change Request Form}

1. Group leaders or their designees approve all W/CRs, verifying the accuracy of the information on the W/CR and that any documents required are appended.

2. If the information is complete and accurate and the required documents are appended, then the originator's group leader signs and dates the W/CR form.

3. Return the approved W/CR to the AWS for processing.

4. AWS submits completed W/CR to Work Control for processing. 


\section{Work/Change Request Form}

Page 1 of 2

1.0 INITIATE CHANGE REQUEST

Title ( 50 char):

Requested By:

Phone \#:

AWS \#:

Group: Program Code:

Cost Acct: Work Package:

Bldg: Room:

AWS Priority: [ ] Urgent [ ] Essential [ ] Routine [ ] Emergency

Reason for and Description of Change (to include any potential hazards)

2.0 SYSTEMS EVALUATION (Check all boxes that apply)

Involves a change, that is not considered to be maintenance, to one or more of the following:

[ ] Process safety significant equipment (IFIT ceiling armor, GB-116 hydrogen detector, hydrogen excess flow valves in Rooms 114 and 305, and PIGMA welder)

[ ] Confinement (PF-4 structure including confinement penetrations, vault doors, ventilation exhaust plenums, ductwork from plenums to exhaust stacks, and supply air intake valves)

[ ] Electrical distribution (13.2 KV and distribution to lighting panels and busducts)

[ ] Positive or negative pressure chilled circulating water system

[ ] Tanks or tank systems required to meet RCRA requirements

[ ] Primary chilled circulating water system

[ ] GPP and line item construction projects

[ ] Flammable gas systems to gloveboxes

[ ] Glovebox or Glovebox Stand I ] UPS

[ ] HVAC

[ ] Emergency Paging

[ ] Deisel Generator

1] CAMs

[ ] Wet Vacuum

[ ] Criticality Alarm

[ ] Dry vacuum

[ ] Industrial waste lines

[ ] Industrial gas services

[] Acid chemical feed

I Emergency lighting

[ ] Vault chilled circulating water [] Industrial water

[ ] PF-4 Trolley

[ ] Security

[ ] Switchgear battery bank

[ ] Fire detection and suppression

[ ] Instrument air

[ ] Facility Control System (FCS)

[ ] Process Air

[ ] Process gas

[ ] Caustic chemical feed

[ ] Caustic waste lines

[ ] Vault racks and shelving [ ] Chemical storage tank berms

[ ] Safety Showers and eyewash

[] In-line \& fixed head air samplers

If any box in Section 2.0 is checked, the following must be attached before this Work/Change request is processed: (1) a copy of the Hazards Analysis Screen, (2) a complete work scope/narrative design summary identifying all elements of the work to be performed and design alternatives considered (where applicable), (3) building, room and/or equipment layout drawings (if applicable), and (4) schedule.

Requester Signature:

Date:

AWs Signature:

Date:

3.0 APPROVAL:

Group Leader Signature:

Date:

For Office Use Only:

Is WR covered under an existing project? [ ] Y [ ] N Project \#

WR \#

Is WR linked to an existing IPP activity? [ ] Y [ ] N Activity \#

\section{1-6 Initiating a Work/Change Request}




\section{Work/Change Request Form (Cont.)}

Page 2 of 2

INSTRUCTIONS

\subsection{INITIATE CHANGE REQUEST}

This section is to be completed by the originator/requester, with the exception of priority which is assigned by the Area Work Supervisor

1. Using 50 characters or less, provide a descriptive title.

2. Fill in the blanks with the requested information

3. Describe the change in sufficient detail to allow an independent reviewer to evaluate the change. Identify potential hazards. Use an extra sheet of paper if necessary and attach to this request

\subsection{SYSTEMS EVALUATION}

Check appropriate boxes and identify all systems directly or indirectly impacted by the proposed change. The requester shall sign and date the Work/Change Request. The responsible AWS shall sign and date the

Work/Change Request indicating that (s)he agrees with the evaluation and that all required documents are attached.

\subsection{APPROVAL}

The requester's group leader shall sign and date the Work/Change Request indicating that (s)he agrees with the evaluation and that all required documents are attached.

Forward the Work/Change Request to Work Control for processing. 


\section{Section 12: Design Change Package Part 1: Authorization of Procurement \& Construction}

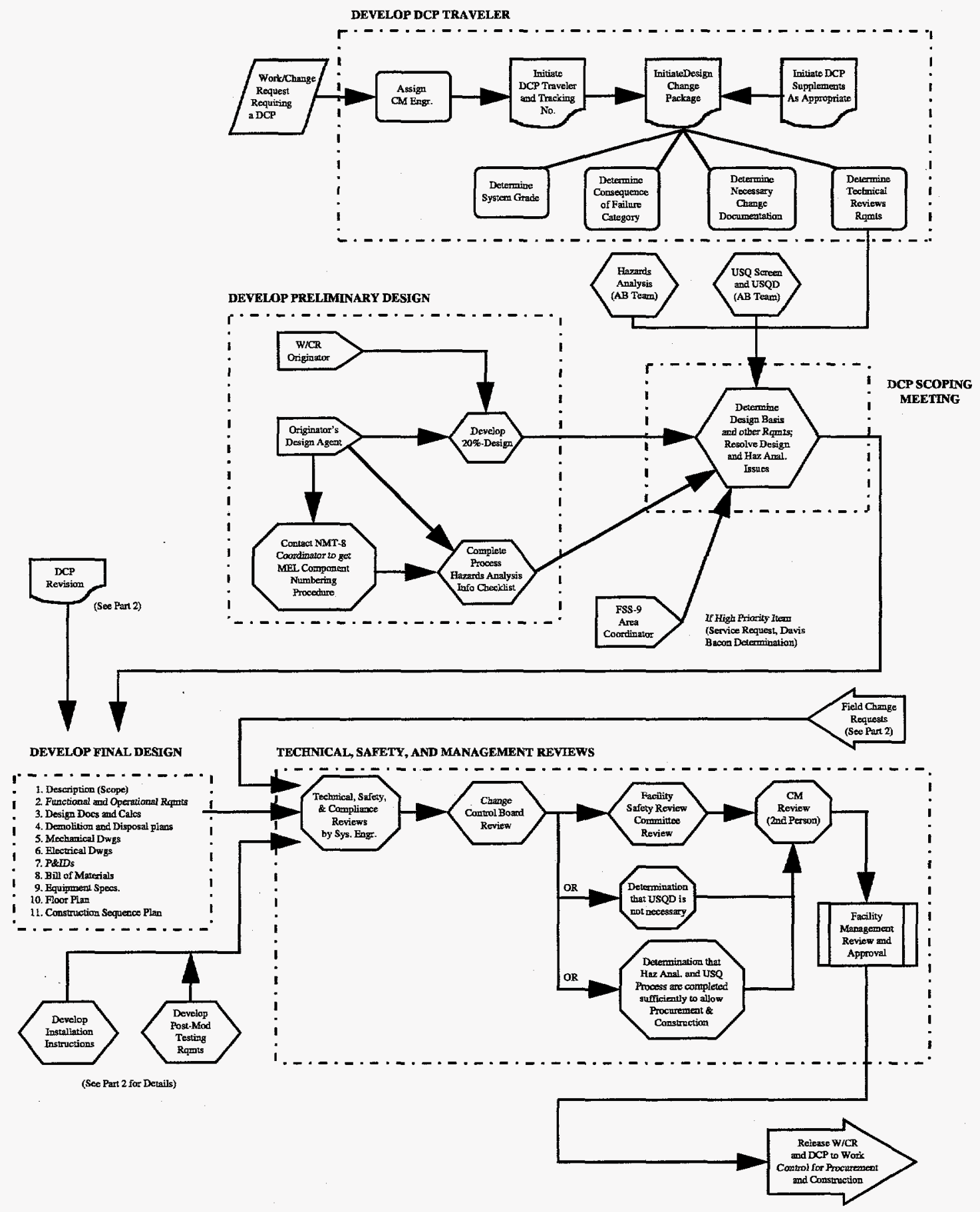




\section{Section 12: Design Change Package Part 2: Installation, Testing, and Closeout}

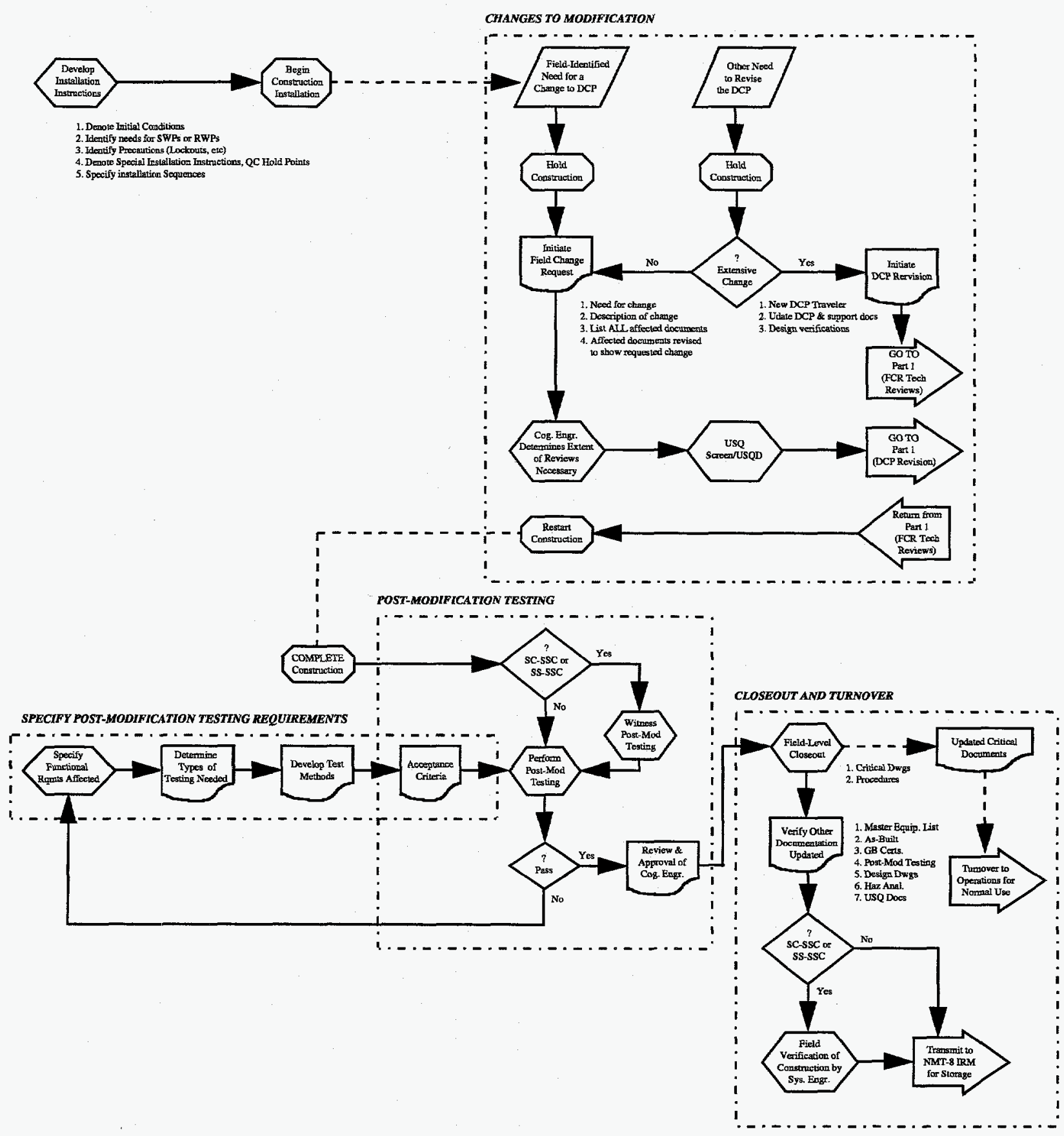




\section{DESIGN CHANGE PACKAGE}

Work/Change Requests (W/CRs) for changes requiring a design change package (DCP) are logged in by Work Control and passed to Configuration Management (CM) for processing. Upon receipt of the W/CR, configuration management assigns a DCP number, for tracking purposes, and a cognizant engineer point of contact having responsibility for working with the requester to develop the DCP. $\mathrm{CM}$ will send a memo to the requester denoting the tracking number assigned and instructions to contact $\mathrm{CM}$ to arrange a scoping meeting (see section 12.1.1) upon selecting a design agent. Direct all questions pertaining to the DCPs through the cognizant engineer (CE).

\subsection{Developing the DCP}

CM is responsible for putting together DCPs. The Design Change Traveler provides instruction for the development, documentation, compilation, and approval of the DCP. A unique sequential DCP tracking number is assigned to each DCP processed. CM establishes and maintains a DCP status report. The assigned number consists of DCP-WW-XXXY-Z where:

- DCP is the acronym for design change package

- WW is fiscal year the DCP was initiated (e.g., 96)

- $\mathrm{XXX}$ is sequential DCP number (e.g., 001)

- $\mathrm{Y}$ is the optional alpha character signifying DCP supplement

- $\mathrm{Z}$ is the numerical revision level of the DCP

DCP supplements may be established at the discretion of the CM engineer. More than one DCP supplement may be initiated at a time for a W/CR per the direction of the $\mathrm{CM}$ engineer.

Develop and process the DCP using the instructions provided on the back of the Design Change Traveler and the required DCP Appendices. Based on the requirements delineated by the $\mathrm{CM}$ engineer in Step 1 of the Design Change Traveler, the DCP requires the completion and attachment of a variety of design documentation, reviews, comments, and approvals. Regardless of the types of design documentation required, the process for developing, reviewing and approving the DCP is, in most cases, completed in the order shown in the Design Change Traveler. The entire design change process comprises the following nine steps.

1. Hold scoping meeting to initiate DCP.

2. Develop design.

3. Verify design. 
4. Approve design.

5. Release design for construction.

6. Construct, test, and document design change.

7. Release change to user.

8. Update Master Equipment List (MEL) and Master Document List (MDL).

9. Close DCP.

\subsubsection{Scoping Meeting}

In preparation for the scoping meeting, the requester must have completed the twenty percent design (discussed in section 11.2.3.1) and the Process Hazards Analysis Information Checklist (PHAIC) (discussed in section 9.2). The CM engineer sets up a scoping meeting for each DCP assigned and will notify the requester as to the place, date, and time. The purpose of this meeting is to get (1) the originator of the W/CR and his/her design agent, (2) the facility engineers responsible for reviewing and approving the design, and (3) a member of the Authorization Basis Team doing the Hazards Analysis and USQ or anyone else necessary, together with the assigned $\mathrm{CM}$ engineer to jointly determine the design basis and other requirements needed to complete the DCP prior to approval for construction. It is through the scoping meeting that design and hazards analysis issues are resolved in order to eliminate any confusion and expedite the change process.

The scoping meeting should also serve to identify the types of documents or databases that may be affected by the proposed change. Examples are

- facility specifications and drawings

- procedures, policies, and associated training

- system design descriptions

- SAR, TSAR, HA

- Master Document List, Master Equipment List

If the DCP is a high priority item, then the FSS-9 area coordinator is included in the scoping meeting so that the service request and Davis-Bacon determination can be done in parallel with the development of the design.

\subsubsection{Design}

The originator of the W/CR is responsible for providing an acceptable design for the proposed change. The following is provided as design guidance: 
- DOE Order 6430.1A, General Design Criteria

- NQA-1, Nuclear Quality Assurance Guideline

- TA-55 facility specifications

- safety classifications of the SSC requirement and the technical basis thereof

- maintenance consequence of failure category (section 4.2.1) and any quality assurance actions needed, including procurement actions

- post-modification testing and acceptance criteria

The originator may use any available resource internal or external to the Laboratory for meeting this requirement. Design agent contacts NMT-8 administrator for the MEL to obtain proper procedure for identifying and numbering equipment at TA-55. A preliminary MEL is prepared to ensure compatibility.

\subsubsection{Issuing Drawing and Project Identification Numbers}

Project identification and Engineering $\mathrm{C}$ drawing numbers are assigned by As-Builting for all new construction and major modifications to structures and systems at TA-55. Similarly, 55Y drawing numbers are assigned by As-Builting for process-related designs such as gloveboxes. Project identification and Engineering $\mathrm{C}$ and $55 \mathrm{Y}$ drawing numbers stay with the project record throughout its life cycle.

It is the responsibility of the design agent to provide one set of D-size and one set of B-size as-built drawings along with an electronic copy of the drawings and project records to As-Builting at completion of the project. The same requirements are in effect when making modifications and/or design revisions.

\subsubsection{Engineering Review, Approval, and Release for Construction}

All DCPs are processed through CM and reviewed by NMT-8 systems engineering. The requester will be notified as to when the DCP was sent for design review and the results of the review. In order for the facility engineers to complete their reviews, information provided in the DCP must be complete and accurate. The requestor has the added benefit of a complete documentation package when the work is completed. The DCP includes, but is not necessarily limited to, the following:

- description of the change (scope of work)

- functional and operational requirements

- post-modification testing and acceptance criteria

- design documents with calculations

- demolition and disposal plans (if any)

- mechanical drawings 
- electrical drawings

- piping and instrumentation drawings

- bill of materials

- equipment specifications

- floor plan (for large jobs)

- plan describing the sequence of construction

- preliminary MEL (if applicable)

After reviewing the package, the system engineer may contact the requestor to resolve any questions. Several iterations may be required before approval is given. Quality design packages will help to keep these iterations to a minimum.

Knowledgeable systems engineers are responsible for design reviews in their discipline. DCP packages are reviewed with emphasis on the following areas:

- personnel safety

- compliance with applicable codes

- compliance with TA-55 standards (i.e., glovebox standards)

- final safety analysis report (FSAR) compatibility

- compliance with U.S. Department of Energy (DOE) Orders

- use of approved repeatable details

- maintainability

- sound engineering practices

- connections to plant services

- demands on plant services (electrical power, cooling water, facility gases, etc.)

- technical correctness/accuracy

- post-modification testing and acceptance criteria

- cost effectiveness

Following approval of the design, and the review and approval by the CCB, ABT, FSRC, CM, and the facility manager, CM releases the W/CR and DCP to Work Control for construction.

\subsubsection{Quality Assurance/Quality Control Review}

All DCPs that modify or otherwise affect facility safety-class or safety-significant structures, systems, or components (SSCs) require a quality assurance/quality control engineering review. The quality engineer should note quality hold points in the Installation Instructions of the DCP. 


\subsubsection{DCP Updates}

The DCP and/or supporting documentation may be revised after the DCP is approved and released for construction via one of two methods:

- DCP Revision

- only for large scale changes to the package

- Field Change Request (FCR)

- for the day-to-day changes required during the construction process

\subsubsection{DCP Revision}

The DCP may be revised any time after initial approval and issue.

1. Initiate and process a new Design Change Traveler. Change the revision level on the DCP Status Report and note accordingly on the new Design Change Traveler.

2. Change the revision level of the DCP and on each of the DCP appendices, as applicable.

3. Ask for a new ESH review, if needed.

4. Issue updated design verifications.

5. Using revision bars, clouds, or other means, note the new revision to each affected DCP design document and supporting documentation.

\subsubsection{Post-Modification Testing}

System engineer identifies post-modification testing and acceptance requirements and witnesses test results for assigned systems.

\subsubsection{Field Change}

The DCP design documents and supporting drawings may be revised with an FCR. Assign each FCR a sequential number following the DCP number.

$\mathrm{CM}$ engineer assigns all FCR numbers and enters information into the data base. Following technical review and approval, the FCR is issued for implementation. An FCR cannot be revised, it can only be voided in its entirety or superseded by another FCR.

Prepare and approve FCRs in accordance with the form and instructions on the back. FCRs are subject to the same level of review as required for the initial issue of the affected documents for only the technical areas addressed by the revision. List approved FCRs in the section 3, Design Drawing and Document Checklist of the Design Change Traveler. 


\subsubsection{DCP Closeout}

\subsubsection{Verifying that Work Was Performed According to DCP Design}

1. Upon reviewing the work after construction is complete, the subcontracting support services foreman signs and dates the DCP Traveler, signifying that it has been performed according to the design provided in the DCP.

2. Upon reviewing the work after construction is complete, AWS signs and dates the DCP Traveler, signifying that it has been performed according to the design provided in the DCP.

3. Upon reviewing the work after construction is complete, the requester signs and dates the DCP Traveler, signifying that it has been performed according to the design provided in the DCP.

4. The subcontracting support services supervisor signs the DCP signifying that all documentation has been completed and included as a record in the DCP (i.e., test and support documents; red-lined as-builts; all drawings, documents and attachments are included, updated and all signature blocks are filled in, etc.).

5. The subcontracting support services supervisor returns the DCP to $\mathrm{CM}$.

\subsubsection{Updating Related Documentation}

1. MEL administrator signs the DCP signifying that the MEL has been updated.

2. Assigned $\mathrm{CM}$ engineer verifies that the Design Drawing and Document Index is complete.

3. Assigned CM engineer verifies that the post-modification testing documentation is complete.

4. Assigned CM engineer verifies that the Glovebox Certification is completed.

5. Assigned CM engineer verifies that design drawings have been red-lined to reflect as-built conditions.

NOTE: If the DCP involved a change or modification to a safety class or safety significant system, then the assigned $\mathrm{CM}$ engineer ensures that the responsible facility system engineer or designee has field verified construction per original design and/or approved FCRs and accompanying red-lined drawings.

6. Resolve discrepancies in accordance with NMT8-FMP-104, Controlling Nonconforming Items, Services, Processes, and Documents.

7. After the field verification has been completed and any nonconforming items have been dispositioned, system engineer or designee signs and dates the DCP. 
8. Assigned $\mathrm{CM}$ engineer verifies that the field change documentation is complete and that the FCR has been entered on the Design Drawing and Document Index.

9. Assigned $\mathrm{CM}$ engineer verifies that the hazards analysis has been completed or that the conditions outlined by the Authorization Basis Team have been met.

10. Assigned $\mathrm{CM}$ engineer verifies that the unreviewed safety question (USQ) screen and/or evaluation has been completed or that conditions outlined by the Authorization Basis Team have been met.

11. Assigned engineer notifies requester that $\mathrm{DCP}$ has been returned to $\mathrm{CM}$ for closeout and to begin the readiness verification as described in 538-GEN, Startup and Restart of Operations of TA-55 Facilities.

12. The DCP remains on hold in CM until after readiness verification is complete in the event that additional work is deemed necessary by the readiness verification team.

13. After readiness has been determined, $\mathrm{CM}$ closes $\mathrm{DCP}$.

\subsubsection{Transmitting and Storing Records}

1. Assigned $\mathrm{CM}$ engineer verifies that documentation needed from the subcontracting support services has been included in the package.

2. Assigned $\mathrm{CM}$ engineer completes a transmittal form listing all drawings and documents sent for as-builting and/or for updating the MDL.

3. Recipient of the drawings and/or documents signs the transmittal. Place a copy of the signed transmittal with the DCP.

4. Assigned CM engineer completes a DCP closure notice and sends it to the requester, with a copy to the Facility Safety, Quality, and Issues Management (FSQ\&IM) Office.

5. Assigned $\mathrm{CM}$ engineer or the configuration manager signs and dates the Traveler in the space provided.

6. Transfer closed DCP to NMT-8 Information Resources Management (IRM) for storage.

7. NMT-8 IRM signs and dates the DCP upon receipt.

\subsubsection{Required Records}

Required records are the DCP, the subcontracting support services work package, and all supporting documentation, e.g., test results, drawings, calculations, etc. 
DCP-

TITLE:

Date:

AWS/phone:

CM Point of Contact/phone:

Requestcr/phone:

Comments

\begin{tabular}{|l|l|l|l|l|l|}
\hline \multicolumn{1}{|c|}{ Requirement Description } & Required & Actionee & Date Rec'd & Comments \\
\hline $\begin{array}{l}\text { CM Kick-off Meeting } \\
\text { To be Attended as required by: CM, Systems Eng., Requester, } \\
\text { Design Agent, Authorization Basis Agent, ICI, and AWS }\end{array}$ & & & & & \\
\hline $\begin{array}{l}\text { Provide Detailed Design with all Applicable } \\
\text { Drawings, \& List of Materials } \\
\text { Ref: DOE Order 6430.1A, NQA-1, TA-55 Facility } \\
\text { Specifications/Policies/rocedures, FSS Standards }\end{array}$ & & & & & \\
\hline $\begin{array}{l}\text { Design Criteria, Functional and Operational } \\
\text { Requirements and Specifications } \\
\text { Ref: All Applicable Codes and Standards }\end{array}$ & & & & & \\
\hline $\begin{array}{l}\text { Special Design Requirements and Variances } \\
\text { Example: Venting of pressure relief in glovebox }\end{array}$ & & & & & \\
\hline $\begin{array}{l}\text { Seismic Analysis } \\
\text { Calculations and restraints, coordinating with the design } \\
\text { engineer to provide adequate seismically qualified mounting } \\
\text { and installation instructions and details/drawings }\end{array}$ & & & & & \\
\hline $\begin{array}{l}\text { Glovebox and Equipment } \\
\text { Drawings, Vendor Manuals, Specifications, Parts List \& } \\
\text { Reliability/Availability/Maintainability Information } \\
\text { Assignment of Master Equipment List Component } \\
\text { Identification }\end{array}$ & & & & & \\
\hline $\begin{array}{l}\text { Mechanical } \\
\text { Process Flow Diagrams, P \& I Diagrams, Drawings, and } \\
\text { Repeatable Details }\end{array}$ & & & & & \\
\hline $\begin{array}{l}\text { Electrical } \\
\text { Single Line Diagrams, Panel Schedules, Internal and External } \\
\text { Connection \& Wiring Diagrams, Drawings, and Repeatable } \\
\text { Details }\end{array}$ & & & & & \\
\hline $\begin{array}{l}\text { Instrumentation \& Controls } \\
\text { Control and Detection Requirements, Set Points, Drawings, } \\
\text { and Repeatable Details }\end{array}$ & & & & & \\
\hline $\begin{array}{l}\text { Inspection \& Testing } \\
\text { Plans and Requirements }\end{array}$ & & & & & \\
\hline $\begin{array}{l}\text { Maintenance } \\
\text { Set Points and Requirements }\end{array}$ & & & & \\
\hline
\end{tabular}




\section{Design Change Traveler}

Page 1 of 8

Date

DCP -

\subsection{INITIATE DCP}

Title:

Requesting Point-Of-Contact: Phone/Pager:

System Grade: [ ] SC [ ] SS [ ] MC [ ] BOP

Management Level: [ ] M1 [ ] M2 [ ] M3 [ ] M4

Assigned Engineer: Organization:

Required

Change Documentation

Completed \& Attached (AE initials)

$[\sqrt{ }]$ yes

Approved Change Request.

[ ] yes [ ] N/A

Design Checklist

[ ] yes [ ] N/A

Installation Instructions .

[ ] yes [ ] N/A

Post-Modification Testing Requirements.

[ ] yes [ ] N/A

Glovebox Certification

\subsection{REVIEW CHANGE PACKAGE}

Required

[ ] yes [ ] no

[ ] yes [ ] no

[ ] yes [ ] no

[ ] yes [ ] no

[ ] yes [ ] no

[ ] yes [ ] no

[ ] yes [ ] no

[ ] yes [ ] no

[ ] yes [ ] no

[ ] yes [ ] no

[ ] yes
Review Type

Architectural

Electrical

Fire Protection

Gloveboxes

HVAC

Instr. \& Control

Mechanical

Security

Seismic

QA/QC

\section{Reviewed and Approved}

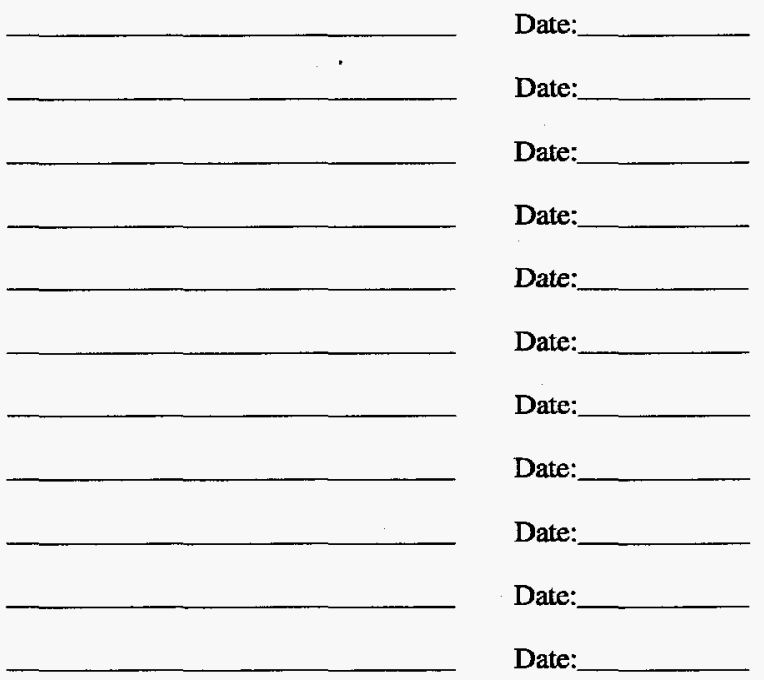




\section{Design Change Traveler (Cont.)}

\section{INSTRUCTIONS}

Record the date in the top left hand corner and the DCP number in the top right hand corner.

\section{$1.0 \quad$ INITIATE DCP}

Section 1 is completed by Configuration Management.

Title: Provide a brief descriptive title for the proposed change

Requesting Point of Contact (POC): List the name and phone/pager number of the requesting group's POC for the change.

System Grade: Identify the highest grade of the SSCs impacted by the proposed change.

Management Level: Identify the highest management level to be applied to the proposed change.

Assigned Engineer: The assigned engineer is the point of contact in Configuration Management or, in the case of GPP or Line Item funding, is the project manager.

The assigned engineer identifies what change documentation is required by checking the appropriate boxes.

\subsection{REVIEW CHANGE PACKAGE}

The assigned engineer identifies which discipline reviews are needed and checks the appropriate boxes. Upon receipt of design, the assigned engineer provides a copy of the design to the Authorization Basis Team for the hazards analysis and forwards the DCP package to Systems Engineering for design review and approval. If the design is approved or approved as noted, the systems engineer(s) signs and dates the Traveler in the space provided. If not approved, the DCP is returned to CM with an explanation of non-conformance. 


\section{Design Change Traveler (Cont.)}






\section{Design Change Traveler (Cont.)}

\section{INSTRUCTIONS}

\subsection{DESIGN DRAWING AND DOCUMENT INDEX}

The purpose of the Design Drawing and Document Index is to provide a complete listing of all drawings and documents developed or revised to support design and implementation of the design change.

Record DCP number in the top right hand corner. Attach continuation sheets as necessary.

List all new or revised design drawings, field change requests, figures, sketches, specifications, calculations, and other documents to support the proposed change. For each entry, the preparer shall list the latest revision being used. If listed documents are later issued with a new revision, the revision shall be added to the index in the space provided. 


\section{Design Change Traveler (Cont.)}

DCP -

4.0 APPROVE CHANGE FOR PROCUREMENT/CONSTRUCTION

CCB Approval Required

[ ] yes [ ] no

[ ] Approve [ ] Disapprove [ ] Conditional (conditions attached)

Meeting Date

CCB Member

Date

\section{Safety Evaluation}

1. Preliminary Hazards Analysis Completed

[ ] yes [ ] N/A [ ] Conditional (see attachment)

2. USQ Screen Approved; Number:

[ ] yes [ ] N/A [ ] Conditional (see attachment)

3. USQ Evaluation Approved; Number:

[ ] yes [ ] N/A [ ] Conditional (see attachment)

\section{Authorization Basis Team}

Required

[ ] yes [ ] no

$[\sqrt{ }]$ yes

$[\sqrt{ }]$ yes
FSRC Chair

Configuration Management

Facility Manager

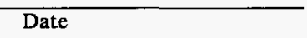

Date

Date

$\mathbf{5 . 0}$

FIELD CLOSEOUT

1. Constructed per Design

$$
\text { Support Service Supervisor }
$$

Area Work Supervisor

Requester

2. Design Change Package documentation complete

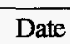

Date

Support Service Supervisor

Date 


\section{Design Change Traveler (Cont.)}

\section{INSTRUCTIONS}

\subsection{APPROVE CHANGE FOR PROCUREMENT/CONSTRUCTION}

CCB Approval: Approval of the Configuration Control Board (CCB) is required if the change leads to a positive Unreviewed Safety Question Determination (USQD). If the CCB does not approve the package, they are responsible for providing a written explanation, to the person that initiated the change request, detailing their reasons for rejection.

Safety Evalnation: An Anthorization Basis Team member signs the DCP Traveler signifying that

- the hazards analysis and USQ Screen and/or Evaluation have been completed, or

- a hazards analysis, USQ Screen and/or Evaluation are not needed, or

- the hazards analysis and USQ Screen and/or Evaluation have not been completed but sufficient review has been performed to allow procurement and construction to begin. (A memo outlining any conditions for release will be provided to the requester with a copy attached to the DCP Traveler.)

An Authorization Basis Team member signature is not required when the change has been previously analyzed under a prior USQ evaluation.

FSRC: Approval of the FSRC Chair is required for all changes that have warranted a positive USQD.

Configuration Management: A member of Configuration Management, other than the assigned engineer, approves the DCP prior to release for procurement or construction.

Facility Manager: The Facility Manager approves the DCP prior to release for procurement or construction.

NOTE: Early procurement can proceed prior to the release of the DCP with a memo of authorization from CM thru the facility manager.

\subsection{FIELD CLOSEOUT}

Support Service Supervisor: The Subcontractor Supervisor signs and dates the DCP Traveler after construction has been completed, signifying that (s)he has reviewed the work and that it has been performed according to the design provided in the DCP.

Area Work Supervisor: The AWS signs and dates the DCP Traveler after construction has been completed, signifying that (s)he has reviewed the work and that it has been performed according to the design provided in the DCP.

Requester: The Requester signs and dates the DCP Traveler after construction has been completed, signifying that (s)he has reviewed the work and that it has been performed according to the design provided in the DCP.

Support Service Supervisor: The Subcontractor Supervisor signs the DCP signifying that all documentation has been completed and included as a record in the DCP (i.e., test and support documents; red-lined as-builts; all drawings, documents and attachments are included, updated and all signature blocks are filled in, etc.). 


\section{Design Change Traveler (Cont.)}

Page 7 of 8

DCP -

\subsection{CLOSE DESIGN CHANGE PACKAGE}

1. Information provided to update the Master Equipment List?

[ ] Yes [ ] N/A

$$
\text { MEL Administrator }
$$$$
\text { Date }
$$

2. Design Drawing and Document Index complete?

[ ] Yes

3. Post-modification testing complete?

4. Glovebox Certification complete?

5. Design drawings red-lined to reflect as-built conditions? (Field verification of red-lines required for safety class and safety significant systems.)

Field verified? [ ] yes [ ] N/A

6. All field changes completed satisfactorily and approved?

[ ] Yes [ ] N/A

7. Hazards Analysis complete?

[ ] Yes [ ] N/A

8. USQ Evaluation complete?.

9. Documentation complete?

10. Red-lines sent for as-builting and/or documents transferred to update MDL? (if yes, attach copy of transmittal)

11. DCP return from field notice sent?

12. DCP closure notice sent to requester? [ ] Yes [ ] N/A

12. DCP closure notice sent to requester?.... [ ] Yes [ ] N/A

\section{Configuration Management}

Transferred to NMT-8 IRM for Archive

$[\sqrt{ }]$ Yes

Received by: 


\section{Design Change Traveler (Cont.)}

\section{INSTRUCTIONS}

\section{CLOSE DESIGN CHANGE PACKAGE}

1. The Master Equipment List (MEL) Administrator signs the DCP signifying that the MEL has been updated.

2. The assigned CM engineer verifies that the Design Drawing and Document Index is complete.

3. The assigned $\mathrm{CM}$ engineer verifies that the post-modification testing documentation is complete.

4. The assigned $\mathrm{CM}$ engineer verifies that the Glovebox Certification is completed

5. The assigned $\mathrm{CM}$ engineer verifies that design drawings have been red-lined to reflect as-built conditions. If the DCP involved a change or modification to a safety class or safety significant system, the assigned CM engineer shall ensure that the responsible facility system engineer or his/her representative has field verified construction per original design and/or approved Field Change request(s) and accompanying red-lined drawings. Discrepancies shall be resolved using procedure NMT8FMP-104, Controlling Nonconforming Items. The system engineer or his/her representative signs and dates the DCP after the field verification has been completed and any nonconforming items have been dispositioned.

6. The assigned CM engineer verifies that the field change documentation is complete and that the FCR has been entered on the Design Drawing and Document Index.

7. The assigned $\mathrm{CM}$ engineer verifies that the hazards analysis has been completed or that the conditions outlined by the Authorization Basis Team have been met.

8. The assigned CM engineer verifies that the USQ Screen and /or Evaluation has been completed or that conditions outlined by the Authorization Basis Team have been met.

9. The assigned $\mathrm{CM}$ engineer verifies that documentation needed from $\mathrm{JCI}$ has been included in the package.

10. The assigned $\mathrm{CM}$ engineer completes a transmittal form listing all drawings and documents sent for as-builting and/or for updating the MDL. The recipient of the drawings and/or documents signs the transmittal. A copy of the signed transmittal is placed with the DCP.

11. The assigned CM engineer completes a DCP closure notice and sends it to the requester, with a copy to the FSQ\&IM office. At completion of steps 1-11 the assigned CM engineer or the configuration manager signs and dates the Traveler in the space provided.

The closed DCP is transferred to NMT-8 IRM for storage. IRM shall sign and date the DCP upon receipt. 


\section{Installation Instructions}

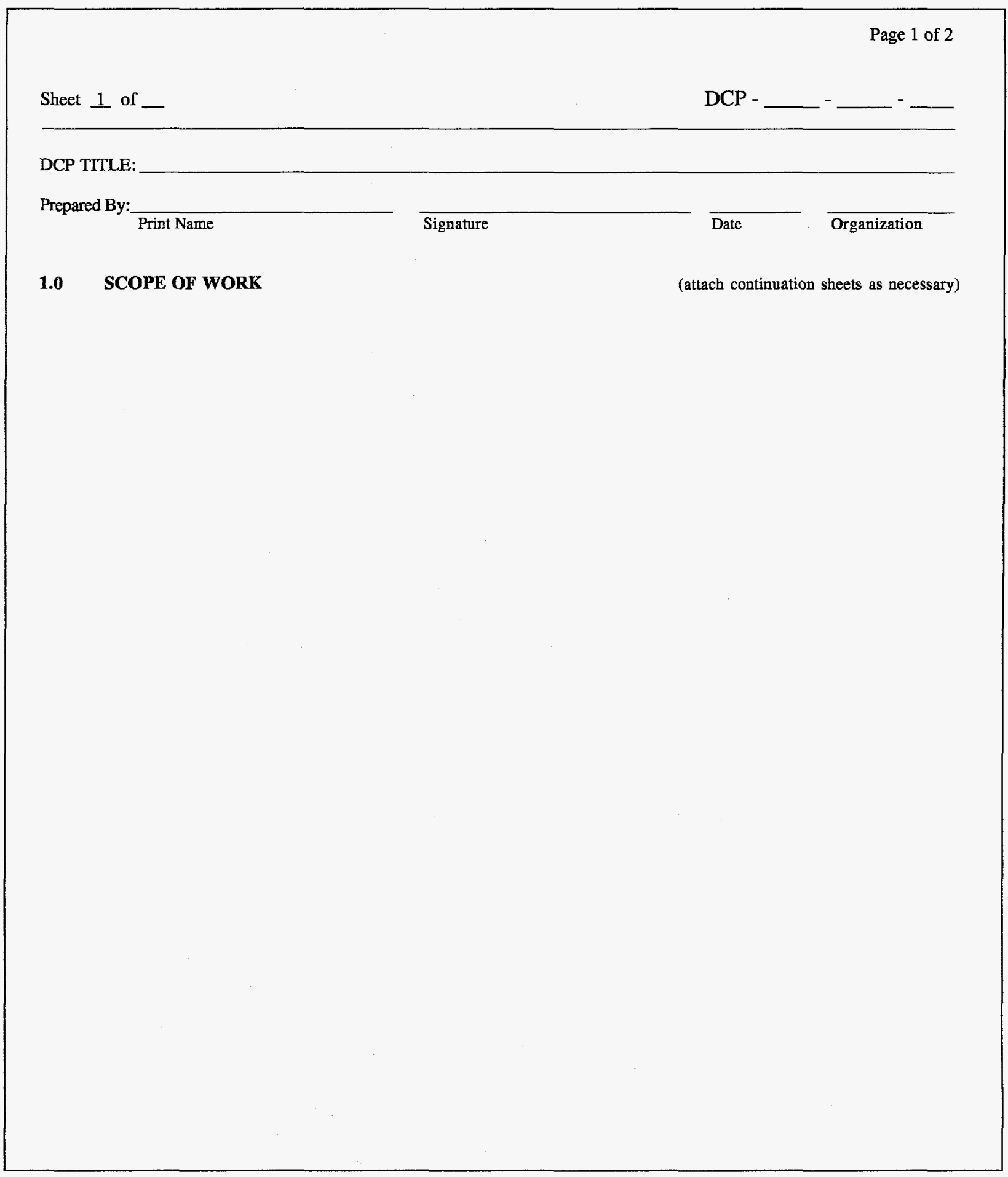




\section{Installation Instructions (Cont.)}

Page 2 of 2

\section{INSTRUCTIONS}

Record the DCP number and the numerical revision in the top right-hand corner in the space provided. Consecutively number each sheet.

\subsection{SCOPE OF WORK}

Briefly describe the scope of work for the subject installation.

Depending on the complexity of the installation, add continuation sheets, as necessary, for 2.0 through 4.0 .

2.0

\section{INITIAL CONDITIONS}

Denote any initial conditions that must be in place prior to beginning field installation. For example, compensatory measures, required equipment operating modes, required equipment to be operable, etc.

\subsection{PRECAUTIONS}

Denote any special precautions that must be followed prior to beginning work. For example, tagout of any breakers. Include any precautionary notes for possible system actuations of equipment malfunctions stemming from the proposed work.

\subsection{INSTALLATION REQUTREMENTS}

1. Denote any special installation specifications, quality control hold points, or other considerations essential to quality work.

2. If applicable, specify installation sequences that must be followed during the installation process.

3. Where appropriate, include space to sign and document when each step is completed. Place sign-offs in the order of the installation sequence. 
Post-Modification Testing Form






\section{Post-Modification Testing Form (Cont.)}

\section{INSTRUCTIONS}

Record the DCP number and revision in the top right hand corner in the space provided. Use additional sheets as necessary. Consecutively number each sheet.

\subsection{TEST REQUIREMENTS}

This section is completed during the design process, i.e., Step 2 of the Design Change Traveler.

\subsection{Test Requirement}

Specify all post-modification testing required to verify that the modified/impacted SSC(s) satisfy their design and functional requirements prior to placing the $\mathrm{SSC}(\mathrm{s})$ in service. Types of testing considered should include the following:

a. Dimensional and Physical Configuration Inspections

Specify any post-installation inspections or measurements that are required. For example, the test requirement may call for verification that support locations are in accordance with drawing xyz.

\section{b. Nondestructive Examinations}

Specify any post-installation nondestructive examinations that are required.

c.

Functional Testing

Specify all functional testing that is required to verify that the subject change meets its design performance requirements and has not inadvertently degraded associated SSCs during the construction process. The objective of the postmodification testing is to assure that the modified SSC (and associated SSCs) are fully operable and able to meet their design basis functional requirements.

\subsection{Acceptance Criteria}

Clearly specify explicit acceptance criteria for each post-modification test specified in Section 1.1. See the following examples:

\section{Acceptance Criteria (continued)}

a. The test requirement may call for verification that supports are located in accordance with drawing $x y z$; the acceptance criteria should either specify a dimensional tolerance, e.g., $+/-5^{n}$, or state: "all as-built dimensions shall be within the tolerance noted on drawing xyz"

b. The test requirement may call for a motor operated valve to be stroked in both directions; as a minimum, the acceptance criteria must delineate the acoeptable stroke time (with min/max tolerances) from open-to-closed and closed-to-open (in addition to verifying functionality of limit switches and attendant instrumentation).

When complete, the preparer shall sign and date in the space provided.

\subsection{TEST RESULTS}

This section is completed after construction and prior to releasing the impacted SSC(s) to the user.

\section{$2.1 \quad$ Test Results}

Record the actual test results or reference and attach the completed test plan, or other document that shows the actual results.

\subsection{Pass/Fail}

Compare the test results in Section 2.1 to the acceptance criteria specified in Section 1.2. Determine if the subject SSC(s) passed or failed and check off the appropriate column.

\subsection{Performer/Witness}

The individual who performed the test shall sigil and date in the space provided. If the SSC was in a Safety-class or Safety-significant system, a witness shall also sign and date (verifying that (s)he monitored the test and concurs with the results).

The Cognizant Engineer shall review the testing, results, and document package. Upon his/her approval and concurrence, (s)he shall sign and date in the space provided. 


\section{Glovebox Certification}

\begin{tabular}{|c|c|c|c|c|}
\hline \multirow{2}{*}{\multicolumn{2}{|c|}{ Sheet 1 of }} & \multirow{2}{*}{\multicolumn{3}{|c|}{ DCP - }} \\
\hline & & & & \\
\hline \multicolumn{5}{|c|}{ DCP TITLE: } \\
\hline No. & Date & Finding & Certifier & Item Inspected \\
\hline \multicolumn{5}{|c|}{ Electrical Services } \\
\hline 1.1 & & & & Circuits are properly identified at penetrations \\
\hline 1.2 & & & & Circuits are properly identified at breaker panels \\
\hline 1.3 & & & & Voltage and wiring have been checked \\
\hline 1.4 & & & & Instrumentation receptacles and cables identified \\
\hline 1.5 & & & & Glovebox frame properly grounded \\
\hline 1.6 & & & & Other \\
\hline \multicolumn{5}{|c|}{$2.0 \quad$ Fire Safety } \\
\hline 2.1 & & & & $\begin{array}{l}\text { Heat sensors are connected. Operability test must be performed in accordance with } \\
\text { NMT 8-FMP-913-R01. }\end{array}$ \\
\hline 2.2 & & & & Fire screens protect the HEPA filters \\
\hline 2.3 & & & & Combustible loading is acceptable \\
\hline 2.4 & & & & Gloves are protected from hot equipment or operations \\
\hline 2.5 & & & & Equipment cooling water circuits have over-temperature and loss of flow interlocks \\
\hline $\mid 2.6$ & & & & Other \\
\hline \multicolumn{5}{|c|}{ 3.0 Seismic Safety } \\
\hline 3.1 & & & & Enclosure support properly attached to the floor \\
\hline 3.2 & & & & Heavy objects on top of or inside enclosure properly secured \\
\hline \multicolumn{5}{|c|}{ 4.0 Glovebox Integrity } \\
\hline 4.1 & & & & Enclosure interior meets smoothness standards \\
\hline 4.2 & & & & Fabricator certified that enclosure is helium leak-tight \\
\hline 4.3 & & & & Helium leak test performed after enclosure installed \\
\hline 4.4 & & & & Service panels, filter hat and flanged penetrations have approved gaskets \\
\hline 4.5 & & & & Window frame bolts have been torqued $(20 \pm 5$ in. $-1 \mathrm{~b})$ \\
\hline 4.6 & & & & Zipper window gaskets have proper zippers \\
\hline 4.7 & & & & Unused penetrations plugged inside and outside \\
\hline 4.8 & & & & Gloves are properly attached to glove rings \\
\hline 4.9 & & & & HEPA filters to Zone 1 exhaust have been properly installed and DOP tested \\
\hline
\end{tabular}




\section{Glovebox Certification (Cont.)}

\begin{tabular}{|c|c|c|c|c|}
\hline \multirow{2}{*}{\multicolumn{2}{|c|}{ Sheet 2 of }} & \multirow{2}{*}{\multicolumn{3}{|c|}{$\mathrm{DCP} \cdot-\cdot-$}} \\
\hline & & & & \\
\hline No. & Date & Finding & Certifier & Item Inspected \\
\hline \multicolumn{5}{|c|}{ Glovebox Integrity (Continued) } \\
\hline 4.10 & & & & Hoods have the required face velocity \\
\hline 4.11 & & & & $\begin{array}{l}\text { Enclosure pressure gauges (Magnehelic or Photohelic) are "zeroed" and respond to } \\
\text { changes in pressure }\end{array}$ \\
\hline 4.12 & & & & Other \\
\hline \multicolumn{5}{|c|}{ 5.0 Mechanical Services } \\
\hline 5.1 & & & & All gas and liquid services are labeled \\
\hline 5.2 & & & & Industrial water piped into enclosures have "dead-man" valves to prevent flooding \\
\hline 5.3 & & & & $\begin{array}{l}\text { Gas service lines to enclosures are } 3 / 8 \text { inch o.d. or smaller except with special } \\
\text { approval }\end{array}$ \\
\hline 5.4 & & & & $\begin{array}{l}\text { No positive pressure cooling water except for limited volume systems is piped } \\
\text { into enclosures }\end{array}$ \\
\hline 5.5 & & & & $\begin{array}{l}\text { Positive pressure chilled circulating water is used to cool equipment exterior to the } \\
\text { enclosure }\end{array}$ \\
\hline 5.6 & & & & Chilled or heated piping is properly insulated \\
\hline 5.7 & & & & House and wet vacuum lines are trapped to prevent flooding of lines or enclosures \\
\hline 5.8 & & & & $\begin{array}{l}\text { All gas supplies entering gloveboxes have pressure regulating valves, check } \\
\text { valves, gauges near work stations, and filters }\end{array}$ \\
\hline 5.9 & & & & $\begin{array}{l}\text { All pressure regulating valves (PRV) for gas services except instrument air are set } \\
\text { at less than } 25 \text { psig }\end{array}$ \\
\hline 5.10 & & & & $\begin{array}{l}\text { At least one gauge is provided downstream of all PRVs to verify indications of the } \\
\text { PRV gauges }\end{array}$ \\
\hline 5.11 & & & & Glovebox service lines have been traced to facility service lines to verify labeling \\
\hline 5.12 & & & & Flanges of wet vacuum and liquid-carrying lines are plastic-wrapped \\
\hline 5.13 & & & & $\begin{array}{l}\text { Supply lines for air-driven stirrers, vibrators, pumps, etc., inside gloveboxes have } \\
\text { solenoid valves interlocked to glovebox pressure }\end{array}$ \\
\hline 5.14 & & & & Air-operated cylinders have PRVs and flow-regulating valves \\
\hline 5.15 & & & & $\begin{array}{l}\text { Air-operated cylinders with shafts penetrating contaminated enclosures have HEPA } \\
\text { filters and exhaust to Zone } 1 \text { ductwork }\end{array}$ \\
\hline 5.16 & & & & $\begin{array}{l}\text { Vacuum pumps have metal piping to enclosures and exhaust through metal piping } \\
\text { and approved filters to the Zone } 1 \text { system }\end{array}$ \\
\hline 5.17 & & & & $\begin{array}{l}\text { Pressurized piping, vessels, columns, etc., have been evaluated and found adequate } \\
\text { for operating pressures }\end{array}$ \\
\hline 5.18 & & & & Other \\
\hline
\end{tabular}




\section{Glovebox Certification (Cont.)}

\begin{tabular}{|c|c|c|c|c|}
\hline \multirow{2}{*}{\multicolumn{2}{|c|}{ Sheet 3 of }} & \multirow{2}{*}{\multicolumn{3}{|c|}{$\mathrm{DCP}-{ }_{-}^{-} \longrightarrow$}} \\
\hline & & & & \\
\hline No. & Date & Finding & Certifier & Item Inspected \\
\hline \multicolumn{5}{|c|}{ Inert Atmosphere Enclosures } \\
\hline 6.1 & & & & The damper in the Zone 1 exhaust line is locked in the full open position. \\
\hline 6.2 & & & & Pressure relief devices (oil bubblers) are filled with oil to the proper level. \\
\hline 6.3 & & & & $\begin{array}{l}\text { Bubbler bypass piping is installed per repeatable detail with manual and solenoid } \\
\text { valves. }\end{array}$ \\
\hline 6.4 & & & & $\begin{array}{l}\text { The enclosure, airlock, and connecting piping have been helium leak checked after } \\
\text { installation. }\end{array}$ \\
\hline 6.5 & & & & $\begin{array}{l}\text { Recirculating purifiers (Dri-Trains) have HEPA filters, PRVs and flow meters } \\
\text { (where required) in gas supply lines }\end{array}$ \\
\hline 6.6 & & & & $\begin{array}{l}\text { Dri-Train recirculating lines are hard soldered and equipped with high vacuum } \\
\text { shut-off valves and inlet and outlet HEPA filters inside the enclosure }\end{array}$ \\
\hline 6.7 & & & & $\begin{array}{l}\text { Photohelic or other pressure controllers have been "zeroed" and tested for proper } \\
\text { operation of makeup and exhaust solenoid valves }\end{array}$ \\
\hline 6.8 & & & & Dri-Train vacuum pumps have approved filters and exhaust into the Zone 1 system \\
\hline 6.9 & & & & Dri-Trains are of the type approved for PF-4 service \\
\hline 6.10 & & & & Other \\
\hline \multicolumn{5}{|c|}{ Radiation and Criticality Safety } \\
\hline 7.1 & & & & $\begin{array}{l}\text { Criticality assessment has been performed and approved criticality limits have been } \\
\text { posted and pegboards are in place }\end{array}$ \\
\hline 7.2 & & & & Hand monitors are in place near work stations \\
\hline 7.3 & & & & Fixed head air samplers are properly mounted on the enclosures \\
\hline 7.4 & & & & CAM air sample tubes are in place at hood faces \\
\hline 7.5 & & & & Hand and foot monitors are available in the working area \\
\hline 7.6 & & & & MASS System and enclosure numbers are posted \\
\hline 7.7 & & & & Radiation shielding is adequate for the operation \\
\hline 7.8 & & & & Other \\
\hline \multicolumn{5}{|c|}{ Connection to Zone 1 (but not for normal operations) is } \\
\hline \multicolumn{2}{|c|}{ Authorized by } & Sys & Engineer $(G$ & (eboxes) \\
\hline \multicolumn{5}{|c|}{ Glovebox meets facilities requirements for normal operations } \\
\hline & & Sys & Engineer (C & veboxes) \\
\hline
\end{tabular}


Glovebox Certification (Cont.)

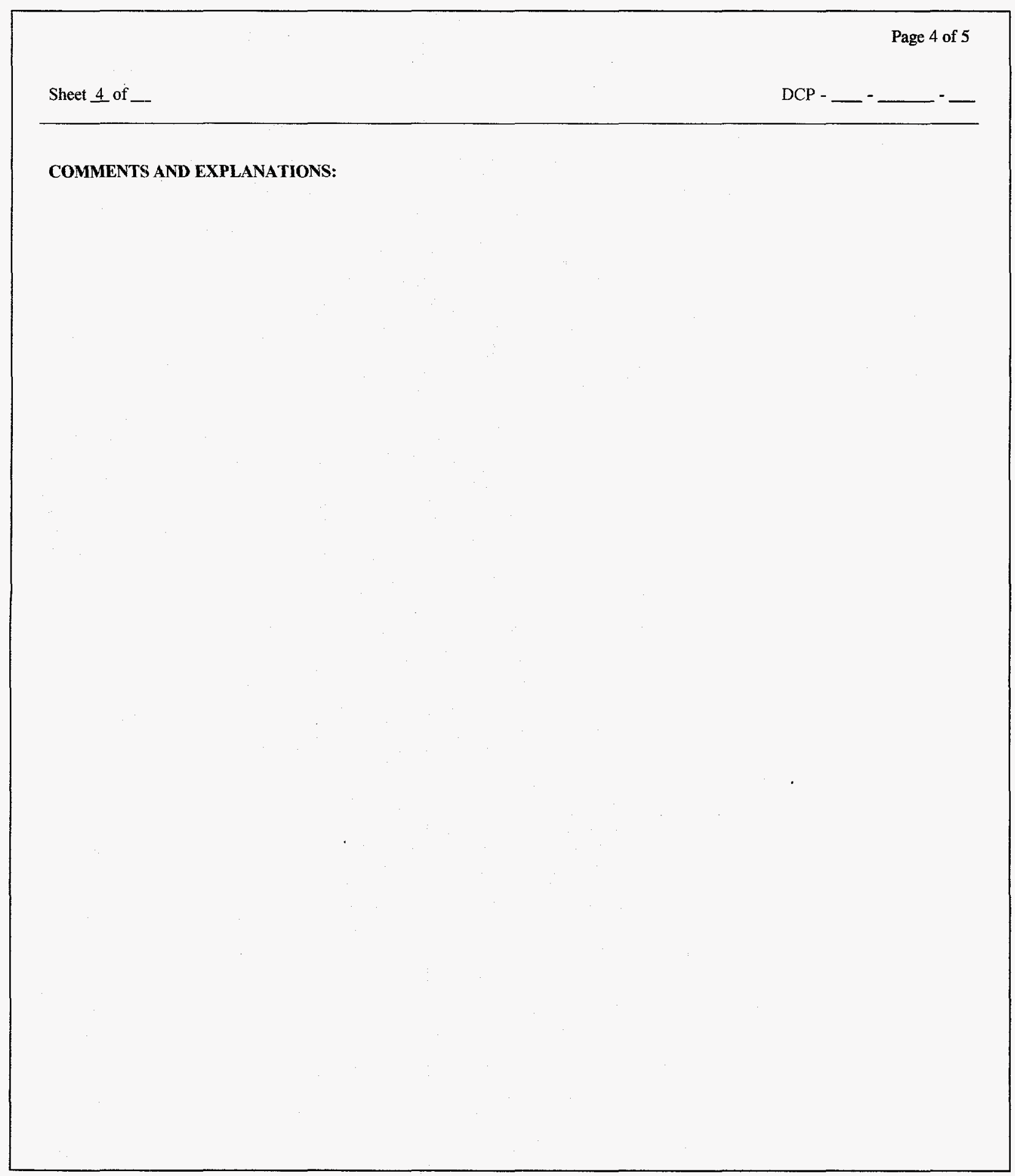

12-26 Design Change Package 


\section{Glovebox Certification (Cont.)}

\section{INSTRUCTIONS}

Certification that gloveboxes, hoods, equipment, and mechanical and electrical services meet TA-55 standards will be done by qualified NMT-8 personnel.

Inspections may be performed by individuals alone or by teams of qualified individuals. Inspections should be performed during appropriate phases of construction to avoid costly changes after construction is completed.

Findings may be:

- "Conforming" (C)

- "Not Applicable" (NA)

- "Nonconforming - OK" (NC-OK),

- "Nonconforming-Must Correct" (NC-MC).

All findings, except " $\mathrm{C}$ ", must be explained at the end of the certification form. 


\section{Field Change Request}

Page 1 of 3

Sheet 1 of

DCP FCR -

DCP TITLE:

Prepared By: Print Name

Signature

Date

Organization

1.0 DESCRIPTION OF FIELD CHANGE 


\section{Field Change Request (Cont.)}

Page 2 of 3

Sheet 2 of

DCP $-\ldots$, FCR -

2.0

IMPACTED DOCUMENTS (attached)

Document

2.1

2.2

2.3

2.4

2.5

2.6

2.7

2.8

3.0 DESIGN VERIFICATION AND APPROVAL (Completed by reviewers and CE)

Design Review

Required:

Review Type

Reviewed and Approved

Date

[r] Yes

Discipline:

\section{USQ Determination}

Required:

Review Type

Reviewed and Approved

Date

$$
[\checkmark] \text { Yes }
$$

USQ Screen

[ ] No [ ] Yes

USQ Evaluation

[ ] No [ ] Yes

CCB Approval

All review and comments properly addressed

$\mathrm{CE}$ : 


\section{Field Change Request (Cont.)}

Page 3 of 3

\section{INSTRUCTIONS}

The purpose of this form is to document and process field revisions to approved DCPs released to construction.

Record the DCP number and the assigned Field Change Request (FCR) number in the top right hand corner in the space provided (obtain the FCR number from the $\mathrm{CM}$ ). Consecutively number each sheet. Attach continuation sheets as necessary.

\subsection{DESCRIPTION OF FIELD CHANGE}

The Preparer shall provide a description of the proposed field change and any significant impacts it will/may have on the approved design.

\subsection{IMPACTED DOCUMENTS}

1. The Preparer shall list all documents that must be revised as a result of the proposed field change. These documents shall include DCP document forms as well as drawings, specifications, etc. (S)he shall also include the revision of the subject document that will require updating to reflect the proposed field change.

2. Each revised document listed shall be attached to the FCR. The attached documents shall accurately reflect the proposed field change(s).

\subsection{DESIGN VERIFICATION AND APPROVAL}

1. The required level of review is determined and coordinated by the cognizant engineer (CE).

2. At the CE's discretion, formal review, comment, and approval by the individuals noted in this section may be delayed. However, they shall be accomplished prior to placing the impacted SSC(s) in service. It is strongly recommended that significant changes be approved prior to constructing the proposed revision in the field. This is especially true if it is a significant or irreversible change, e.g., pouring concrete.

\section{Design Review}

The FCR is subject to the same level of review required for the initial issue of the affected documents for only the technical areas directly impacted by the revision. For example, the initial issue of the Installation Instructions may have had an ES\&H review, ALARA review, training review, and security review. If the proposed revision impacts only

ALARA, then only an ALARA review is required in addition to the Design Review, which is required for all FCRs. Technical Discipline Reviews are required only for those disciplines directly impacted by the proposed revision.

The CE initiates/performs the required reviews, per the above guidance. The required reviews are conducted and documented per procedure or applicable governing procedures for the responsible review organizations. After all comments are resolved, each reviewer shall sign and date the FCR accordingly.

\section{USQ Determination}

A USQ Screen shall be performed for all FCRs. If a USQ Evaluation is required, it shall also be performed. CCB approval of the change is required if a USQ evaluation is needed. Note that if the USQ Evaluation is positive, the field change cannot be made until DOE approval is obtained.

The CE shall ensure that all appropriate reviews are complete and (s)he concurs with the proposed revision. (S)he shall also verify that the FCR is logged into the Design Document Index. The CE shall verify his/her concurrence by signing and dating in the space provided. (S)he shall then attach the FCR (with all attendant drawing red-lines and revisions) to the DCP original. 


\section{Records Transmittal Form}

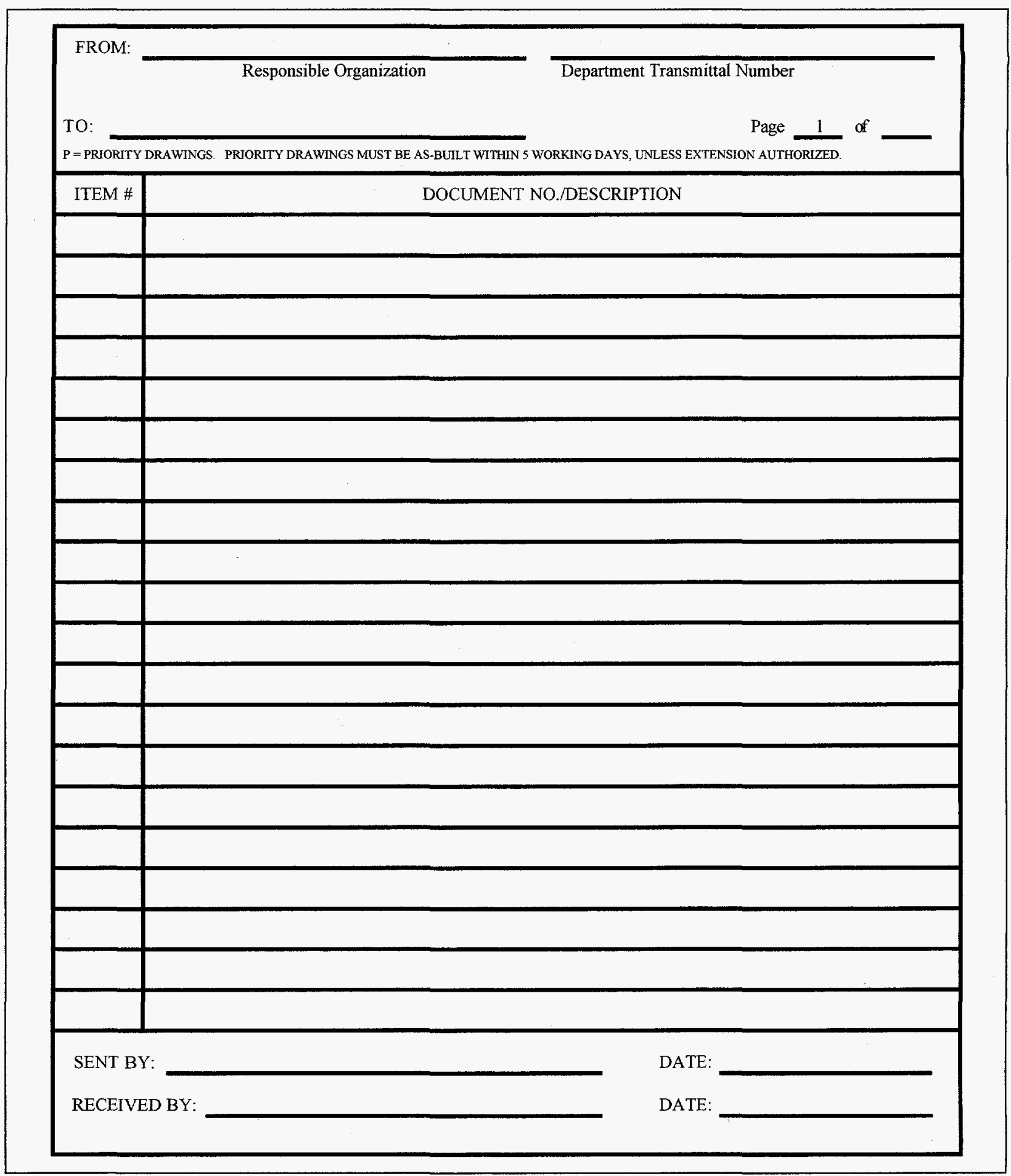




\section{Design Change Package Close-Out Memorandum}

\section{memorandum}

To:

Date:

From: Configuration Management

Subject: DESIGN CHANGE PACKAGE CLOSE-OUT

Design Change Package has been closed and is available for review in the NMT-8 Information Resource Management Center.

If you have any questions, call Configuration Management at 5-9491.

Cy: $\quad$ Referenced DCP

FSQ\&IM, MS E500

, MS

, MS 


\section{Design Change Package Tracking Number Memorandum}

\section{memorandum}

To:

Date:

From: Configuration Management

Subject: DESIGN CHANGE PACKAGE TRACKING NUMBER

Work/Change Request Number was received by Configuration

Management on The tracking number for the Design Change

Package is

Upon selecting a design agent and meeting the requirements outlined in Section 10.1.1 in the TA-55 Change Control Manual, contact Configuration Management at 5-9491 to schedule a Scoping Meeting.

Cy: Referenced DCP

Dave Post, MS E583

Ken Courtney, MS E500

, MS

, MS 


\section{Design Change Scoping Meeting Memorandum}

\section{memorandum}

To: Distribution

Date:

From: Configuration Management

Subject: DESIGN CHANGE SCOPING MEETING

Your presence is requested at a Design Change Scoping Meeting scheduled for

(Time) on (Date) in (Location)

If you are unable to attend, please send a knowledgeable representative in your place.

Distribution:

Info. Cy: Referenced DCP

Dave Post, MS E583

Ken Courtney, E500 


\section{Design Review Notification Memorandum}

\section{memorandum}

To:

Date:

From: Configuration Management

Subject: DESIGN REVIEW NOTIFICATION

The design submitted for Design Change Package has been

reviewed by systems engineering and found to be:

[ ] UNACCEPTABLE. Your DCP has been placed on hold. Please contact the Configuration Management at 5-9491.

[ ] ACCEPTABLE. Your DCP will be forwarded to Work Control for scheduling and implementation.

Cy: Referenced DCP

Dave Post, MS E583

Ken Courtney, MS E500

David Romero, MS E583

MS

MS 


\section{Design Change Package Returned From Field Memorandum}

\section{memorandum}

To:

Date:

From: $\quad$ Configuration Management

Subject: $\quad$ DESIGN CHANGE PACKAGE RETURNED FROM FIELD

Design Change Package (DCP) has been returned to configuration management $(\mathrm{CM})$ for closeout. This $\mathrm{DCP}$ will remain open and available for review until after readiness has been verified. Please notify the $\mathrm{CM}$ when the readiness process has been completed so that the DCP can be closed.

If you have any questions, call the CM at 5-9491.

Cy: Referenced DCP

Dave Post, MS E583

Bob Swift, FSQ\&IM, MS E500

MS

MS 


\section{Design Change Package Close-Out Memorandum}

\section{memorandum}

To:

Date:

From: Configuration Management

Subject: DESIGN CHANGE PACKAGE CLOSE-OUT

Design Change Package has been closed and is available for review in the NMT-8 Information Resource Management Center.

If you have any questions, call Configuration Management at 5-9491.

Cy: $\quad$ Referenced DCP

FSQ\&IM, MS E500

, MS

MS 


\section{DEFINITIONS}

\subsection{Acronyms}
ABT
Authorization Basis Team
AP
administrative procedure
API
American Petroleum Institute
ASME
American Society of Mechanical Engineers
AWS
area work supervisor; the supervisor who is responsible for maintenance and modifications performed in a specific area of TA-55
AWWA American Waterworks Association
BIOS basic input/output system
BOP balance of plant; SSCs that have no safety class, safety significant, or mission critical function
CAM continuous air monitor
CCB Configuration Control Board; body consisting of one or more individuals authorized by the NMT division director to evaluate proposed changes at TA-55 and to specify their disposition
CE
cognizant engineer
CM
configuration management
DCP
design change package
DOE
U.S. Department of Energy
EA environmental assessment
EDS electrical distribution system
EIS environmental impact statement
FCR Field Change Request
FCS Facility Control System
FSAR final safety analysis report; documents the adequacy of safety analysis for a nonreactor nuclear facility to ensure that it can be operated and maintained in compliance with applicable laws and regulations

FSQ\&IM Facility Safety, Quality, and Issues Management (Office) 
FSRC Facility Safety Review Committee

FSS Facilities, Security, and Safeguards (division)

GPP general plant project

HA hazards analysis

HEPA high-efficiency particulate air (filter)

HSI human-system interface

IAS instrument air system

IFIT Isotope Fuels Impact Tester

IRM Information Resources Management

JCO justification for continued operation

LCO limiting conditions of operation

LSSS limiting safety system settings

MDL Master Document List; computerized database that contains facility document information, such as type, number, version, etc.

MEL Master Equipment List; computerized database that contains facility component information such as design requirements, TA-55 and manufacturer's identification numbers, etc.

MSDS Material Safety Data Sheet

NEMA National Electrical Manufacturers Association

NEPA National Environmental Policy Act

NFPA National Fire Protection Association

NMT Nuclear Materials Technology (Division)

PFD process flow diagram

PHA preliminary hazards analysis

PHAIC Process Hazards Analysis Information Checklist

P\&ID piping and instrumentation drawing

PML Preventative Maintenance List

PrHAs Process Hazards Analyses

RCRA Resource Conservation and Recovery Act 
SAR

SNM

SOP

SSC

TSRs

UPS

USQ

USQD

VCR

W/CR

WR safety analysis report; document prepared in accordance with DOE Order 5480.23 that summarizes the safety analysis performed to evaluate the effectiveness of measures taken to control the hazards associated with an activity. It defines the minimum safety requirements for operation of the activity, including institutional safety programs.

software change request for the TA-55 FCS

special nuclear material

safe operating procedure

structure, system, or component; structures provide support and enclosure such as buildings or free-standing tanks.

Systems are collections of components assembled to perform a function such as the ventilation system and wet vacuum system. Components are items of equipment such as pumps, valves, and relays.

technical safety requirements; define the bounding conditions for safe operation, and the bases thereof, with the management and administrative controls required to ensure safe operation of nuclear facilities. (TSRs are replacing OSRs for nonreactor facilities.)

uninterruptible power supply

unreviewed safety question; proposed change, test, or experiment or existing condition that does one or all of the following

- significantly increases the probability of, or the consequences of, an accident or malfunction of safetyrelated equipment previously evaluated in the safety analysis

- creates the possibility of an accident or the malfunction of safety-related equipment not previously evaluated in the safety analysis

- reduces the safety margins as defined in the bases of the TSRs

unreviewed safety question determination

Variance Change Request

Work/Change Request

Work Request 


\subsection{Terms}

\author{
accident analysis \\ archive software
}

as-built

authorization

basis

change

change control

configuration

management

controlled SSC

design basis bounding accidents included in the FSAR

process of making a copy of the software, placing it in a secure place, and recording its location

documentation verified by physical inspection as depicting the actual physical configuration and verified as consistent with the design requirements

safety envelope for the facility defined by safety analysis documents and agreed upon by DOE to authorize operations

any alteration or addition, temporary or permanent, to the facility configuration, facility documentation, design requirements, specifications, facility software, procedures or processes, or introduction of new technology or the conduct of tests or experiments not described in the hazards analysis. Identical replacements or approved equivalents are not changes.

process that ensures all changes are properly identified, reviewed, approved, implemented, tested, and documented

integrated management program that establishes consistency among the design requirements, physical configuration, and facility documentation, and maintains this consistency throughout the life of the facility as changes occur

an SSC whose proper functioning and physical condition are essential to the operation of PF-4 or to preventing the release of radioactive materials; any SSC that is classified as safety class, safety significant, or mission critical

set of requirements that bound the design of systems, structures, or components within a facility. The design basis explains "why" a design requirement has been specified in a particular manner or as a particular value. Design basis consists of the design inputs, the design constraints, and the design analysis and calculations. It includes topical areas such as seismic qualification, fire protection, and safe shutdown. The design basis encompasses consideration of such factors as facility availability, facility efficiency, costs, and maintainability. 
design change
package

design documents

design inputs

design output

design

requirements

documentation

documented approved equivalent replacement

hazard

hazard analysis

line item funding

margin of safety

mission critical the complete package of documentation (including the work order request, traveler, worksheets, preliminary and final design, review and permit data, design drawings, and approval signatures) that relate to the design and implementation of a change at TA-55

drawings, calculations, specifications, or other documents that define either the design requirements or design basis of the facility or SSC

criteria, parameters, bases, and other design requirements upon which a detailed final design is based

documents that define technical requirements

engineering requirements reflected in design output documents (such as drawings and specifications) that define the functions, capabilities, capacities, physical sizes and dimensions, limits and set points, etc.

any written or electronically stored information describing, defining, specifying, reporting, or certifying activities, procedures, or results

change that involves replacing one component with another that is identical, meets all design specifications, or has been demonstrated and documented to be equivalent

anything that can cause an adverse effect

determination of material system, process, and plant characteristics that can produce undesirable consequences, followed by the assessment of hazardous situations associated with a process or activity. Largely qualitative techniques are used to pinpoint weaknesses in design or operation of the facility/operation that could lead to accidents.

type of funding for projects costing in excess of $\$ 1.2 \mathrm{M}$

difference between the peak value calculated by accident analysis (or the acceptance limit) and the established safety limit

structures, systems, and components that are not classified as safety class or safety significant, but the failure of which could result in large cost impacts and substantial interruptions of the programmatic mission of TA-55 
peer review

safety-class

safety evaluation

safety significant

TA-55 Hazards Analysis

variance documented, in-depth, critical review performed by peers who are independent of the work being reviewed (i.e., not involved as a participant, supervisor, technical reviewer, or advisor in the work being performed and, to the extent practical, sufficiently free from funding considerations to perform an impartial review)

structures, systems, and components, the failure of which could adversely affect the environment or safety and health of the public as identified by safety analysis. The phrase "adversely affect" means Evaluation Guidelines are exceeded. Safety-class structures, systems, and components provide a preventive or mitigative function necessary to keep hazardous material exposure to the public below the offsite Evaluation Guidelines.

record required by DOE Order 5480.21 to document the review of a change. This document records the scope of the evaluation and the logic for determining whether or not an unreviewed safety question exists. This is the record required for a USQD.

structures, systems, and components not designated as safety-class, but the preventive function of which is a major contributor to defense in depth (i.e., prevention of uncontrolled material releases) and/or worker safety as determined from hazards analysis

analysis of process hazards at TA-55, PF-4, with estimates of frequency and consequences, associated with processes at TA-55 and used as input into the FSAR for the development of the facility safety basis. As used in this procedure, the HA is composed of (1) the TA-55 Hazards Analysis and (2) the NMT Division Hazards/ Accident Analysis Database for Glovebox Operations, Utility System Operations, and Maintenance Operations (referred to as the Glovebox Database).

temporary change to a controlled SSC for a prespecified period of time to allow the SSC to operate during a modification, installation, or test period 


\section{REFERENCES}

- 538-GEN, Startup and Restart of Operations of TA-55 Facilities

- 560-GEN, Reviewing and Approving New and Changed TA-55 Procedures

- 588-GEN, Preparation of a Process Hazards Analyses (PrHAs) at TA-55

- Administrative Requirement (AR 1-3), Standard Operating Procedures and Special Work Permits

- Administrative Requirement (AR 1-6), Safety Analysis and Review System

- Administrative Requirement (AR 1-14), Environment, Safety, and Health Facility Design Review

- Director's Policy (DP) No. 112, Configuration Management

- DOE Order 232.1, Occurrence Reporting and Processing of Operations Information

- DOE Order 5480.21, Unreviewed Safety Questions, December 1991

- DOE Order 5480.22, Technical Safety Requirements, February 1992

- DOE Order 5480.23, Nuclear Safety Analysis Reports, April 1992

- DOE Order 5480.31, Startup and Restart of Nuclear Facilities, September 1993

- DOE Order 6430.1A, General Design Criteria

- DOE-STD-1073-93, Parts 1 and 2, Guide for Operational Configuration Management Program

- Laboratory Standard LS114-01.1, Unreviewed Safety Question Determination

- LASL Final Environmental Impact Statement, December 1979

- N45.2.11, American National Standards Institute (ANSI) QA Requirements for the Design of Nuclear Power Plants

- NMT Division Hazards/Accident Analysis Database for Glove Box Operations, Utility System Operations, and Maintenance Operations (referred to as the Glove Box Database)

- NMT-8-CMO-93-020, Critical Systems vs. Safety Class Systems at PF-4

- NMT8-FMP-104, Controlling Nonconforming Items, Services, Processes, and Documents

- NMT8-FMP-801, Work Order Request Initiation and Work Order Package Control

- NMT8-FMP-804, Performance of SSC Walkdowns 
- NMT8-FMP-805, TA-55 Procedure for Development of As-Built Drawings, in preparation

- NMT8-FMP-806, Identifying and Numbering TA-55 Equipment

- NQA-1, Nuclear Quality Assurance Guideline

- Operational Safety Requirements for the Plutonium Facility (TA-55-4), September 1988

- PRD 112.01, Program Requirements Document, TA-55 Facilities Management Configuration Management Program Plan

- Project Documents, Volume 1, Facilities Engineering Standards; Facilities, Security and Safeguards Division

- SS-TA-55-110-03.1, Quality Management Plan

- SS-TA-55-112-01.1, Configuration Management Policy for TA-55

- TA-55 Facility Safety Analysis Report (FSAR)

- TA-55 Final Safety Analysis Report, 1978

- TA-55 Hazards Analysis

- TA-55 Operational Safety Requirements, May 1996

- TA-55 PED-112.02, TA-55 Facilities Management As-Built Drawing Project Plan

- UCRL-15910, Lawrence Livermore National Laboratory report, Design and Evaluation Guidelines for Department of Energy Facilities Subjected to Natural Phenomena Hazards 


\section{APPENDIX A}

\begin{tabular}{|c|c|c|c|}
\hline \multicolumn{4}{|c|}{ IMPORTANT PHONE NUMBERS } \\
\hline & NAME & TELEPHONE & PAGER \\
\hline As-Built Drawings & Ron Holmes & $665-0063$ & $996-0561$ \\
\hline Area Work Supervisor Team Leader & John Parker & $665-5349$ & $104-6814$ \\
\hline Area 1 & Tim Gallegos & $667-3878$ & 996-0589 \\
\hline Area 2 & Felix Chavez & $667-1872$ & 996-0754 \\
\hline Area 3 (300 Area, PF-4) & Jay Rutten & $667-1937$ & $104-6592$ \\
\hline Area 4 & Larry Reese & $665-9797$ & 104-6805 \\
\hline Area 5 & Ray Olivas & $665-1285$ & $104-6766$ \\
\hline Area $7\left({ }^{238} \mathrm{Pu}\right.$ Areas $)$ & Michelle Ferran & $667-1956$ & $104-8032$ \\
\hline Area 9 & John Borrego & $667-2314$ & $996-0594$ \\
\hline Area 10 & Jack Simpson & $667-1939$ & $996-1261$ \\
\hline Area 11 & Sharon Dunn & $665-3473$ & 104-6829 \\
\hline Area 12 & Victor Salazar & $667-2314$ & 104-6314 \\
\hline \multirow[t]{4}{*}{ Authorization Basis Team } & Derek Gordon & $667-1951$ & $104-2372$ \\
\hline & Mark Devolder & $665-3947$ & $104-2603$ \\
\hline & Dan Pappas & $667-0314$ & $104-2811$ \\
\hline & Ron Selvage & $667-7562$ & $104-3466$ \\
\hline \multirow[t]{4}{*}{ Configuration Management } & Tom Blum & $667-0695$ & \\
\hline & Richard Elliot & $665-9854$ & $996-0560$ \\
\hline & Ben Garcia & $665-9491$ & 104-6499 \\
\hline & Eliud Vigil & $667-7768$ & \\
\hline Facilities Management Group, NMT-8 & $667-2648$ & & \\
\hline Facility Manager & Dave Post & $667-0648$ & \\
\hline FSS-9 Area Coordinator & Steve Salazar & $667-2315$ & \\
\hline Hazards Analysis & \multicolumn{3}{|c|}{ (See Authorization Basis Office) } \\
\hline Maintenance & Tom Carter & $667-7619$ & $104-8593$ \\
\hline Master Equipment List Coordinator & Butch Michel & $667-2704$ & 104-1477 \\
\hline \multirow[t]{2}{*}{ Operations Center } & & $667-7784$ & \\
\hline & & $667-3330$ & \\
\hline Planning & Ken Courtney & $667-6790$ & \\
\hline \multirow[t]{6}{*}{ Systems Engineering } & David Romero & $665-4321$ & $996-0843$ \\
\hline & Ralph Lundin & $665-5087$ & \\
\hline & David Schmitt & $667-9434$ & $104-8830$ \\
\hline & Darryl Gutierrez & $665-8183$ & $996-0604$ \\
\hline & David Rael & $665-7371$ & 996-0590 \\
\hline & Isaac Suazo & $667-7920$ & $104-1566$ \\
\hline USQ & \multicolumn{3}{|c|}{ (See Authorization Basis Office) } \\
\hline Work Control & Dee Hoisington & $667-9748$ & \\
\hline
\end{tabular}




\section{APPENDIX B}

\section{PRIORITIZING WORK}

\section{B.1 Work Control Prioritization of Design Change Packages (and Associated Work Requests)}

Formal prioritization of TA-55 design change packages (DCPs) along with the Work Requests (WR) that are specifically related to a DCP is a process that enables the Nuclear Materials Technology (NMT) division to prioritize review and approval of DCPs based on criteria which includes: the importance of the associated project, the project schedule disposition, customer expectations, potential ramifications on other related projects, and funding considerations.

\section{B.2 DCP/WR Prioritization Overview}

All DCPs at TA-55 begin as a work request. The work request is the initiating action which launches work to be performed at TA-55. A completed work request form, (approved by the group leader and submitted by the requester and area work supervisor [AWS]) is delivered to the Work Control Office at which point it is officially logged into work control. From information provided on the work request form, the Work Control Office identifies whether the WR requires a DCP. In the event that a DCP is required Configuration Management (CM) is notified and assigns a DCP number to this WR. It is now the responsibility of the requesting organization or its designated design agent to develop the DCP design (specifications, drawings, repeatable details, etc.) in conformance with TA-55 standards. Once the DCP design is complete it is submitted to CM to start the NMT-8 CM and systems engineering review and approval stage of the DCP process.

Prioritization of DCPs begins when the NMT Planning \& Scheduling Office is notified that a new DCP has been initiated by CM. It is the responsibility of the Planning Office to coordinate communications between work control, $\mathrm{CM}$, the requester, and the DCP Prioritization Subcommittee to identify DCPs to be prioritized. The Planning Office reviews the WR/DCP information to ascertain which project(s) are affected and may also contact the originator to clarify the urgency of this WR/DCP. (An alternative prioritization route is that the requester may at any time in the process, identify their WR/DCP as urgent and request prioritization via the Planning Office). 


\section{B.3 DCP Anticipated Hot List}

Using this information the Planning Office prepares a listing of those DCPs which have been identified for prioritization. This listing is typically referred to as the DCP "Anticipated Hot List" and is prepared primarily for the DCP Prioritization Subcommittee. (The DCP Anticipated Hot List is not the same as the DCP "Hot List" which is a listing of those DCPs which have already been given priority by the DCP Prioritization Subcommittee. The Hot List and the DCP Prioritization Subcommittee are discussed in the following section). The DCP Anticipated Hot List is intended to provide management with the ability to view multiple DCPs against each other in order to develop a relative sense of prioritization.

\section{B.4 DCP Prioritization Subcommittee/The DCP Hot List}

The DCP Prioritization Subcommittee was created by the NMT Management Team specifically to address the volume of DCPs confronting NMT-8 CM. The committee is composed of representative NMT group leaders, NMT project leaders, Program Office personnel, and a representative from $\mathrm{CM}$ and the Planning Office. DCP status is reviewed every 4-6 weeks and subcommittee meetings are scheduled whenever volume and/or priorities need reevaluation. Using the DCP Anticipated Hot List as a basis for discussion, the purpose of the subcommittee is to decide which DCPs receive prioritization in the CM DCP Review and Approval phase and in the assignment of craft resources in the work control Plan of the Day. (DCPs having received prioritization by the subcommittee automatically have WR prioritization through the Plan of the Day). Following discussion a consensus is reached by the subcommittee identifying those DCPs which are to receive prioritization. Those DCPs are then transferred from the DCP Anticipated Hot List to the DCP Hot List. The updated DCP Hot List is then delivered by the Planning Office to the Work Control Office to provide direction as to which WR/DCPs are to receive prioritization in the Plan of the Day work assignment of crafts. 
This report has been reproduced directly from the best available copy.

It is available to DOE and DOE contractors from the Office of Scientific and Technical Information, P.O. Box 62,

Oak Ridge, 'TN 37831.

Prices are available from (615) 576-8401.

It is available to the public from the

National Technical Information Service,

US Department of Commerce,

5285 Port Royal Rd.

Springfield, VA 22616. 